\title{
The Atmospheric Chemistry Suite (ACS) of Three Spectrometers for the ExoMars 2016 Trace Gas Orbiter
}

O. Korablev ${ }^{1}$ F. Montmessin ${ }^{2}$ - A. Trokhimovskiy ${ }^{1}$ A.A. Fedorova ${ }^{1}$ - A.V. Shakun ${ }^{1}$. A.V. Grigoriev ${ }^{1}$ - B.E. Moshkin ${ }^{1}$ N.I. Ignatiev ${ }^{1}$ - F. Forget ${ }^{3}$ - F. Lefèvre ${ }^{4}$. K. Anufreychik ${ }^{1}$ - I. Dzuban ${ }^{1}$. Y.S. Ivanov ${ }^{5}$ Y.K. Kalinnikov ${ }^{6}$ - T.O. Kozlova ${ }^{1}$. A. Kungurov ${ }^{1}$ - V. Makarov ${ }^{1}$ - F. Martynovich ${ }^{1}$ - I. Maslov ${ }^{1}$ - D. Merzlyakov ${ }^{1}$. P.P. Moiseev ${ }^{7}$ - Y. Nikolskiy ${ }^{1}$ - A. Patrakeev ${ }^{1}$. D. Patsaev ${ }^{1}$ - A. Santos-Skripko ${ }^{1}$. O. Sazonov ${ }^{1}$ - N. Semena ${ }^{1}$ A. Semenov ${ }^{1}$ V. Shashkin ${ }^{1}$ - A. Sidorov ${ }^{7}$ A.V. Stepanov ${ }^{1,8}$. I. Stupin ${ }^{1}$ - D. Timonin ${ }^{1}$ - A.Y. Titov ${ }^{1}$ - A. Viktorov $^{7}$ - A. Zharkov ${ }^{1}$ - F. Altieri' ${ }^{\text { }}$ G. Arnold ${ }^{10}$ • D.A. Belyaev ${ }^{1}$ - J.L. Bertaux ${ }^{1,2}$ • D.S. Betsis ${ }^{1} \cdot$ N. Duxbury ${ }^{8}$. T. Encrenaz ${ }^{11}$ - T. Fouchet ${ }^{11}$ - J.-C. Gérard ${ }^{12}$ - D. Grassi ${ }^{9}$. S. Guerlet ${ }^{3}$ - P. Hartogh ${ }^{13}$. Y. Kasaba ${ }^{14}$ - I. Khatuntsev ${ }^{1}$. V.A. Krasnopolsky ${ }^{15,16}$ • R.O. Kuzmin ${ }^{1,17}$ • E. Lellouch $^{11}$. M.A. Lopez-Valverde ${ }^{18}$ • M. Luginin ${ }^{1}$ A. Määttänen ${ }^{1,4}$ - E. Marcq $^{2}$.

J. Martin Torres ${ }^{19,20}$ - A.S. Medvedev ${ }^{13}$ - E. Millour ${ }^{3}$ - K.S. Olsen ${ }^{4}$ - M.R. Patel ${ }^{21}$.

C. Quantin-Nataf ${ }^{22}$ - A.V. Rodin ${ }^{1,15}$ - V.I. Shematovich ${ }^{23}$ - I. Thomas $^{24} \cdot$ N. Thomas $^{25}$.

L. Vazquez $^{26}$ - M. Vincendon ${ }^{27}$ - V. Wilquet ${ }^{24}$ - C.F. Wilson ${ }^{28}$ - L.V. Zasova ${ }^{1}$.

L.M. Zelenyi ${ }^{1}$ • M.P. Zorzano ${ }^{19,29}$

Received: 1 March 2017 / Accepted: 13 October 2017 / Published online: 30 November 2017

(C) The Author(s) 2017. This article is published with open access at Springerlink.com

Abstract The Atmospheric Chemistry Suite (ACS) package is an element of the Russian contribution to the ESA-Roscosmos ExoMars 2016 Trace Gas Orbiter (TGO) mission. ACS

ExoMars-16

Edited by Håkan Svedhem and Christopher T. Russell

O. Korablev

korab@iki.rssi.ru

1 Space Research Institute (IKI), 84/32 Profsoyuznaya, 117997 Moscow, Russia

2 LATMOS/IPSL, UVSQ Université Paris-Saclay, UPMC Univ. Paris 06, CNRS, Guyancourt, France

3 LMD CNRS Jussieu, Paris, France

4 LATMOS/IPSL, UPMC Univ. Paris 06 Sorbonne Universités, UVSQ, CNRS, Paris, France

5 Main Astronomical Observatory MAO NASU, Kyiv, Ukraine

6 VNIIFTRI, Mendeleevo, Moscow Region, Russia

7 Scientific Production Enterprise Astron Electronics, Orel, Russia

8 Physics Department, Lomonosov Moscow State University, Moscow, Russia

9 IAPS-INAF, Rome, Italy

10 German Aerospace Center DLR, Berlin, Germany

11 LESIA, Observatoire de Paris, PSL Research University, CNRS, Sorbonne Universités, UPMC Univ. Paris 06, Univ. Paris Diderot, Sorbonne Paris Cité, Paris, France

12

LPAP, Université de Liège, Liège, Belgium 
consists of three separate infrared spectrometers, sharing common mechanical, electrical, and thermal interfaces. This ensemble of spectrometers has been designed and developed in response to the Trace Gas Orbiter mission objectives that specifically address the requirement of high sensitivity instruments to enable the unambiguous detection of trace gases of potential geophysical or biological interest. For this reason, ACS embarks a set of instruments achieving simultaneously very high accuracy (ppt level), very high resolving power $(>10,000)$ and large spectral coverage $(0.7$ to $17 \mu \mathrm{m}$ - the visible to thermal infrared range). The near-infrared (NIR) channel is a versatile spectrometer covering the $0.7-1.6 \mu \mathrm{m}$ spectral range with a resolving power of $\sim 20,000$. NIR employs the combination of an echelle grating with an AOTF (Acousto-Optical Tunable Filter) as diffraction order selector. This channel will be mainly operated in solar occultation and nadir, and can also perform limb observations. The scientific goals of NIR are the measurements of water vapor, aerosols, and dayside or night side airglows. The mid-infrared (MIR) channel is a cross-dispersion echelle instrument dedicated to solar occultation measurements in the 2.2-4.4 $\mu \mathrm{m}$ range. MIR achieves a resolving power of $>50,000$. It has been designed to accomplish the most sensitive measurements ever of the trace gases present in the Martian atmosphere. The thermal-infrared channel (TIRVIM) is a 2-inch double pendulum Fourier-transform spectrometer encompassing the spectral range of 1.7-17 $\mu \mathrm{m}$ with apodized resolution varying from 0.2 to $1.3 \mathrm{~cm}^{-1}$. TIRVIM is primarily dedicated to profiling temperature from the surface up to $\sim 60 \mathrm{~km}$ and to monitor aerosol abundance in nadir. TIRVIM also has a limb and solar occultation capability. The technical concept of the instrument, its accommodation on the spacecraft, the optical designs as well as some of the calibrations, and the expected performances for its three channels are described.

Keywords Mars · Atmosphere · High-resolution spectrometer · Fourier-spectrometer · Echelle $\cdot$ Cross-dispersion

13 Max-Planck-Institut für Sonnensystemforschung, Göttingen, Germany

14 Tohoku University, Sendai, Miyagi, Japan

15 Moscow Institute of Physics and Technology (MIPT), Dolgoprudny, Moscow Region, Russia

16 Catholic University, Washington DC, USA

17 Vernadsky Institute of Geochemistry and Analytical Chemistry GEOKHI, Moscow, Russia

18 Instituto de Astrofisica de Andalucía/CSIC, Granada, Spain

19 Department of Computer Science, Luleå University of Technology, Kiruna, Sweden

20 Instituto Andaluz de Ciencias de la Tierra (CSIC-UGR), Granada, Spain

21 Open University, Milton-Keynes, UK

22 Laboratoire de Géologie de Lyon, Université Lyon, Lyon, France

23 Institute of Astronomy RAS, Moscow, Russia

24 Royal Belgium Institute of Aeronomy BIRA/IASB, Brussels, Belgium

25 University of Bern, Bern, Switzerland

26 Facultad de Informatica, Universidad Complutense de Madrid, Madrid, Spain

27 Institut d'Astrophysique Spatiale IAS, CNRS/Université Paris Sud, Orsay, France

28 Physics Department, Oxford University, Oxford, UK

29 Centro de Astrobiología, INTA-CSIC, Madrid, Spain 


\section{List of acronyms}

$\begin{array}{ll}\text { ACS } & \text { The Atmospheric Chemistry Suite } \\ \text { AOTF } & \text { Acousto-Optical Tunable Filter } \\ \text { AR } & \text { Antireflection } \\ \text { BE } & \text { Block of Electronics } \\ \text { BSM } & \text { Bi-level Switch Monitor } \\ \text { CNRS } & \text { Centre National de la Recherche Scientifique } \\ \text { CaSSIS } & \text { Colour and Stereo Surface Imaging System } \\ \text { CPLD } & \text { Complex Programmable Logic Device }\end{array}$

CRISM Compact Reconnaissance Imaging Spectrometer for Mars

ESA European Space Agency

FOV Field Of View

FPGA Field-Programmable Gate Array

FREND Fine Resolution Epithermal Neutron Detector

FWHM Full Width at Half Maximum

GCM General Circulation Model

HV-HPC High-Voltage High-Power Commands

IFG Interforogram

IKI Space Research Institute in Moscow, Russia

IR Infrared

ITL Integrate Then Read

IWR Integrate While Read

IUVS Imaging Ultraviolet Spectrograph

LATMOS Laboratoire Atmosphères, Milieux, Observations Spatiales

MATMOS Mars Atmospheric Trace Molecule Occultation Spectrometer

MAVEN Mars Atmosphere and Volatile EvolutioN

MAWD Mars Atmospheric Water Detector

MCD Mars Climate Database

MCT Mercury-cadmium-telluride

MEX Mars Express

MGS Mars Global Surveyor

MIR Middle-infrared (channel)

MLI Multi-Layer Insulation

MOPD Maximal Optical Path Difference

MRO Mars Reconnaissance Orbiter

NIR Near-infrared (channel)

NOMAD Nair and Occultation for Mars Discovery

OPD Optical Path Difference

PCB Printed Circuit Board

PFM Proto-flight Model

PID Proportional-Integral-Derivative

PPI Parallel Port Interface

PWM Pulse Width Modulation

ROIC Read-Out Integrated Circuit

Roscosmos State Space Corporation

RUSALKA Russian acronym for Manual Spectral Analyzer of the Atmosphere

Constituents

SNR Signal-to-noise

SMOW Standard Mean Ocean Water 
SOIR Solar Occultation Infrared

SPICAM-IR Spectroscopy for the Investigation of the Characteristics of the Atmosphere of Mars, the IR channel

SPICAV Spectroscopy for the Investigation of the Characteristics of the Atmosphere of Venus

SRF Spectral Response Function

TES Thermal Emission Spectrometer

TGO Trace Gas Orbiter

THEMIS Thermal Emission Imaging System

TIMM-2 Solar occultation spectrometer on Phobos Grunt (arbitrary acronym)

TIRVIM Thermal Infra-Red in honor of Professor Vassily Ivanovich Moroz (1931-2004).

VIRTIS-H Visible and InfraRed Thermal Imaging Spectrometer with High resolution

\section{Introduction}

The detailed studies of the Martian atmosphere and climate were identified as the primary scientific goal of the ExoMars Trace Gas Orbiter (TGO) as reported in Zurek et al. (2011). TGO is a project initiated by the European Space Agency (ESA): it was conceived to carry a powerful set of atmospheric instruments to establish a detailed inventory of the trace gases existing in the Martian atmosphere as a response to the putative presence of methane, initially reported by the FKM group (Formisano et al. 2004; Krasnopolsky et al. 2004; and Mumma et al. 2009). The final configuration of the TGO project is based on a ESA-Roscosmos cooperation that started in 2011. On the Russian side, a suite of spectroscopic instruments for the studies of the Mars atmosphere in the infrared spectral range, the Atmospheric Chemistry Suite (ACS) was proposed. Selected by the Solar System Panel of the Space Council of Russian Academy of Science this instrument was introduced by Roscosmos as one of the two Russian contributions to TGO. The set of TGO instruments was discussed and later approved by the European Space Agency and Russian Federal Space Agency, Roscosmos, in 2012; the final ExoMars cooperation agreement was signed in March 2013. The TGO payload includes three other instruments: the Nadir and Occultation for Mars Discovery (NOMAD), the Fine Resolution Neutron Detector (FREND), and the Colour and Stereo Surface Imaging System (CASSIS, a high-resolution color stereo camera).

ACS is a set of three spectrometers (-NIR, -MIR, and -TIRVIM, see below and Figs. 1, 2) intended to observe Mars atmosphere in solar occultations, nadir and limb geometry. It was built by Space Research Institute (IKI) in Moscow (Russia) within a very constrained timeframe (only three years separate the approval of the mission and the delivery of the proto-flight model, PFM). ACS design leverages on previous developments thus providing high technology readiness levels at the onset of the project: two of the three channels were initially conceived and built for the unsuccessful Phobos-Grunt project (Korablev et al. 2012, 2013), while one instrument flew onboard the International Space Station from 2009 to 2012 (Korablev et al. 2011). Some components/subsystems were contributed by LATMOS (CNRS) in France. This paper is intended to give a comprehensive overview of the scientific objectives of the instrument as they have been implemented: the concept of the instrument is described, with details on the optical scheme retained for each channel. A preliminary set of instrument testing was conducted on the ground and verified during the cruise, whose principal outcomes are discussed in the following section. The expected performances, updated 
Fig. 1 Spectral coverage of three ACS channels, operating modes and main atmospheric targets. The spectral coverage of the NOMAD instrument, the other infrared spectrometer of the TGO payload is also shown for comparison
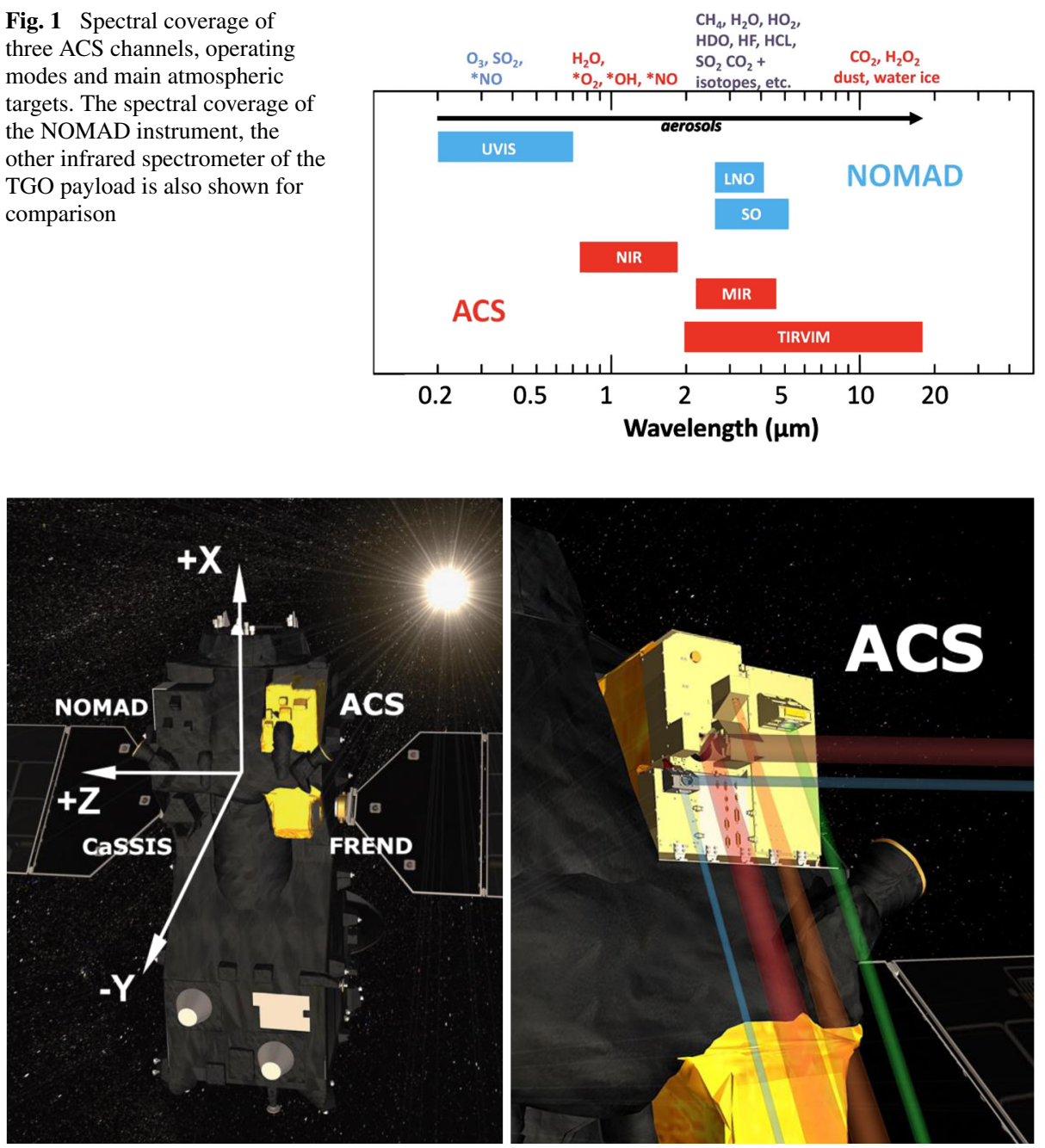

Fig. 2 (a) The TGO platform and its payload, including ACS. The reference frame of the spacecraft is shown. (b) The configuration of the nadir and occultation FOVs of the three ACS science channels

with the latest information collected to date during the flight, are presented and compared to our current knowledge of the various species targeted. The observations planned during the Science Phase of the TGO mission are then discussed.

ACS-NIR follows the lineage of the SPICAM-IR instrument operating in orbit around Mars since 2004 (Korablev et al. 2006), a copy of this instrument having been later associated to SPICAV onboard the Venus Express mission. The SPICAM-IR instrument family concept relies on a simple and light-weight pencil-beam AOTF spectrometer ( 800 grams total mass) covering the spectral range of 1 to $1.7 \mu \mathrm{m}$ with a spectral resolution of $\sim 3.5 \mathrm{~cm}^{-1}$ with a resolving power of $\sim 2,000$. This small instrument has continuously delivered highquality data for the last 14 years to help us characterize the Martian climatic processes and aeronomy phenomena (Montmessin et al. 2017). ACS-NIR with its ten-fold better spectral resolution will significantly enhance the fidelity of atmospheric measurements. 
In the previous ExoMars cooperation, TGO was planned to carry a solar occultation Fourier-transform spectrometer MATMOS (Wennberg et al. 2011) as a core instrument for sensitive trace gases measurements with $\lambda / \Delta \lambda \approx 72,000$ in the characteristic $\mathrm{C}-\mathrm{H}$ range. NOMAD (Vandaele et al. this issue) covers the most important 3- $\mu$ m range with spectral resolution of $\sim 20,000$, but the accessible spectral intervals are narrow. Acquisition of a wider wavelength domain at once provides a strategic advantage by maximizing the number of gaseous species simultaneously mapped. A way to achieve high spectral resolution while pushing off the boundaries of the spectral range covered is an echelle cross-dispersion concept. Employing this principle ACS-MIR is intended to recover some of MATMOS capabilities. ACS-MIR has no direct prototype. Some solutions regarding its optics were verified in TIMM-2 for Phobos-Grunt (Korablev et al. 2013), but the instrument as a whole is completely new. It is a solar occultation only cross-dispersion spectrometer that covers the $2.2-4 \mu \mathrm{m}$ range with a spectral resolving power of 50,000 and a signal-to-noise ratio (SNR) of $>5000$ per pixel per 1s-acquisition.

ACS-TIRVIM is a Fourier-spectrometer built around a 2-inch double-pendulum interferometer with cryogenically-cooled $\mathrm{HgCdTe}$ detector, allowing operation in nadir and in solar occultation. The primary goal of TIRVIM is the long-term monitoring of atmospheric temperature profiles and aerosol state in nadir as demonstrated by MGS/TES (Smith 2004). On TGO TIRVIM fills the niche of the limb radiometer MCS (Schofield et al. 2011). The instrument covers the spectral range from 1.7 to $17 \mu \mathrm{m}$ and capitalizes on previously developed Fourier-spectrometers for Mars 96, Mars Express and Phobos-Grunt missions (Moroz et al. 1990; Formisano et al. 1997 2005; Korablev et al. 2012). The TIRVIM abbreviation honors Prof Vassilii Ivanovich Moroz, the IR astronomer and the leader of planetary school in IKI during 1968-2004, who introduced the Fourier-transform spectrometers and pursued their development in this institution.

\section{Science Objectives}

The ACS scientific objectives reflect the overall TGO mission philosophy and address the specific investigations defined in Zurek et al. (2011). These scientific objectives have driven the ACS development through the flow down of measurement requirements to their implementation in the instrument concept definition and later throughout its fabrication (see Table 1).

The scientific objectives of ACS can be broadly separated into three main categories: (1) first and foremost, the instrument is intended to provide "Breakthrough" science by contributing to the establishment of the most precise detection or upper limit values for a list of trace gases that could be potentially found in the Martian atmosphere, (2) ACS shall also contribute in a unique way to a so-called "Novel" science since it will be able to deliver a self-consistent dataset enabling the study of the quasi-complete atmospheric chemistry cycle controlled by the $\mathrm{HO}_{x}$ radicals as well as the study of $\mathrm{H}_{2} \mathrm{O}$ and its isotope $\mathrm{HDO}$ in their gaseous phase, addressing here the crucial topic of the fate on geological timescales of water on Mars, then (3) comes the "Climatological" science focus of ACS with the continuous delivery of key climatic parameters to constrain the environmental background in which the species targeted by the "Breakthrough" and "Novel" science objectives are observed.

\section{1 "Breakthrough" ACS Science}

The TGO mission concept was in large part promoted by the three nearly simultaneous (in the first half of the 2000's) pioneering works that reported for the first time the detection of methane in the Martian atmosphere (the FKM group: Formisano et al. 2004; 
Table 1 ACS science objective traceability matrix

\begin{tabular}{|c|c|c|c|c|}
\hline Objectives & Scientific Requirements & $\begin{array}{l}\text { Measurement } \\
\text { Requirements }\end{array}$ & $\begin{array}{l}\text { Functional } \\
\text { Requirements }\end{array}$ & $\begin{array}{l}\text { Predicted } \\
\text { Performances }\end{array}$ \\
\hline \multirow{2}{*}{$\begin{array}{l}\text { Breakthrough } \\
\text { Science }\end{array}$} & $\begin{array}{l}\text { Reassess } \mathrm{CH}_{4} \text { abundance in the } \\
\text { Martian atmosphere with very } \\
\text { high sensitivity (fraction of } \\
\text { ppbv detection level) }\end{array}$ & $\begin{array}{l}\text { Observe } 3 \mu \mathrm{m} \text { band system of } \\
\mathrm{CH} 4 \text { with } \\
\text { SNR }>1,000 \\
\text { and } \lambda / \Delta \lambda>10,000\end{array}$ & Solar Occultation & $\begin{array}{c}\text { SNR }>5,000 \\
\& \lambda / \Delta \lambda>50,000 \\
\leftrightarrow 25 \text { pptv of } \mathrm{CH}_{4} \\
\text { per } 1 \text {-sec. acquistion }\end{array}$ \\
\hline & $\begin{array}{l}\text { Detect a series of companion } \\
\text { trace gases of potential } \\
\text { geophysical or biological origin }\end{array}$ & $\begin{array}{l}\text { Observe } 2-4 \mu \mathrm{m} \text { range to } \\
\text { detect } \\
\text { SNR }>1,000 \\
\text { and } \lambda / \Delta \lambda>10,000\end{array}$ & Solar Occultation & Cf. table 1 for list \\
\hline \multirow[b]{2}{*}{ Novel Science } & $\begin{array}{l}\text { Characterize the } \mathrm{HDO} / \mathrm{H}_{2} \mathrm{O} \\
\text { spatial and seasonal variability }\end{array}$ & $\begin{array}{l}\text { Observe the } 2.7 \mu \mathrm{m} \text { range } \\
\text { with } S N R>500 \\
\text { and } \lambda / \Delta \lambda>3,000 \\
\end{array}$ & Solar Occultation & $\begin{array}{c}\mathrm{SNR}>5,000 \\
\& \lambda / \Delta \lambda>50,000 \\
\leftrightarrow \mathrm{HDO} / \mathrm{H}_{2} \mathrm{O}<0.1 \% \\
\end{array}$ \\
\hline & $\begin{array}{l}\text { Assess the oxidation state of } \\
\text { the atmosphere by measuring } \\
\text { the abundance and variability } \\
\text { of the HOx radicals }\end{array}$ & $\begin{array}{l}\text { Measure } \mathrm{O}_{2}(0.76 \mu \mathrm{m}), \mathrm{HO}_{2} \\
(2.94 \mu \mathrm{m}), \mathrm{OH}^{*} \\
\text { vs. } \mathrm{z} \text { vs. Ls vs. Lat }\end{array}$ & $\begin{array}{l}\text { Nadir and Solar } \\
\text { Occultation }\end{array}$ & $\begin{array}{l}\text { Profile up to } 60 \mathrm{~km} \\
\text { with } \\
0.02 \% \text { error on } \mathrm{O}_{2} \\
0.5 \% \text { error on } \mathrm{HO}_{2} \\
\end{array}$ \\
\hline \multirow{3}{*}{$\begin{array}{l}\text { Climatological } \\
\text { Science }\end{array}$} & $\begin{array}{l}\text { Characterize the main climatic } \\
\text { parameters in space and time }\end{array}$ & $\begin{array}{l}\text { Measure T ( } 15 \mu \mathrm{m} \text { ) vs. altitude } \\
\text { Measure dust / cloud opacity ( } 9 \\
\& 12 \mu \mathrm{m}) \\
\text { Measure parameters vs. Ls \& Lat }\end{array}$ & Nadir & $\begin{array}{l}\text { T from o to } 45 \mathrm{~km} \\
\text { with } 7 \mathrm{~km} \text { res. } \\
\text { dust / cloud opacity } \\
\text { error } \sim 0.05 \\
\end{array}$ \\
\hline & $\begin{array}{l}\text { Correlate measurements of } \\
\text { trace and main gases to } \\
\text { address the role of electro and } \\
\text { heterogeneous chemistry }\end{array}$ & $\begin{array}{l}\text { Measure dust / water ice } \\
\text { cloud opacity, combine with } \\
\text { info on abundance of HOx } \\
\text { radicals }\end{array}$ & $\begin{array}{l}\text { Nadir and Solar } \\
\text { Occultation }\end{array}$ & See above \\
\hline & $\begin{array}{l}\text { Provide an updated model of } \\
\text { surface thermal inertia }\end{array}$ & $\begin{array}{l}\text { Measure } T_{\text {surf }} \text { Vs. lon vs. lat vs. } \\
\text { local time }\end{array}$ & Nadir & $\begin{array}{l}T_{\text {sur }} \text { with } 1 \mathrm{~K} \text { error with } \\
2 \mathrm{~h} \text { sampling of the } \\
\text { diurnal cycle }\end{array}$ \\
\hline
\end{tabular}

Krasnopolsky et al. 2004; as well as Mumma et al. 2009; note that the latter observations were reported first in Mumma et al. 2004, but profound refinement of their inversion technique was implemented before the reference publication of 2009).

The discovery of methane revived hopes of Mars still being an active planet from a geological or biological perspective. However, the tenuous nature of the reported detections and the issues related to the observation methods made it clear that new measurements would have to be done, this time with an accuracy avoiding any confusion caused by instrumental artefacts. The TGO concept was born on this basis and also on acknowledging the fact that existing instrumental set ups could fulfill the requirements of ultra-high accuracy for a trace gas like methane. With ACS, these requirements have been overachieved, providing sensitivity levels about 100 times better than existing platforms orbiting Mars and around 10 times better than performances achieved on the ground by the Mars Science Laboratory rover (Webster et al. 2015). The latter set recently reported the observation of sporadic (day-to-week lifetime) methane plumes associated with 6 to 7 ppbv pulses of $\mathrm{CH}_{4}$. The same intriguing feature of transience was also reported by Mumma et al. (2009), suggesting a dominant seasonal signature in complete contradiction with theory. Indeed, even the most advanced photochemical models (Lefèvre and Forget 2009) predict a 300-year lifetime for $\mathrm{CH}_{4}$, and this short-scale variability defies our current understanding of the main mechanisms controlling chemistry and physics of the Martian atmosphere (see the "Novel" science subs-section thereafter).

While $\mathrm{CH}_{4}$ constitutes a central target for the "Breakthrough" science, ACS instrument will be used for the search and the quantification thereof of the abundance of a suite of companion trace gases: ${ }^{13} \mathrm{CH}_{4}, \mathrm{C}_{2} \mathrm{H}_{2}, \mathrm{C}_{2} \mathrm{H}_{4}, \mathrm{C}_{2} \mathrm{H}_{6}, \mathrm{CH}_{2} \mathrm{O}, \mathrm{H}_{2} \mathrm{~S}$, OCS, $\mathrm{N}_{2} \mathrm{O}, \mathrm{HCl}, \mathrm{HCN}$. ACS was designed to improve detection capabilities over previous investigations by at least 


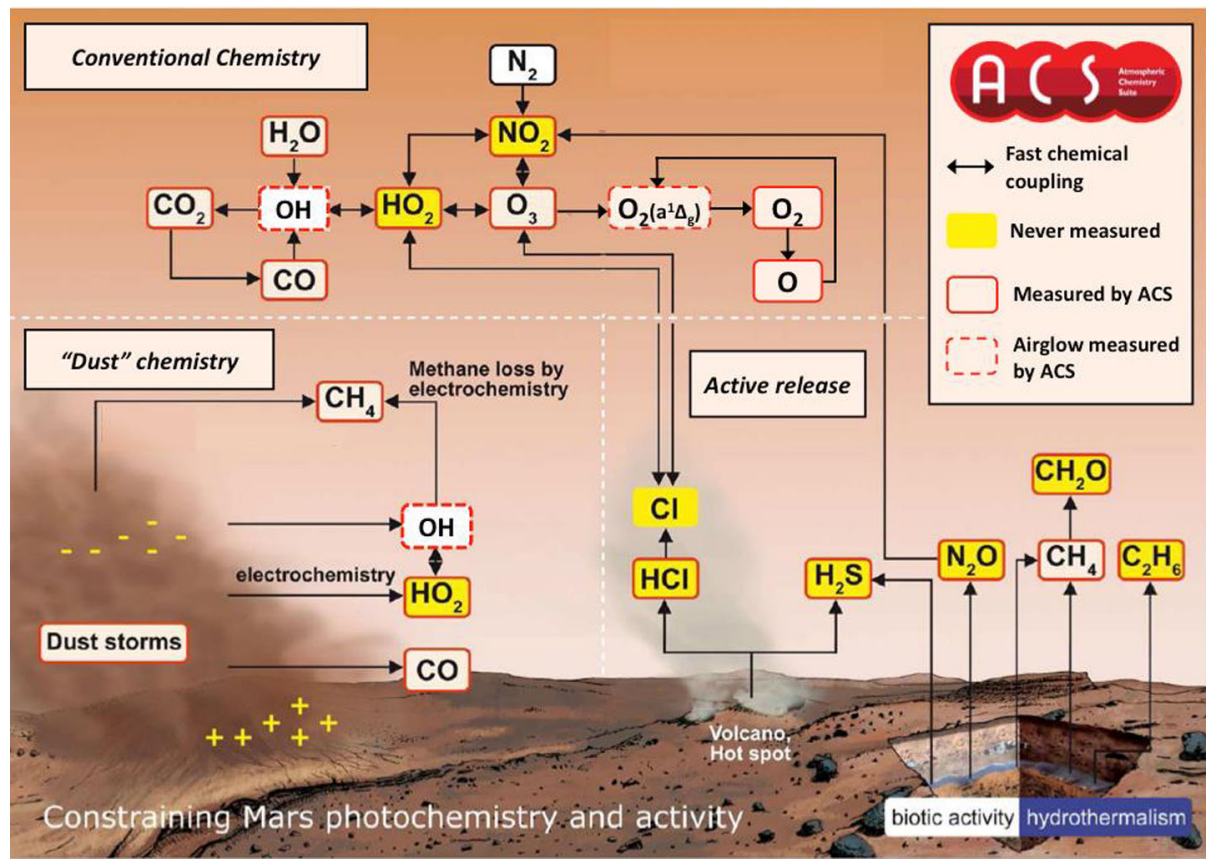

Fig. 3 The main photochemical pathways known or expected to occur on Mars and their relation to ACS measurement capabilities

one and up to several orders of magnitude (Table 1). Many of these gases may be indicators of subsurface activity (Fig. 3).

$\mathrm{HCl}$ is known to be outgassed by volcanoes on Earth and thus would point to the existence of seepages. Detection of $\mathrm{C}_{2} \mathrm{H}_{6}$ above $1 \mathrm{ppbv}$ would be indicative of active geochemical processes, as its production from biology and $\mathrm{CH}_{4}$ oxidation is expected to be several orders of magnitude smaller.

Both volcanism and biology produce $\mathrm{H}_{2} \mathrm{~S}$, but its presence would be indicative of an active surface or subsurface. $\mathrm{N}_{2} \mathrm{O}$ should have no significant abiotic source on Mars and thus its detection would rather point to a biogenic origin. Isotopologues are powerful probes of the origin and chemistry of trace gases. On Earth, the correlation between the ratio of $\mathrm{CH}_{4}$ over higher order alkanes and the isotopic composition of $\mathrm{CH}_{4}$ allows the discrimination between a biogenic and abiogenic source. ACS can detect as little as 25 pptv of ${ }^{13} \mathrm{CH}_{4}$, equivalent to $2 \%$ precision on the ${ }^{12} \mathrm{CH}_{4} /{ }^{13} \mathrm{CH}_{4}$ for a 45 ppbv abundance, which can potentially put constraints to help establishing the origin of Martian methane.

ACS will allow identification and quantification of a large majority of the targetable species (listed previously) simultaneously. Such capability of observing most gases during the same acquisition is a critical feature, which enables the estimation of the oxidation rate and the lifetime of chemical species controlled by both homogeneous and heterogeneous processes. Regions of active release, if present, will be localized using the observed concentration patterns that will be further refined by the application of the three-dimensional (3-D) models developed in our team (Forget et al. 1999; Lefèvre et al. 2004; Hartogh et al. 2005). Depending on the gases observed, or through ratios with isotopologues, fundamental information on the nature of the source (biogenic vs. abiotic) will be deduced. 


\section{2 "Novel" ACS Science}

HDO and $\mathrm{H}_{2} \mathrm{O}$ Cycles On Mars, the mean D/H ratio in water vapor is enriched by a factor of $5 \pm 2$ compared to the terrestrial ratio (SMOW). This strongly suggests that water escaped from the planet over ages, leading to an enrichment of the heavier isotope. Quantifying the amount of escaped water requires refinement of the present $\mathrm{D} / \mathrm{H}$ ratio and the differential escapes of $\mathrm{D}$ and $\mathrm{H}$. By measuring simultaneously the $\mathrm{H}_{2} \mathrm{O}$ and $\mathrm{HDO}$ columns, ACS will establish a reference value for the present Martian D/H ratio. Over the course of the mission, ACS shall provide a globally and seasonally averaged unbiased value at a precision level better than $1 \%$. The difference in mass, vertical distribution, and chemistry determines the differential escape of $\mathrm{D}$ and $\mathrm{H}$. ACS will simultaneously measure the $\mathrm{H}_{2} \mathrm{O}$ and HDO vertical profiles from the surface up to $60 \mathrm{~km}$. These measurements become increasingly powerful when coupled with the measurements of $\mathrm{D}$ and $\mathrm{H}$ performed by the MAVEN IUVS instrument at higher altitudes (see Clarke et al. 2017).

By measuring jointly $\mathrm{HDO}$ and $\mathrm{H}_{2} \mathrm{O}$ ACS will uniquely constrain the physics of the HDO cycle. Isotopic fractionation at condensation induces a strong distillation process depleting water vapor in deuterium (Fouchet and Lellouch 2000; Montmessin et al. 2005; Villanueva et al. 2015). The ACS observations of the HDO cycle over a full Martian year will validate our current understanding of the driving processes and potentially identify new ones. Such an understanding is a prerequisite to determine whether the perennial caps exhibit a different $\mathrm{D} / \mathrm{H}$ ratio from the atmosphere. With the secular variations of the obliquity, isotopic fractionation at condensation may have archived the Martian climate history via $\mathrm{D} / \mathrm{H}$ stratification in the polar caps. An in situ analysis of the isotopic composition of the polar caps is a must, yet such measurements are unlikely within the next decades. ACS can partially satisfy this kind of investigation by observing the deuterated content of the air masses flowing off the northern summer cap during the sublimation season, thereby opening the path for future measurements.

Oxidation State of the Martian Atmosphere On this topic, "Novel" science would emerge from a quantitative understanding of the chemistry that oxidizes trace and main gases in the Martian atmosphere. Such quantitative understanding of the Martian atmospheric chemistry requires knowledge of how the abundances of trace gases vary in space and time, and how they correlate with relevant environmental parameters including dust, water ice and temperature (the "Climatological" science part of ACS). Previous satellite experiments have demonstrated the importance of global mapping at all seasons to pinpoint the sources, sinks, and processes controlling the distribution of water vapor, dust (Smith 2004) or $\mathrm{O}_{3}$ (Perrier et al. 2006).

Similarly, ACS will acquire 2-D (Lat, Lon) maps reconstructed from profiling the key species needed to quantify the oxidizing capacity of Mars atmosphere $\left(\mathrm{CO}, \mathrm{H}_{2} \mathrm{O}, \mathrm{HO}_{2}, \mathrm{NO}_{2}\right)$ and the $\mathrm{OH}$ production rate. This information is required for characterizing the lifetime of trace species released in the atmosphere from the surface at different locations and seasons. The vertical profile of these trace gases will be established from $10 \mathrm{~km}$ up to $60 \mathrm{~km}$ at a vertical resolution of half a scale height $(\sim 5 \mathrm{~km})$.

Such understanding is a required step to determine the lifetime of trace gases and hence to understand their distribution. Oxidation of trace gases is believed to result from gas-phase chemical cycles catalyzed by hydrogen radicals. However, some relevant species have never been measured (Fig. 3). Heterogeneous electrochemical processes triggered by clouds or dust storms could also be important in regulating the amount of oxidants (Delory et al. 2006; Atreya et al. 2006). The simultaneous tracking of multiple tracers by ACS is intended to provide the needed information to help quantify the oxidation rate of trace gases on Mars, both 
by homogeneous and heterogeneous processes. In doing so, ACS will test our quantitative understanding of the gas-phase chemistry: hydrogen radicals $\left(\mathrm{HO}_{x}: \mathrm{H}, \mathrm{OH}, \mathrm{HO}_{2}\right)$ are produced in the Martian atmosphere by the photolysis of $\mathrm{H}_{2} \mathrm{O}$ and then initiate catalytic cycles that recycle $\mathrm{CO}_{2}$ from its photolysis product $\mathrm{CO}$. The concurrent mapping of $\mathrm{CO}$ and $\mathrm{H}_{2} \mathrm{O}$ will be a key measurement to determine the global oxidation rate of $\mathrm{CO}$ by $\mathrm{OH}$. ACS will also provide a renewed characterization of the $\mathrm{HO}_{x}$ abundance and variability. Detection of $\mathrm{HO}_{2}$ will give a direct access to a member of the $\mathrm{HO}_{x}$ family (Fig. 3).

Concurrent measurement of $\mathrm{HO}_{2}$ and its source molecule $\mathrm{H}_{2} \mathrm{O}$ will be a major step forward to validate, improve, and understand quantitatively the processes responsible for the oxidation of trace gases in the Mars atmosphere. New information on the production of $\mathrm{HOx}$ will also be provided by the measurement of $\mathrm{OH}$ airglow, reported by Clancy et al. (2013). ACS will also observe $\mathrm{O}_{3}$ through the $\mathrm{O}_{2}\left(\mathrm{a}^{1} \Delta_{g}\right)$ dayglow, which are very sensitive to the local abundance of $\mathrm{HO}_{x}$. As on Earth, $\mathrm{N}$ and $\mathrm{Cl}$ compounds might also produce oxidants and play an important role in Mars photochemistry. With upper limits on $\mathrm{NO}_{2}$ and $\mathrm{HCl}$ improved by two orders of magnitude (in solar occultation), ACS will provide observations needed to quantify the role of the $\mathrm{N}$ and $\mathrm{Cl}$ species in the chemical equilibrium of the Martian atmosphere.

ACS will also be used to test the hypothesis of electrochemical activity and heterogeneous chemistry. Model simulations (performed by the ACS science team members) have shown that current observations of $\mathrm{CH}_{4}$ imply the existence of an unknown sink that is $>300$ times more efficient than the loss predicted by conventional chemistry (Lefèvre and Forget 2009). Delory et al. (2006), Farrell et al. (2006) proposed that $\mathrm{CH}_{4}$ could be destroyed by electrochemical processes triggered by the strong electric fields within dust storms. If true, these mechanisms should produce detectable increases in $\mathrm{HO}_{2}(>200 \mathrm{ppbv}$ ) and $\mathrm{CO}\left(>15,000\right.$ ppmv) from the electrochemical dissociation of $\mathrm{H}_{2} \mathrm{O}$ and $\mathrm{CO}_{2}$, respectively (Fig. 3, and Delory et al. 2006). Through its ability to observe the spatial distribution of $\mathrm{CH}_{4}, \mathrm{HO}_{2}, \mathrm{CO}$, and aerosol dust simultaneously, ACS will provide a definitive answer on electrochemistry in dust storms as a cause for the apparently reduced lifetime of $\mathrm{CH}_{4}$ on Mars. Heterogeneous reactions on ice cloud particles have also been proposed to explain discrepancies between $\mathrm{O}_{3}$ measurements and model calculations (Lefèvre et al. 2008). Concurrent observations of $\mathrm{HO}_{2}, \mathrm{O}_{2}\left(\mathrm{a}^{1} \Delta_{g}\right)$, and water ice by ACS will help us test this kind of hypothesis.

In addition, ACS will put us in the position of testing the $\mathrm{CH}_{4}$ gas-phase loss mechanisms. Independent of possible heterogeneous loss processes, $\mathrm{CH}_{4}$ is in theory oxidized by reactions with $\mathrm{OH}$ and $\mathrm{O}\left({ }^{1} \mathrm{D}\right)$. ACS observations of $\mathrm{H}_{2} \mathrm{O}, \mathrm{HO}_{2}$, and the $\mathrm{OH}$ emission will be used to constrain the $\mathrm{OH}$ chemistry, whereas the $\mathrm{O}_{2}\left(\mathrm{a}^{1} \Delta_{g}\right)$ airglow will constrain the $\mathrm{O}\left({ }^{1} \mathrm{D}\right)$ abundance. ACS will also have the ability to detect the main intermediate product of $\mathrm{CH}_{4}$ oxidation, $\mathrm{CH}_{2} \mathrm{O}$. Simultaneous detection of $\mathrm{CH}_{4}$ and $\mathrm{CH}_{2} \mathrm{O}$ will provide new information for a quantitative understanding of what is thought to be the conventional loss mechanism of $\mathrm{CH}_{4}$. ACS will also determine the role of $\mathrm{Cl}$ in the chemistry of $\mathrm{CH}_{4}$. As in the Earth's stratosphere, $\mathrm{Cl}$ could contribute up to $30 \%$ of the loss of Martian $\mathrm{CH}_{4}$. By performing the most sensitive search for $\mathrm{HCl}$ to date, ACS will provide the required information to evaluate how much $\mathrm{CH}_{4}$ can be destroyed by $\mathrm{Cl}$ in the atmosphere of Mars.

\section{3 “Climatological” ACS Science}

The nadir mapping capability of ACS NIR and TIRVIM channels will provide a global view of the spatial and temporal variability of trace gases, with sensitivity all the way down to the surface level, even under conditions of high dust loading. Concurrent mapping and 
vertical profiling of standard climatic variables (dust, clouds, temperature) will relate the trace species to their environmental context, providing a continued long-term monitoring of the present climatic conditions.

In addition, the unique characteristics of the TGO orbit will allow a detailed sampling of the diurnal cycle of the main climatic properties of the Martian atmosphere. As designed, the TGO orbit during the Science Phase will produce a complete daily cycle every two months, yielding a representative atmospheric state every hour of the day. No other spacecraft in the past was able to perform this kind of survey and TGO will thus open a new era of investigations, constraining Martian climate variability from diurnal through seasonal up to interannual timescales. This kind of information has long remained the unique feature of landed missions. With TGO and ACS, a detailed study of atmospheric wave amplitude and propagation thanks to temperature profiling will be carried out in an unprecedented way. Diurnal variations of the surface temperature will also place the most detailed constraints to date for retrieving the thermal inertia properties of the surface and may actually reveal departures from simple surface representations indicative of a more complex behavior of the thermal wave propagation inside the Martian regolith.

Correlating trace species variability with environmental variations (temperature measurements) is important as it controls gas-phase reaction rates and hence the lifetime of trace species. Knowledge of the water-ice and dust particles distribution is also essential to test the hypothesis of heterogeneous reactions on ice clouds, electrochemical processes in dust storms, or the presence of airborne $\mathrm{CH}_{4}$ clathrate particles. The correlation of the spatial distribution and temporal variation of trace gases with the environmental parameters is known to be critical for a comprehensive understanding of the dominant climatic mechanisms.

ACS will map the water vapor, the dust and water ice column densities for a full Martian year. Together with the previous surveys by MGS/TES, Odyssey/THEMIS, MEX/SPICAM, and MRO/CRISM, ACS will add to the long-term perspective necessary to determine if there are any inter-annual climate trends and further help to identifying the driving mechanisms. In particular, ACS-NIR will extend the over 15 Martian years of $1.38 \mu \mathrm{m}$ water band monitoring initiated by Viking/MAWD, and also pursued by SPICAM-IR. Ultimately, such multi-annual surveys are crucial to test the models that are used to simulate the ancient climates under different orbital and solar forcing conditions.

In solar occultation, ACS will measure routinely the vertical temperature profile from near-surface up to $160 \mathrm{~km}$. Solar occultation profiles will also yield the dust and water ice number density and particle size distribution. These environmental observations will allow estimation of the available surface area for heterogeneous reactions, sedimentation rates, and feedback mechanisms between the dust and water cycles (scavenging and super-saturation). With its nadir mapping capability, ACS will provide a global view of the spatial distribution of temperature dust and water ice cloud opacities. These measurements are a prerequisite for correlating aerosols and condensates with observed variations in the trace gas maps, and hence for identifying the role of heterogeneous chemistry and electrochemistry in the atmosphere.

\section{ACS Design}

\subsection{ACS Architecture}

ACS includes three separate spectrometers. On the TGO spacecraft the instrument occupies the slot at the upper deck (Fig. 2). ACS has several optical openings allowing observations in 


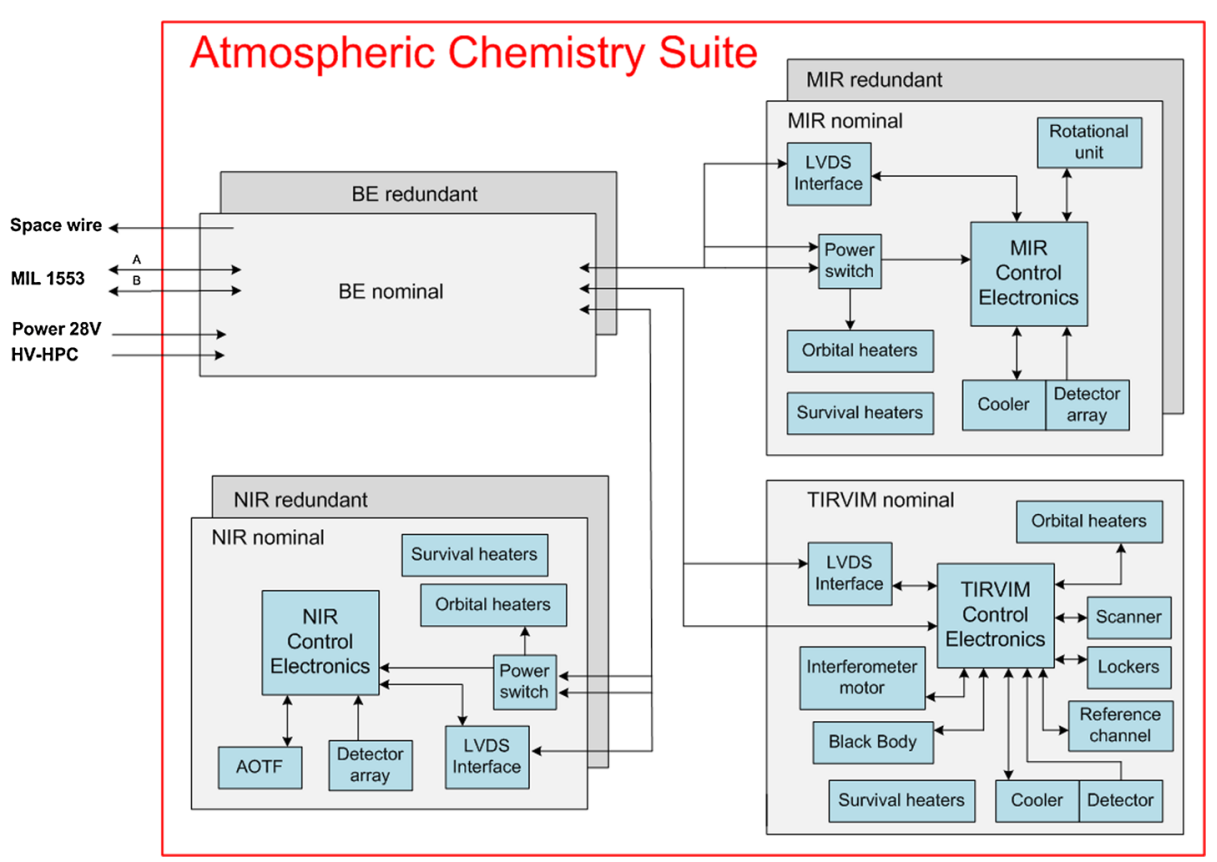

Fig. 4 The ACS block diagram

$\operatorname{nadir}(\overrightarrow{-Y}, \overrightarrow{-X}$ spacecraft coordinates, Fig. 2). The accuracy of spacecraft attitude control is $\pm 1 \mathrm{mrad}$. The main opening of NIR is pointed to the nadir direction. The scanner mirror rotates within full $360^{\circ}$ with minimal step $0.1^{\circ}$, allowing to point in nadir, to the internal blackbody, and to the open space, which is necessary for absolute calibration of TIRVIM. TIRVIM is also equipped with a separate solar port.

The ACS block diagram is shown in Fig. 4, and its concept design-in Fig. 5. The instrument consists of four blocks bolted together and sharing the mechanical and thermal interfaces to the spacecraft. Roughly two thirds of its mass allocation of $33.5 \mathrm{~kg}$ is dedicated to larger channels, MIR and TIRVIM. The remaining mass is shared between the smaller NIR channel, the main electronics (Block of Electronics, BE), and the mechanical structure, thermal insulation, fixation brackets, etc. The BE is the only electrical interface of the ACS with TGO in terms of power, commands and data. The science channels can be operated together or standalone, or in any combination. The BE, MIR and NIR channels have two fully redundant sets of electronics. Either set of electronics in a science channel can be used with either set in the BE. The redundant set of the TIRVIM electronics could not be accommodated because of limited mass allocation. The ACS-BE turns on the scientific channels powering redundant $24-\mathrm{V}$ lines. These internal power lines are conditioned and isolated from the spacecraft $28-\mathrm{V}$ power line.

General measurement and interface parameters of ACS are summarized in Table 2.

Following the TGO requirements, the ACS suite regulates its thermal characteristics, minimizing the thermal flux to the spacecraft. Low-conductive titanium brackets are used for the mechanical fixation at the TGO honeycomb deck. The whole instrument is covered by MLI thermal blanket manufactured and tailored by NIIKAM (Russia). The MLI has a good conductivity, and can resist temperature loads during TGO aerobreaking. The thermal control is provided by several radiators placed at the upper plane of TIRVIM and MIR 

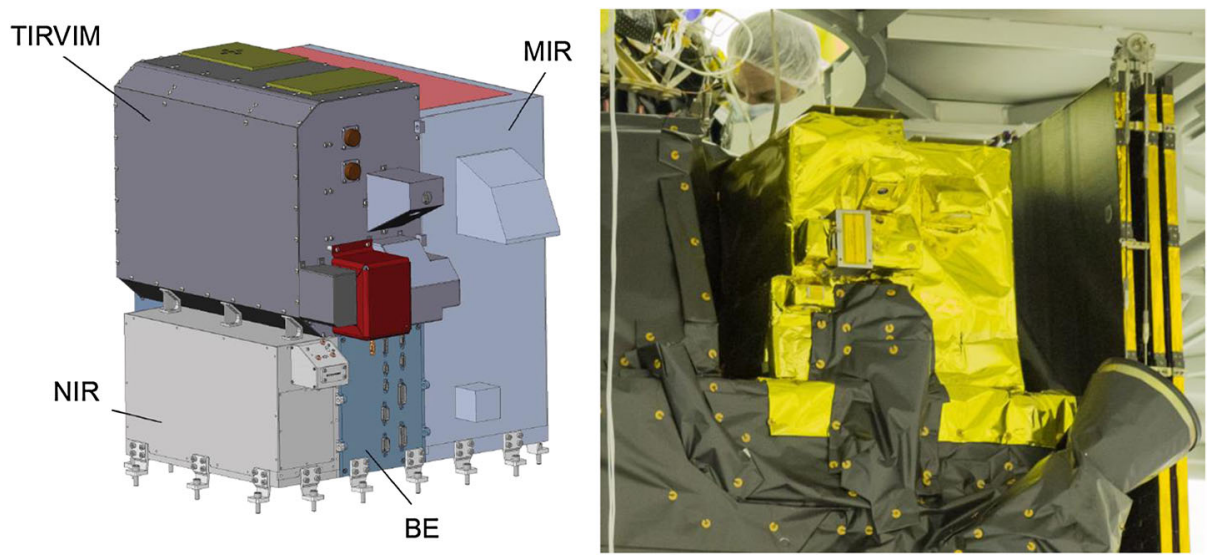

Fig. 5 (a) The concept design of ACS showing its four blocks: The NIR channel, MIR channel, the TIRVIM channel and the electronic block. The instrument's radiators are on the upper panels of TIRVIM and MIR. (b) The ACS protoflight model mounted on the TGO spacecraft (at premises of TAS-F, Cannes, France)

channels (+X axis of the spacecraft, see Fig. 1), and by means of several independent operational and survival thermal control systems. The radiators are covered by EKOM-1 enamel by Kompozit (Russia), and are solar-blind.

During the cruise and aerobraking phases the BE is OFF, and the temperature in the scientific channels is maintained at acceptable level by dedicated survival heaters subsystems (Fig. 4). These systems include thermosensors and heaters and are powered via dedicated power line $(20-40 \mathrm{~V})$ directly from the spacecraft, bypassing the BE.

TIRVIM is thermally insulated from other ACS constructions by means of plastic brackets and MLI patches. Some parts of TIRVIM could not be covered by MLI, and in order to diminish the thermal emission they were gold-coated by EKOMET (Russia). One of the two TIRVIM radiators drains the heat from the Stirling cooler, and the other regulates the overall instrument's temperature. For maintaining a stable thermal environment it is planned that TIRVIM will be permanently ON when in TGO science orbit around Mars. It will predominantly perform nadir measurements, and will occasionally measure while the spacecraft is in solar occultation attitude.

\subsection{NIR Channel}

Concept The ACS NIR channel employs the same optical layout as the SPICAV/SOIR (Solar Occultation Infrared) instrument on the ESA Venus Express mission, that is a combination of an echelle spectrometer and an acousto-optic tunable filter (AOTF) for the selection of diffraction orders. In space research this scheme was proposed and prototyped for the measurements of the terrestrial atmosphere (Korablev et al. 2002) and first implemented in space for Venus Express (Nevejans et al. 2006). NOMAD on TGO (Vandaele et al., this issue) employs the same principle and includes two similar SOIR-type spectrometers. The echelle-AOTF combination allows one to reach high spectral resolution in a compact and robust design. Several diffraction orders can be sequentially acquired during one measurement and they can be located anywhere within the entire spectral range thanks to the AOTF tuning versatility. Within the NIR range, atmospheric spectra are generally featureless, dominated by dust particle continuum properties, yet a number of spectral intervals can be used 
Table 2 Measurement and interface parameters of the three scientific channels of ACS and the overall values for the whole instrument

\begin{tabular}{|c|c|c|c|c|}
\hline Parameter & NIR & MIR & TIRVIM & ACS \\
\hline $\begin{array}{l}\text { Operation } \\
\text { modes }\end{array}$ & $\begin{array}{l}\text { Nadir (dayside } \\
\text { and night side), } \\
\text { SO, Limb }\end{array}$ & $\begin{array}{l}\text { Solar occultation } \\
\text { (SO) }\end{array}$ & $\begin{array}{l}\text { Nadir (dayside and } \\
\text { night side), SO }\end{array}$ & Nadir, SO, Limb \\
\hline $\begin{array}{l}\text { Field of view } \\
\text { (FOV) }\end{array}$ & $2 \times 0.02^{\circ}$ & $10 \times 0.5$ arc min & $\begin{array}{l}\varnothing 2.5^{\circ} \text { in nadir full } \\
\text { solar disk in SO }\end{array}$ & \\
\hline Spectral range & $0.73-1.6 \mu \mathrm{m}$ & $2.3-4.3 \mu \mathrm{m}$ & $1.7-17 \mu \mathrm{m}$ & $0.73-17 \mu \mathrm{m}$ \\
\hline $\begin{array}{l}\text { Instantaneous } \\
\text { spectral range }\end{array}$ & $\begin{array}{l}50 \times 100 \mathrm{~cm}^{-1} ; \\
16 \mathrm{~nm} \text { at } 1.37 \mu \mathrm{m}\end{array}$ & $\begin{array}{l}10 \times(0.09-0.27 \mu \mathrm{m}) \\
\text { ex. } 3.13-3.41 \mu \mathrm{m}\end{array}$ & Full range & \\
\hline $\begin{array}{l}\text { Time to } \\
\text { measure one } \\
\text { spectrum }\end{array}$ & $\begin{array}{l}5 \mathrm{~s} \text { Nadir } \\
50 \mathrm{~ms} \mathrm{SO}\end{array}$ & $0.5-2 \mathrm{~s}$ & $\begin{array}{l}6.6 \text { s Nadir (a pair) } \\
1.8 \text { s SO (single) }\end{array}$ & \\
\hline $\begin{array}{l}\text { Number of } \\
\text { spectra per } \\
\text { measurement }\end{array}$ & $\leq 10$ & 1 or 2 & 2 in nadir 1 in SO & \\
\hline $\begin{array}{l}\text { Spectral } \\
\text { resolution/ } \\
\text { resolving } \\
\text { power }\end{array}$ & $\begin{array}{l}\lambda / \Delta \lambda= \\
20,000-27,000\end{array}$ & $\begin{array}{l}\lambda / \Delta \lambda= \\
30,000-50,000\end{array}$ & $\begin{array}{l}0.8 \mathrm{~cm}^{-1} / \\
7600-760 \text { (nadir) } \\
0.13 \mathrm{~cm}^{-1} / \\
45,200-4520 \mathrm{SO}\end{array}$ & \\
\hline $\mathrm{SNR}$ in $\mathrm{SO}$ & 4000 & $2500-5000$ & $50-170^{*}$ & \\
\hline NER in nadir & $0.5 \mathrm{~W} / \mathrm{m}^{2} / \mathrm{sr} / \mu \mathrm{m}$ & $\mathrm{N} / \mathrm{A}$ & $10^{-4} \mathrm{~W} / \mathrm{m}^{2} / \mathrm{sr} / \mathrm{cm}^{-1}$ & \\
\hline Mass & $3.2 \mathrm{~kg}$ & $12.2 \mathrm{~kg}$ & $12 \mathrm{~kg}$ & $33.5 \mathrm{~kg}$ \\
\hline $\begin{array}{l}\text { Power } \\
\text { consumption } \\
\text { during } \\
\text { operations }\end{array}$ & $9 \mathrm{~W}$ & $21 \mathrm{~W}$ & $15 \mathrm{~W}$ & $51 \mathrm{~W}$ (at peak) \\
\hline Survival heaters & $4 \mathrm{~W}$ & $10 \mathrm{~W}$ & $8 \mathrm{~W}$ & $22 \mathrm{~W}$ \\
\hline Volume & $12 \times 35 \times 25 \mathrm{~cm}^{3}$ & $20 \times 50 \times 60 \mathrm{~cm}^{3}$ & $20 \times 44 \times 30 \mathrm{~cm}^{3}$ & $52 \times 60 \times 47 \mathrm{~cm}^{3}$ \\
\hline $\begin{array}{l}\text { Data rate (ICD } \\
\text { allocation) }\end{array}$ & 0.1 Gbit/day & 0.7 Gbit/day & 0.7 Gbit/day & 1.6 Gbit/day \\
\hline
\end{tabular}

Note: *SNR Demonstrated so far in the flight calibrations. Measures are planned to increase the SNR of TIRVIM in SO up to $\sim 1000$

to cover interesting species. The main disadvantage of this design is the narrowness of the selected spectral intervals. In addition, sidelobes of the sinc function representative of the AOTF spectral bandpass imply that adjacent diffraction orders superimpose on top of each other. Also, the echelle grating efficiency quickly decreases away from the blaze angle (center of the detector) and, combined with a similar effect of the AOTF bandpass curve, induces a significant reduction of signal near the edges of the detector.

The closest analogue of NIR is the RUSALKA instrument (Russian acronym for Manual Spectral Analyzer of the Atmosphere Constituents), flown on the International Space Station (ISS) in 2009-2012 (Korablev et al. 2011). RUSALKA covered the spectral range of $0.7-1.65 \mu \mathrm{m}$ with a resolving power of $\lambda / \Delta \lambda \approx 20,000$, and demonstrated its capability to measure terrestrial $\mathrm{CO}_{2}$ and $\mathrm{CH}_{4}$ lines in a nadir viewing. Still, cosmonauts operated 

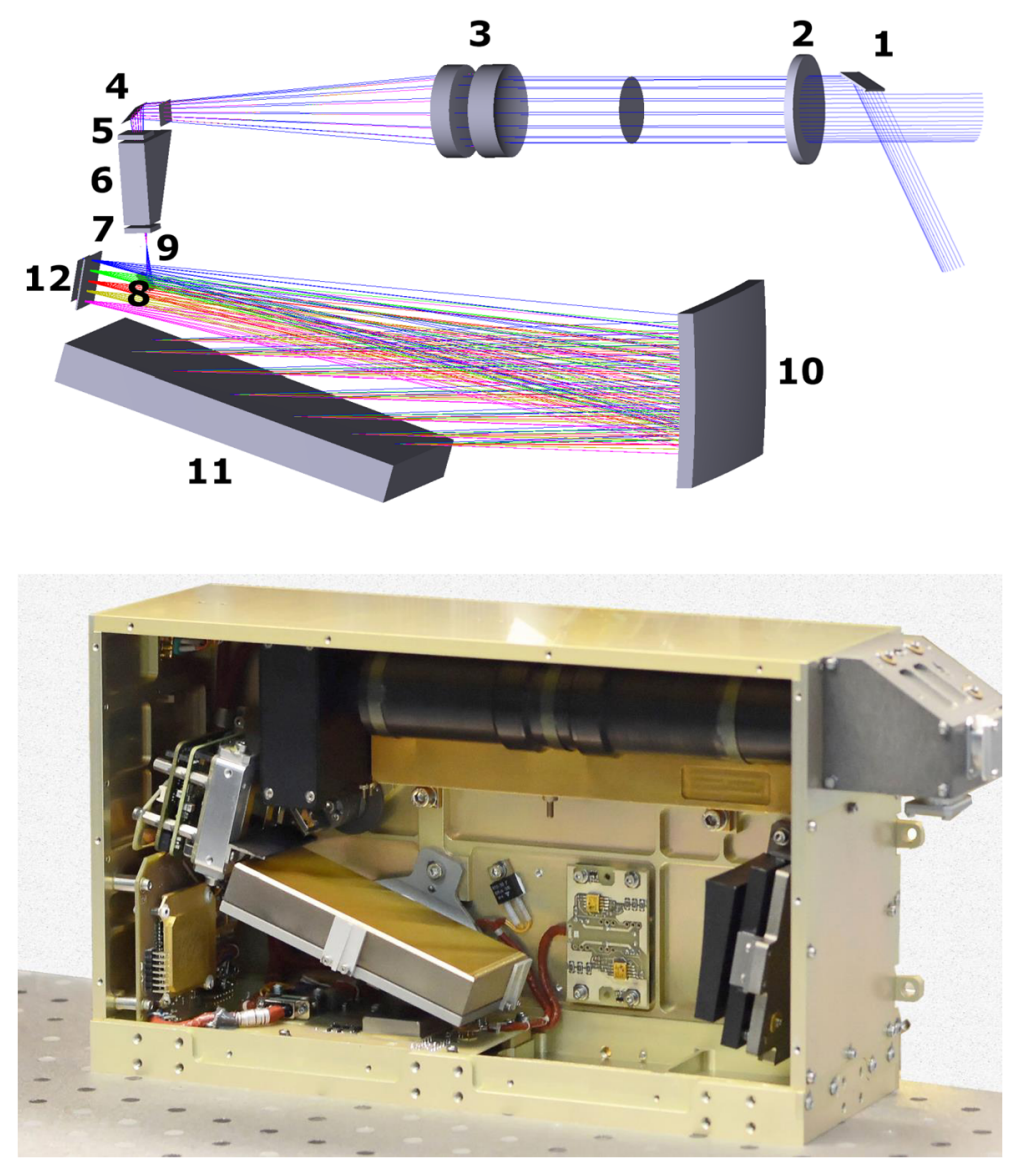

Fig. 6 (a) A simplified optical scheme of the NIR channel. 1-solar periscope; 2-blocking filter; 3-entry telescope; 4, 8-folding mirrors; 5, 7-polarizers; 6-AOTF crystal; 9-slit; 10-collimating mirror; 11-diffraction grating; 12-detector array. (b) Qualification model of ACS-NIR with open cover, showing the main elements of the optical scheme

RUSALKA in the habitable compartment of the ISS, and the instrument was built according to requirements far less stringent than those imposed for a deep space mission such as TGO. ACS NIR is an adaptation of the RUSALKA design with several modifications aimed to improve the sensitivity and the optical quality of the instrument.

ACS NIR can perform nadir and occultation observations using two optical ports. A part of the nadir aperture of the instrument $(\varnothing 20 \mathrm{~mm})$ is blocked by a periscope mirror, forming the solar port.

Optical Scheme The optical scheme of the instrument consists of two main parts (see Fig. 6). The entry part, illuminating the slit of the echelle spectrometer includes the foreoptics, the telescope, and the AOTF with a number of auxiliary elements such as polarizers, diaphragms, etc. The entrance lens doublet has a focal length of $120 \mathrm{~mm}$. A red filter cancels out all wavelengths shorter than $0.7 \mu \mathrm{m}$.

The AOTF is an optical filter based on the principle of acousto-optic diffraction in an anisotropic medium. The central wavelength of the filter spectral response function (SRF) 

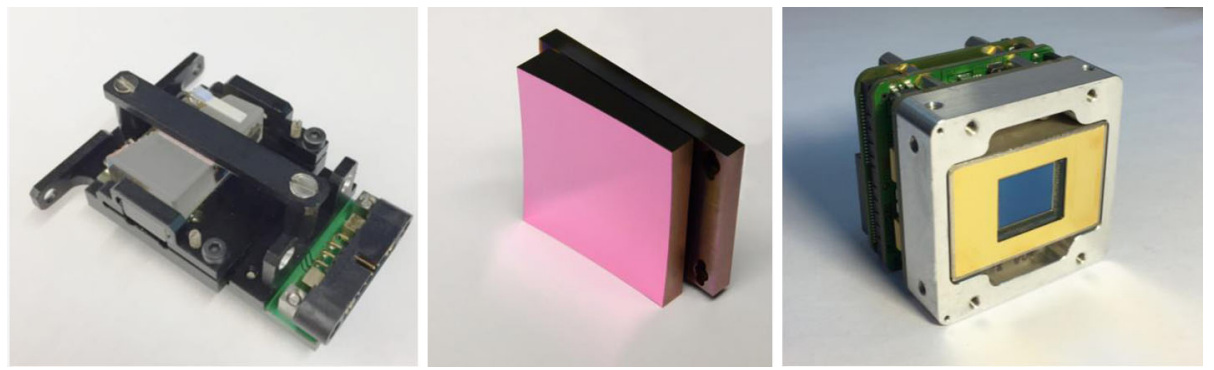

Fig. 7 Key elements of the ACS-NIR: (a) AOTF unit; (b) spectrometer autocollimating mirror; (c) InGaAs detector unit

is determined by the frequency of the ultrasonic wave in a birefringent crystal excited by an acoustic transducer. A non-collinear $\mathrm{TeO}_{2}$ AOTF is employed (Chang 1974). The acoustic wave modifies the refractive index, and diffraction at the resulting distributed structure separates the incident ray into two diffracted beams and a zero-order beam. The acousto-optic interaction length is $27 \mathrm{~mm}$. The diffracted and non-diffracted rays are polarized athwart, permitting the use of polarizers to suppress the unwanted zero order. Besides, the non-diffracted light is separated angularly from the main throughput.

In contrast to previous AOTF-echelle based designs, this AOTF is placed in a converging beam. Therefore, the AOTF unit is a part of the foreoptics: it includes the polarizers and some folding mirrors (Figs. 6a, 7a). The FOV of the instrument is determined by the slit dimensions. The entrance optics, including the AOTF crystal preserves the image of the observed scene with a good quality over the full spectral range. This allows the use of NIR as a hyperspectral imager both with good spectral and spatial resolution. Undesired stray light in the entry part of the optical scheme is suppressed inside a long baffle that also holds the foreoptics elements.

The beam filtered in by the AOTF passes through the slit into the echelle-spectrometer. The slit has a size of $4 \mathrm{~mm} \times 40 \mu \mathrm{m}$, forming a FOV of approximately $2^{\circ} \times 0.02^{\circ}(35 \times 0.35$ $\mathrm{mrad})$. The slit is inclined at $5.5^{\circ}$ around the optical axis to compensate for the tilt of the slit image on the detector. The echelle-spectrometer employs a Littrow auto-collimation scheme, with a single off-axis parabolic mirror. The separation of the incident and the dispersed light is made in the plane perpendicular to the dispersion (along the slit height). A custom-size echelle grating from Spectra Physics Corp., Richardson Grating Laboratories (USA) on a Zerodur $^{\circledR}$ substrate has a blaze angle of $70^{\circ}$ (R3), 24.35 grooves $/ \mathrm{mm}$, and a useful area of $46 \times 102 \mathrm{~mm}^{2}$. The parabolic collimator mirror is fabricated by diamond turning from aluminum alloy (it has a focal length of $200 \mathrm{~mm}, 10^{\circ}$ off-axis, size $58 \times 53 \mathrm{~mm}^{2}$ ). Its surface is additionally polished and coated with copper (Fig. 7b).

Compared with the heritage design of RUSALKA, NIR features a higher slit in combination with a 2D array detector (instead of a linear detector on RUSALKA), which captures the dispersed light along the full dimension of the slit. We adapted for space the infrared camera module XSW-640 from Xenics (Belgium) based on a thermo-electrically cooled (Peltier element) InGaAs array of $640 \times 512$ pixels (Fig. 7c). This detector features a pixel size of $20 \times 20 \mu \mathrm{m}^{2}$, and a spectral range defined by the InGaAs sensitivity domain between 0.4 and $1.7 \mu \mathrm{m}$. The slit is imaged onto the detector with a ratio of $1: 1$, so only a part of the detector's height ( $4 \mathrm{~mm}$ or $\sim 200$ out of 512 pixel lines) is illuminated.

The main specification of the RUSALKA-SOIR design is that the AOTF spectral response function (SRF) width must be aligned with the free spectral range of the echelle 
spectrometer. Expressed in wavenumbers, the free spectral range is independent to wavelength:

$$
\Delta v=\frac{1}{2 a \cdot \sin \theta},
$$

where $1 / a$ is the number of grooves per $\mathrm{cm}$, and $\theta$ is the blaze angle (in autocollimation). If one ignores the dispersion of the $\mathrm{TeO}_{2}$, the width of the SRF is approximately constant in wavenumbers as well. By design, the half-width of the AOTF SRF is $70 \mathrm{~cm}^{-1}$.

The spectral range of the instrument $(0.73-1.6 \mu \mathrm{m})$ corresponds to the echelle diffraction orders from 48 through 105 . The spectral resolution is limited by the slit width and aberrations of the off-axis parabolic collimator. Following the sampling theorem ( 2 pixels per resolution element) the resolving power of an aberration-free spectrometer reaches $R \approx 27,500$. The resolving power is variable over the detector and also depends on the diffraction order, but remains always $\geq 20,000$ (see Sect. 4.1 below).

Electronics and Software The NIR electronics consists of a power board with DC/DC converters and power switch, a processor module board, the XSW-640 detector module and the AOTF control electronics. These three modules of ACS NIR instrument are functionally independent devices and combined only with power lines and digital communication interfaces. Power board and processor module board are fully redundant. Thermal regulation systems are physically and logically separated from the electronics itself. Survival heaters are powered via fully independent line and they are always ON when the rest of the electronics is OFF.

The NIR control electronics is built around the TCM-BF537 processor module. Parallel Port Interface (PPI) of the processor module is used to input video data from the detector. Switchable line serial ports UART0 and UART1 are used to control the detector and AOM, as well as for communication with ACS BE. Serial Clock frequency is $129.17 \mathrm{MHz}$, supporting $8 \mathrm{Mb} / \mathrm{s}$ interface speed with $\mathrm{BE}$ and $115.2 \mathrm{~kb} / \mathrm{s}$ with AOTF and the detector.

An AOTF module includes a microprocessor control system, a digitally controlled frequency synthesizer and a RF power amplifier. It is powered throughout the session, but the RF power to the crystal is sent only by the external command from the NIR control electronics. The same command also sets the frequency and the power of the RF signal. The frequency is set within a range of $64-156 \mathrm{MHz}$ with a $50 \mathrm{kHz}$ step. A limit of $100 \mathrm{~ms}$ for the duration of a single turn $\mathrm{ON}$ is used to protect crystal from overheating.

The detector module is working in the Integrate Then Read (ITR) mode, exposure starts with an external signal. A built-in Peltier cooling system of the detector can operate in the temperature stabilization mode and the temperature can be set with an accuracy of $3 \mathrm{~K}$.

Operations Each NIR observation session starts with a dedicated telecommand. A 64byte command contains all the necessary parameters, including timing (overall time of observation, pauses, exposition time etc.), AOTF and detector settings, and also frame processing customization.

The instrument can be programmed to register sequentially up to ten diffraction orders (10 different AOTF tunings, i.e. acoustic frequencies and therefore 10 relatively small portions of the whole $0.73-1.6 \mu \mathrm{m}$ range).

Depending on the telecommand, the NIR electronics commands the AOTF module to set the required frequency and triggers a detector exposure. After the integration time a single frame is read out within $9 \mathrm{~ms}$ (the ITR mode). At each frequency the instrument always performs two integrations, one with the AOTF ON and another with the AOTF OFF to allow dark subtraction subsequently. Either both frames are transmitted or only their difference. 
The exposure time can be tuned from $0.45 \mathrm{~ms}$ to $100 \mathrm{~ms}$ depending on the observation regime. Furthermore, an on-board image averaging up to 96 single frames can be programmed in flight. The full frames are accumulated and averaged onboard by the NIR electronics for each frequency. In this case the control electronics continues to measure pairs of frames, stacking them in the internal memory. The resulting frame is scaled to fit each pixel value into 16 bits and then can be cut into up to five bands of programmable position and height ( 5 different areas on the detector). Each band contains a 640-pixel spectrum, corresponding to a certain portion of the slit height. Further co-adding along the height of each band into a line is also possible to reduce the data downlink volume.

Measurements for all given frequencies continue in a loop with a programmed duty factor, which will be used to regulate the data rate during nadir measurements.

\subsection{MIR Channel}

Concept The MIR channel is a cross-dispersion spectrometer working in the 2.3-4.2 $\mu \mathrm{m}$ spectral range and acquiring simultaneously up to $0.3 \mu \mathrm{m}$ per measurement. The echelle orders are dispersed along the $x$-axis and separated along the $y$-axis of the focal plane by a secondary dispersion element, making full use of the 2-D detector array. This concept is used in astronomy and has been employed in planetary missions with VIRTIS-H (Visible and InfraRed Thermal Imaging Spectrometer with High resolution) instrument flown on Rosetta and Venus Express (Coradini et al. 2007). VIRTIS-H acquires the spectral range of 2-5 $\mu \mathrm{m}$ instantaneously using an echelle grating and a prism. With a number of diffraction orders of $\sim 10$, the resolving power of VIRTIS-H is $\lambda / \Delta \lambda \approx 2000$. Targeting much higher resolving power, ACS-MIR features an echelle-spectrometer with a higher dispersion, and a steerable secondary dispersion element (reflecting grating). Working at high diffraction orders the instrument captures from 10 to 30 adjacent diffraction orders at once, covering approximately $15 \%$ of the spectral range in a single integration. Steering the secondary disperser allows one to switch from one group of diffraction orders to another, alternating between desired positions during one measurement sequence.

By analogy with MATMOS, several photometric channels for the wavelengths from 200 to $900 \mathrm{~nm}$ were studied for inclusion in MIR (Korablev et al. 2014). Their implementation would have supported aerosols characterization, and allow for measurements of UVabsorbing species. However, this unit did not fit into the initial allocated mass budget of ACS. Instead, aerosol studies will be carried out by combining the measurements made by all ACS channels (and potentially with NOMAD UV-visible spectra).

The Optical Scheme The optical scheme of MIR may be separated into three main parts, the entry optics, the echelle spectrometer, and the secondary disperser (see Fig. 8). All the refractive elements are made in $\mathrm{ZnSe}$ and $\mathrm{CaF}_{2}$, transparent in the visible. Reflective elements are fabricated of aluminum alloy by diamond turning.

Radiation from the sun, passing through the Martian atmosphere, is directed inside the instrument by a periscope, which is imposed by mechanical constraints. A longpass entry filter is made of AR-coated Si 5-mm slab. The telescope forms the image of the solar disk on the slit $(400 \mu \mathrm{m} \times 30 \mu \mathrm{m})$. The FOV of $0.3 \times 4.1 \mathrm{mrad}$ is determined by the slit dimensions.

Similar to the ACS-NIR the echelle-spectrometer of MIR employs the autocollimation Littrow scheme. Two conditions are needed to achieve a high spectral resolution: firstly, the echelle grating must be large enough and have a high linear dispersion. The diffractionlimited resolving power is given by

$$
R_{D L}=\frac{\lambda}{\Delta \lambda} \approx \frac{2 D}{\lambda} \tan \theta
$$


Fig. 8 (a) A simplified optical scheme of the MIR channel. Foreoptics: 1, 3, 5-folding mirrors; 2-blocking filter; 4 -entry telescope.

Spectrometer: 6-slit;

7-primary collimator mirror, 8-secondary collimator mirror, 9- echelle diffraction grating, 10 -folding convex mirror; 11 -collimator of the secondary grating; 12 - steerable secondary grating. Detector and the proximity optics: $13-14$ detector's focusing lenses; 15-cold filter; 16-detector array. (b) Proto-flight model of ACS-MIR with open cover, showing the main elements of the optical scheme
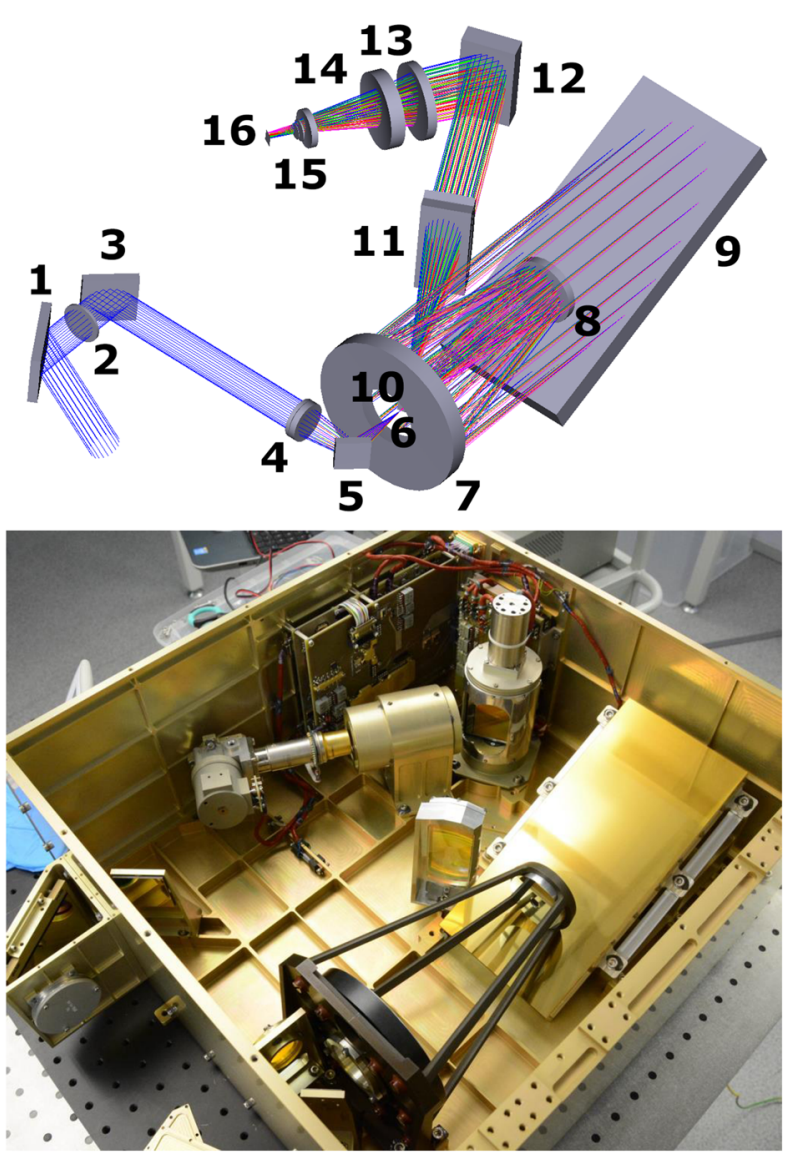

where $D$ is the collimator diameter and $\theta$ is the blaze angle. For the worst case of $4.3 \mu \mathrm{m}$ and $\tan \theta=2$ the ACS requirement of $R \geq 50,000$ implies $D \geq 54 \mathrm{~mm}$ that stays within allocations. The linear dispersion determines a slit-limited resolving power

$$
R_{S l}=2 \tan \theta \frac{f_{c o l}}{\delta_{S l}}
$$

where $f_{c o l}$ is the collimator focal length, and $\delta_{s l}$ is the slit width. IR arrays with a pitch of less than $15 \mu \mathrm{m}$ are not available, and to satisfy minimal sampling the slit should be $2 \times 15 \mu \mathrm{m}$ wide. Then the requirement of $R \geq 50,000$ results in $f_{\text {col }} \geq 500 \mathrm{~mm}$. This value is the principal design driver: it determines the size of the grating and the dimensions of the MIR channel in general. The large focal length in a reasonable volume is achieved using a twomirror collimator designed and fabricated by NIIKI (Sosnovy Bor, Russia; see Fig. 9a). Both mirrors are aspherical. The aperture of the collimator is chosen as a compromise between the desired etendue of the instrument and the suitable size of the grating given $f_{\text {col }} \approx 550 \mathrm{~mm}$.

We use a large custom-made echelle grating from AMOS (Liège, Belgium) with a ruled area of $107 \times 240 \mathrm{~mm}$. The grating is blazed at $63.43^{\circ}(\mathrm{R} 2)$, and has 3.03 grooves per $\mathrm{mm}$ (untypically low number for most grating providers). The grating is ruled on an aluminum substrate using diamond turning. Following Eq. (1) the free spectral range for one diffraction 

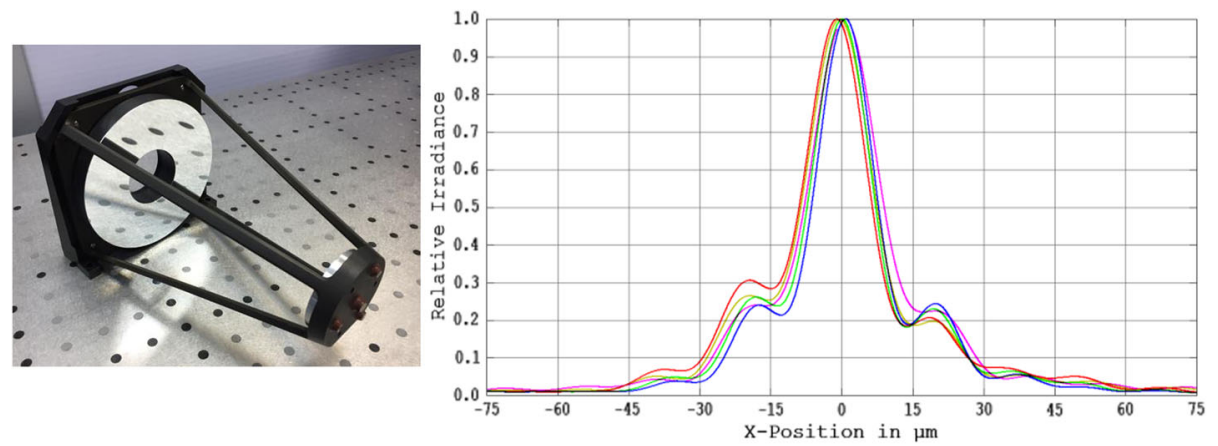

Fig. 9 (a) MIR channel collimator. (b) Design instrument Line Shape Function at $3.3 \mu \mathrm{m}$

order is FSR $\approx 16 \mathrm{~cm}^{-1}$ (or $17.7 \mathrm{~nm}$ at $3.3 \mu \mathrm{m}$ ). The full spectral range is covered with 107 diffraction orders, from 142 to 258 .

The quality of the imaging system is close to the diffraction limit: the spot diagram yields a root mean square (RMS) of $6.5 \mu \mathrm{m}$ in the center of the diffraction orders with a typical degradation toward the edges. Therefore, the resolving power of the spectrometer is aberration and slit-limited. With a $30-\mu \mathrm{m}$ slit a resolving power of $\lambda / \Delta \lambda \geq 50,000$ at $3.3 \mu \mathrm{m}$ is achieved. The optical design of the MIR channel, folded in 3-D, is sensitive to the thermal regime and the mechanical strains. Although verified during the integration and the alignment procedures, the resolving power will have to be confirmed during the science phase of the mission after the thermal and mechanical state of the instrument will be fully settled. Despite a number of Sun observations completed in flight (see Sect. 4), it is not yet possible to characterize completely the spectral resolution. This characterization is planned after completion of the first solar occultation sequence at Mars. In Fig. $9 b$ we present the LSF for the MIR echelle-spectrometer simulated by ray tracing.

Two secondary cross-dispersion diffraction gratings from Richardson Grating Laboratories, USA (plain, custom size, 361 and 180 grooves per $\mathrm{mm}$ ) are mounted back-to-back on a stepper motor axis. The design of the grating positioner designed and fabricated by Astron Electronics (Orel, Russia) capitalizes on MSASI/Bepi Colombo scanner development (Yoshikawa et al. 2010). Though the two-face grating assembly is much heavier than the MSASI scanning mirror, the mechanism moves with a characteristic time of $\sim 0.1 \mathrm{~s}$. Changing the position of the secondary grating in calibrated angular steps of $\sim 1.8^{\circ}$, from 7 to 17 echelle orders can be made during the same acquisition, the final number being wavelength dependent (see Table 3). As a result, for each position of the secondary grating (see Fig. 10) the detector area is covered with a number of stripes, each corresponding to a single echelle diffraction order (see below Sect. 4.2). To switch between the two gratings, the positioner supports fast $180^{\circ}$ overturn.

The detector is a space-grade version of the standard Scorpio MW K508 Sofradir (France) product, with optimized spectral range. Adaptations with respect to this standard detector are: (i) the replacement of the cold filter (bandpass 3.7-4.8 $\mu \mathrm{m}$ ) by a custom filter; (ii) customized AR coating of the entry window; and (iii) adaptation of the cryocooler K508 RICOR (Israel) for operation in space. This detector includes a $640 \times 512$ MWIR retina made of MCT (Mercury Cadmium Telluride, $\mathrm{HgCdTe}$ ) hybridized onto a silicon ROIC (read-out integrated circuit) by indium bumps. The pixel area is $15 \times 15 \mu \mathrm{m}^{2}$. 
Table 3 Design wavelength coverage in function of angle of the secondary grating

\begin{tabular}{lllllll}
\hline $\begin{array}{l}\text { Position } \\
\text { number }\end{array}$ & $\begin{array}{l}\text { Secondary } \\
\text { grating }\end{array}$ & $\begin{array}{l}\text { Secondary } \\
\text { grating relative } \\
\text { angle }\end{array}$ & $\begin{array}{l}\text { Diffraction } \\
\text { orders }\end{array}$ & $\begin{array}{l}\text { Minimum } \\
\text { wavelength, } \\
\mu \mathrm{m}\end{array}$ & $\begin{array}{l}\text { Maximum } \\
\text { wavelength, } \\
\mu \mathrm{m}\end{array}$ & $\begin{array}{l}\text { Wavelength } \\
\text { range, nm }\end{array}$ \\
\hline 3 & 361 & $7.5^{\circ}$ & $205-213$ & 2.790 & 2.899 & 109 \\
4 & 361 & $5.7^{\circ}$ & $214-223$ & 2.665 & 2.790 & 125 \\
5 & 361 & $3.9^{\circ}$ & $224-235$ & 2.529 & 2.665 & 136 \\
6 & 361 & $2.1^{\circ}$ & $236-248$ & 2.397 & 2.529 & 132 \\
7 & 361 & $0.3^{\circ}$ & $249-258$ & 2.304 & 2.397 & 93 \\
9 & 180 & $-1.5^{\circ}$ & Conditional center, not in use & 4.209 & 225 \\
10 & 180 & $-3.3^{\circ}$ & $142-149$ & 3.984 & 3.984 & 296 \\
11 & 180 & $-5.1^{\circ}$ & $150-161$ & 3.688 & 3.688 & 275 \\
12 & 180 & $-6.9^{\circ}$ & $162-174$ & 3.414 & 3.413 & 287 \\
13 & 180 & $-8.7^{\circ}$ & $175-190$ & 3.127 & 3.127 & 270 \\
\hline
\end{tabular}

In order to decrease the thermal background, a number of reflecting diaphragms are located in critical areas near the detector, around the slit, and throughout the instrument, so as beyond its useful area the detector images mostly the reflection from the internal cold baffle.

Electronics The MIR electronics can be separated into five functional modules: power board, control electronics, rotational unit, Scorpio detector, Stirling cryocooler and its own driving system. As stated previously, survival heaters are powered independently.

Similarly with NIR, the MIR control electronics is built around the TCM-BF537 processor module. For fast handling of the Scorpio detector frames it includes a Complex Programmable Logic Device (CPLD) XC2C256. The main function of the CPLD is to synchronize the Scorpio detector, the ADC video processor interface and the PPI. In addition, the CPLD provides a UART interface line switch. CPLD is controlled by register from processor module via the serial interface, running at a speed of $10 \mathrm{Mbit} / \mathrm{s}$. As in NIR, the UART ports of the processor are used to control communication with ACS BE (8 Mb/s interface speed) and with the rotational unit (129.17 MHz interface speed).

Stirling cryocooler motor is controlled by the processor via a dedicated driver. Cooling power is set by a Pulse Width Modulation (PWM) signal $(40 \mathrm{kHz})$. The maximum value of the speed control—about 190 pulses/s, the minimum acceptable value -50 pulses/s. The detector has two in-built temperature sensors. Its temperature is PID-stabilized by the processor software with an accuracy of $\leq 0.1 \mathrm{~K}$.

The Sofradir detector has four video outputs, fed to four parallel ADCs. Data is transmitted to the PPI interface with an overall speed of $4 \times 8 \mathrm{MHz}=32 \mathrm{MHz}$. The dynamic range of the detector is 13 bits. The ADC has a 16 bits resolution, but only 13 most significant are used. After stacking of frames each pixel is described by a 16-bits word, and they are transmitted to the ground.

The Rotational unit is commanded by its own FPGA-based electronics, which enables closed-loop PID regulator using the signal from Hall's sensors and drives the VSS 33.200.0,6-HV vacuum-grade Phytron (USA) motor.

MIR's power board, control electronics and the rotational unit electronics are fully redundant (including the main ADCs). Cross-redundancy is possible for the Stirling cryocooler 
Fig. 10 ACS-MIR secondary grating positioner unit

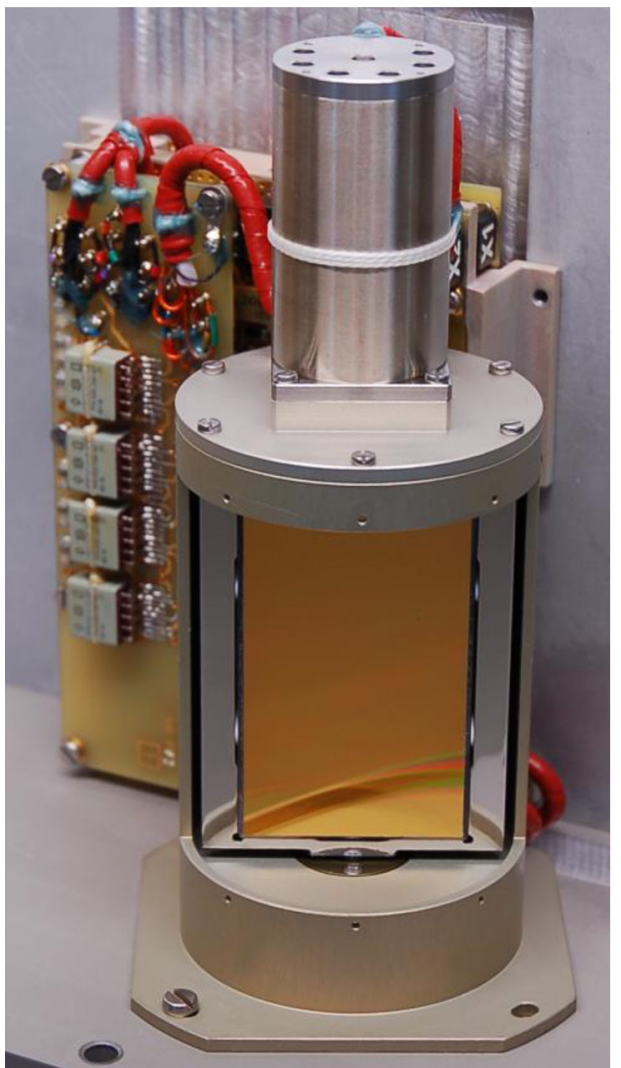

driver, and with the rotational unit electronics; either set can be used with either set of the control electronics.

Measurement Sequence Each MIR observation session starts with a dedicated telecommand from the TGO spacecraft. A 64-byte command contains all necessary timing parameters (overall time of observation, pauses, exposure time, etc.), the grating positioner commands (defining the spectral range), detector settings, and frame processing customization. After the detector precooling time of $\sim 8 \mathrm{~min}$, and rotational unit self-calibration procedure of $\sim 40 \mathrm{~s}$, the MIR channel is ready to record spectra.

Rotational unit receives a command to turn one of the two secondary gratings into the required position, and returns confirmation upon readiness. This triggers the measurement series. In order to increase the effective measurement time, thus improving the signal to noise ratio, the instrument is designed to minimize gaps between frames measurements. The detector is run in an Integrate While Read regime (IWR). While measuring a new frame, the previous one is being simultaneously transmitted to the MIR control electronics, which stacks all frames measured for the current secondary grating position. The readout of the full frame $(640 \times 512$ pixels $)$ using four detector's outputs requires $10.25 \mathrm{~ms}$. The exposure time can be set in the range $0.125-32 \mathrm{~ms}$ with a $0.125 \mathrm{~ms}$ accuracy. The real exposures when observing the Sun are within 3-6 ms, depending on the spectral range. The video signal of each pixel is digitized with resolution of 13 bits. The MIR processor can measure and sum up to 200 consecutive single frames. The result is accumulated in 32-bit words. 
If an occultation session includes measurements with several secondary grating positions, the Rotational unit mechanism allows the spectral range to be shifted with a characteristic time of $\sim 0.1 \mathrm{~s}$ for adjacent positions, $\sim 0.12 \mathrm{~s}$ for positions separated by a step, etc. Up to five positions can be commanded and be measured during an acquisition, though we plan to use only one or two positions during a real occultation. The switch between the two gratings is only possible before a series of measurements, so during a single occultation only one grating can be used.

A single data frame will be accumulated as a result of stacking a number of shorter exposures. Accumulated frames are transmitted to ACS BE. The full frame requires $\sim 0.9 \mathrm{~s}$ to transfer. Each transmitted frame is accompanied by two housekeeping frames with board time, temperatures and setup parameters. If more than one grating position is measured the MIR control electronics transmits data from the previous position to BE while measuring the new position. In order to reduce the downlink volume and/or to increase the number of measured frames per second, lossless compression, and windowing of the frames can be used. Up to 5 bands of programmable position, height and length can be selected to isolate the most interesting spectra. Given the complexity of the diffraction pattern, no line co-adding is foreseen on-board, although the embedded software provides such possibility. Normally full or partial detector frames will be transmitted to the ground with lossless compression.

\subsection{TIRVIM Channel}

Concept TIRVIM is a 2-inch double pendulum Fourier-transform spectrometer (FTS) operating in the 1.7-17 $\mu \mathrm{m}$ spectral range. The primary scientific goal of TIRVIM relates to the Climatological goal of ACS through the monitoring of key climatic parameters, like atmospheric temperature and aerosol abundance from nadir viewing. The instrument leverages from previous developments of IKI in Fourier-spectrometers (Moroz et al. 1990; Formisano et al. 1997; Korablev et al. 2009). One may note its resemblance to 2.5-inch PFS/Mars Express (Formisano et al. 2005), however the mass allocation for TIRVIM on TGO was $12 \mathrm{~kg}$ against $31.4 \mathrm{~kg}$ of PFS, and so simple copy of the dual channel PFS design was excluded.

By concept a FTS measures an interferogram that is then converted into a spectrum, which covers the spectral range limited by the detector and the transparency of the optics. In TIRVIM the whole spectral range is covered by one double-pendulum interferometer with $\mathrm{KBr}$ beamsplitter ( $\mathrm{KBr}$ is transparent from 0.25 to $25 \mu \mathrm{m}$ ). The principal improvements in comparison to PFS are: (i) the possibility to observe in solar occultations, (ii) one-side maximal optical path difference (MOPD) increased to as much as $5 \mathrm{~cm}$, allowing to reach apodized spectral resolution of $0.13 \mathrm{~cm}^{-1}$ (compared to $\approx 1.3 \mathrm{~cm}^{-1}$ for PFS), and (iii) a PVMCT detector cooled by a Stirling machine, thus increasing the sensitivity of the instrument by a factor of $10-20$. The detector is sensitive from 1.7 to $17 \mu \mathrm{m}$ and is employed both for nadir and during solar occultation observations.

While observing Mars in nadir TIRVIM operates as a spectro-radiometer, providing absolute radiometric calibration by periodically measuring the temperature of the internal BlackBody and of the space. While observing during a solar occultation TIRVIM operates as a spectrometer, self-calibrating the relative transmission of the atmosphere by observing the Sun outside the atmosphere.

Initially the instrument design included a short-wave optimization in the 3- $\mu \mathrm{m}$ range for the mapping of putative hydrocarbons in nadir (Korablev et al. 2014). This feature had to be de-scoped because of lack of mass (its implementation involved an additional mechanism, and significant electronics). For the same reason the redundant pyroelectric detector for 


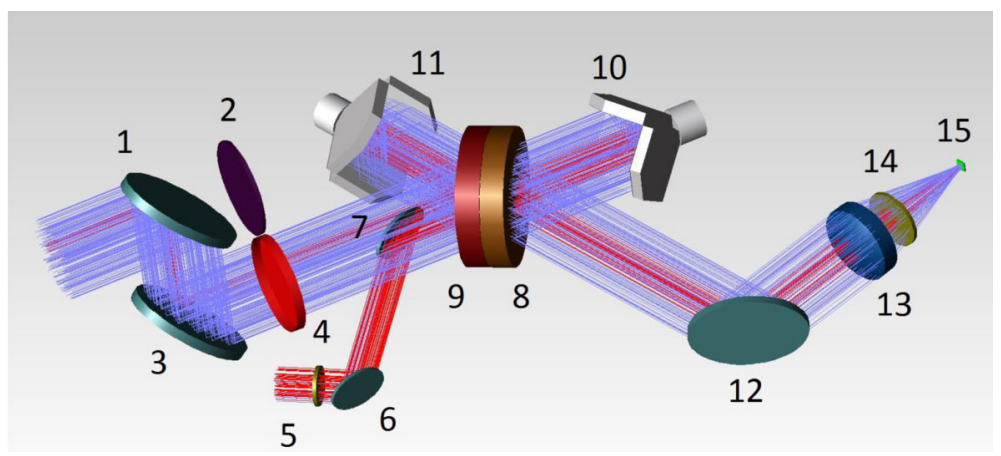

Fig. 11 A simplified optical scheme of the TIRVIM channel. Foreoptics: 1 -scanning flat mirror (rotates around TGO Z axis); 2-calibration blackbody; 3-fixed flat mirror; 4-inlet window. Solar entry: 5-blocking filter and field stop $(\mathrm{Ge}) ; 6,7$-folding mirrors. Interferometer: 8-compensator $(\mathrm{KBr})$; 9-beam-splitter (KBr); 10, 11-corner-cube hollow retro-reflectors. Detector assembly: 12-fixed flat mirror; 13-aspheric plano-convex ZnSe lens, 14-MCT detectors inlet window (Ge), 15-MCT detector sensitive area. Red lines trace solar channel rays, blue lines trace Mars channel rays. The reference channel is not shown on this scheme
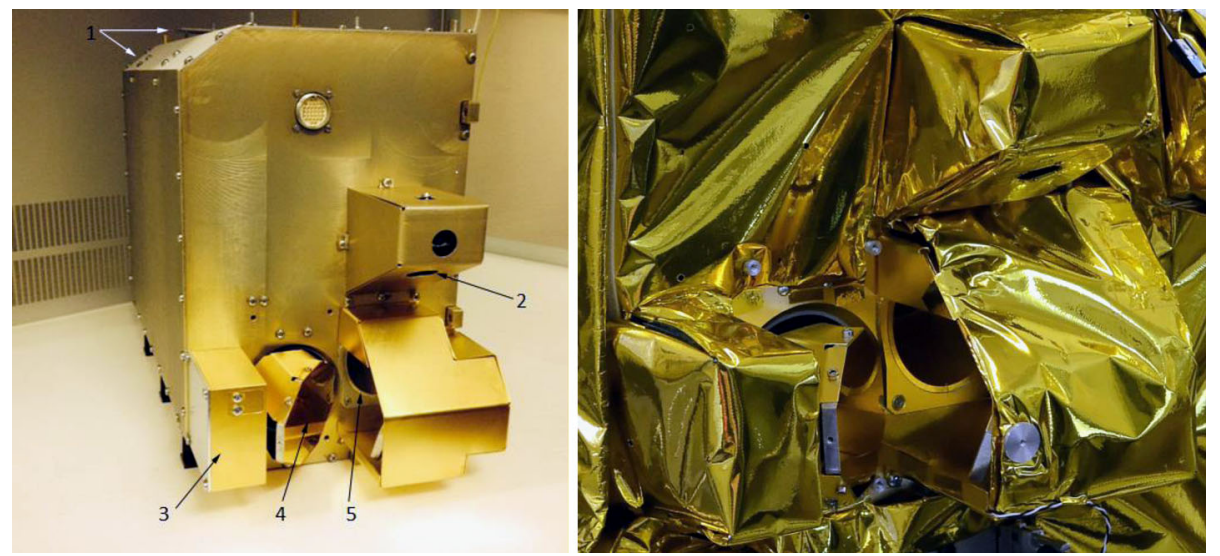

Fig. 12 (a) ACS-TIRVIM channel outlook without MLI. (b) Close-up of the entry optics, covered with MLI. 1-radiators, 2-Sun optic inlet, 3-Scanner, 4-Scanner mirror, 5-Scanner optic inlet. The blackbody simulator in inside the instrument casing, under the scanner mirror 4

solar occultation had to be cancelled as well. Eventually, main science requirement was put on nadir observations.

Optical Scheme A simplified optical scheme of TIRVIM is presented in Fig. 11. It consists of the following main parts: a sun periscope, a scanner, a blackbody simulator, the interferometer with a reference channel, and the detector with its proximity optics.

The scanning device of TIRVIM (see Fig. 12) allows it to point its optical axis to nadir, to the limb, and also to the internal blackbody and to the open space to obtain absolute radiometric calibration. It is rigorously not a scanner but a one-dimensional positioner. The main element is the flat mirror $\left(85 \times 60 \mathrm{~mm}^{2}\right)$, which can be rotated within $360^{\circ}$ with a step of $0.1^{\circ}$. It can be pointed to three principal directions: nadir, open space, and the black body, but also to any intermediate position, including the direction to the Sun. 


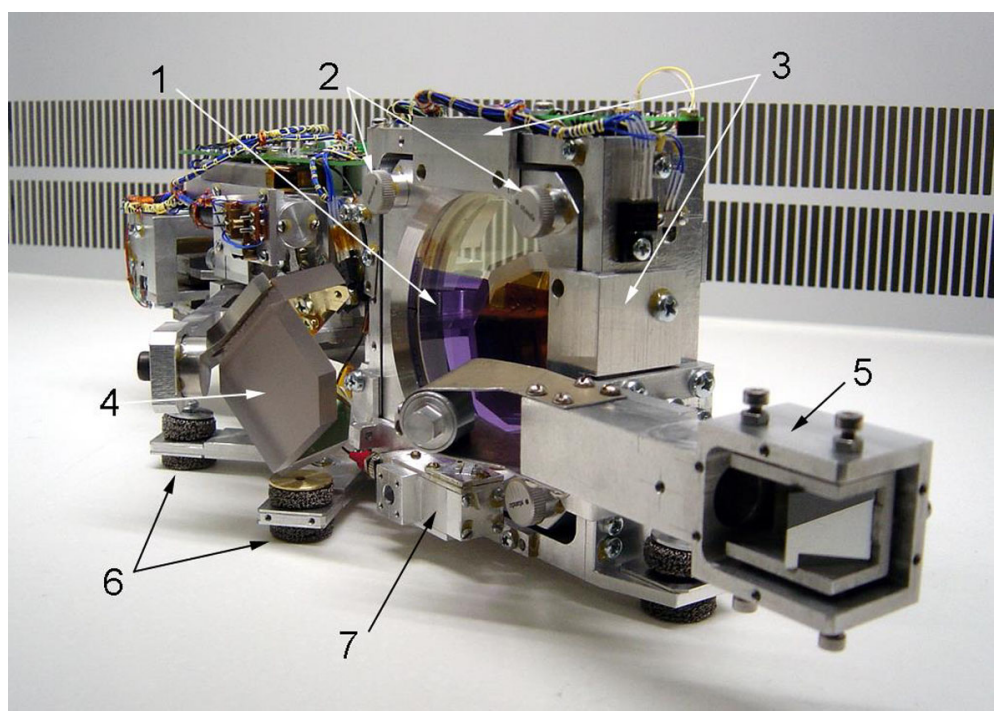

Fig. 13 A picture of the TIRVIM interferometer unit. Some parts and subsystems: 1-beam-splitter; 2-adjustment screws, 3-auxiliary brackets for alignment, 4-retro-reflector, 5-solar port, 6-vibro-dissipators, 7-laser of the reference channel

The second optical port of the instrument is the solar periscope. Its direction is fixed and co-aligned with solar ports of NIR and MIR channels, i.e. pointed to the direction of $67^{\circ}$ with $\overrightarrow{-Y}$ spacecraft axis (see Fig. 2). The solar periscope includes a blocking filter and two elements folding the solar radiation into the interferometer. The aperture of the solar port is $\sim 10 \mathrm{~mm}$ wide which constitutes $\sim 4 \%$ of the useful interferometer aperture.

The Black Body was fabricated in IKI, its emitting surface is painted with space-qualified EKOM-2 enamel by Kompozit (Russia). Its temperature is regulated by either the survival heaters, or the operational thermal control systems of TIRVIM.

The interferometer is the core unit of TIRVIM (see Fig. 13). Most of principal design solutions are inherited from AOST/Phobos-Grunt, but the TIRVIM interferometer is larger ( $2^{\prime \prime}$ against $1^{\prime \prime}$ ). The length of the double-pendulum arm (from the rotation center to the center of the corner-cubes) is $130 \mathrm{~mm}$. The interferometer pendulum full swing results in MOPD of $5 \mathrm{~cm}$, so the spectral resolution, if defined as 1/MOPD is $0.2 \mathrm{~cm}^{-1}$. The spectral resolution defined at FWHM of the instrument function is better $(0.603 / \mathrm{MOPD}), \approx 0.13 \mathrm{~cm}^{-1}$ (see Table 2). For nadir observations the OPD is reduced to $0.8-1 \mathrm{~cm}$ (the spectral resolution is of $1.3-1 \mathrm{~cm}^{-1}$ or $\approx 0.8$ at FWHM). The double pendulum is mounted pending on a Flexural Pivot by Riverhawk Company (USA) and propelled by a momentum motor built in IKI. The hollow retro-reflectors are from PLX Inc. (USA), modified in IKI so they can withstand mechanical loads during the launch. Their useful diameter is $\varnothing 50.8 \mathrm{~mm}$. The beamsplitter and the compensator are made of $\mathrm{KBr}, \varnothing 88 \mathrm{~mm}$ and are $12 \mathrm{~mm}$ thick.

The reference channel allows for a precise synchronization of the interferogram sampling, and the wavelength link of the retrieved spectrum. The reference signal is generated from the interference of radiation of a monomode laser diode within the main interferometer of TIRVIM. The fraction of the aperture used for the reference channel is small. A distributed-feedback laser diode for the wavelength of $760 \mathrm{~nm}$ was supplied by Eagleyard Photonics (Germany). The channel includes also a Si photodiode detector and a number of 
optical elements necessary to introduce the laser beam into the interferometer. In all the operation modes the digitalization of the two-side interferogram is performed at each one out of two zero crossings of the reference signal. Therefore the sampling theorem is satisfied for all wavelengths longer than $1.52 \mu \mathrm{m}$. The germanium inlet window blocks all the radiation below $1.7 \mu \mathrm{m}$, removing aliasing.

Radiation is focused onto the detector sensitive element with an aspheric plano-convex ZnSe lens. The photovoltaic MCT detector unit is custom-built in Russia. It is sensitive in the range of 1.7-17 $\mu \mathrm{m}$; a germanium inlet window determines its short-wavelength cutoff. The diameter of the sensitive element is $1.5 \mathrm{~mm}$, and the specific detectivity peaking at $14.5 \mu \mathrm{m}$ is $\mathrm{D}^{*}$ of $1 \times 10^{11} \mathrm{~cm} \mathrm{~Hz}^{1 / 2} \mathrm{~W}^{-1}$. The sensitive element is mounted in a Dewar and cooled down to $65 \mathrm{~K}$ with a rotary Stirling cooler from RICOR (Israel), similar to that of MIR channel. The beamsplitter, AR-coated Ge windows, objective aspheric ZnSe lens and aluminum mirrors with gold coating are supplied by Spectral Systems LLC (USA).

The FOV is determined by the diameter of the sensitive element of the detector size, and the focal length of the detector's proximity ZnSe lens. When observing in nadir the full FOV diameter of $2^{\circ}$ is used. From the TGO orbit $(\sim 400 \mathrm{~km})$ the track width on the surface of Mars is $14 \mathrm{~km}$. When pointed to the Sun the instrument's FOV is limited by the diameter of the solar disk diameter $\left(\sim 0.35^{\circ}\right)$.

Electronics The electronics of the TIRVIM channel is organized around the Central processor. It interacts with BE through the LVDS interface, interprets its telecommands, acquires interferograms and housekeeping data, processes them, packs and sends them back to BE. It controls, directly or via two auxiliary processors, all TIRVIM subsystems, the thermal regime, the scanner, and other mechanisms.

The scanner operation is controlled using its encoder or backup Hall sensors. There are two multi-usable arresters; one is immobilizing the double pendulum, and the other the entire interferometer unit (Fig. 13) mounted on vibration dumpers. The operation thermal stabilization system controls, by means of the central processor, the thermal regime of all critical optical parts. It includes six collocated heater-sensor pairs placed at the blackbody, at the fixed mirror, at the "front wall", in two locations within the interferometer unit, and near the body-fixed optical elements. The maximum dissipated power is $16 \mathrm{~W}$.

The Interferometer processor provides closed-loop PID stabilization of the interferometer OPD alternation speed, controls temperature and current of the diode laser, and other interferometer functions. The temperature and the current of the diode laser are set by telecommand in the ranges of $14^{\circ}-35^{\circ} \mathrm{C}$ and $43-75 \mathrm{~mA}$ respectively. The embedded software allows for searching of optimal PID coefficients values in flight. The position of the interferometer pendulum arms is registered by a Hall sensor. It triggers at zero OPD, and the interferometer processor moves the pendulum with respect to this point. In fact, the Hall triggers not exactly at $\mathrm{OPD}=0$ but the shift, in units of the reference channel period, is known.

The Stirling processor provides PID-stabilization of the cryogenic detector temperature. It gets information about temperature in the cryogenic zone from a dedicated thermo-sensor. The nominal temperature in the cold zone is $68 \mathrm{~K}$.

The reference channel detector (Si photodiode) registers the interference of the monochromatic laser light. If the OPD alternates evenly, the signal is a sine function, allowing one to close the loop of interferometer mirrors motion. The reference signal is transferred to the square wave, which serves to govern the pendulum motor and triggers the conversion of the main ADC.

The signal from the cooled MCT detector after a preamplifier goes to variable-gain amplifier (eight gain levels $1,2,4, \ldots, 128$ set by telecommand) and bandpass shaper, which 
gets the signal ready for the AD-conversion. The main ADC provides the interferogram sampling in 18 bits, 16 of them being effectively used. The central processor governs the amplification coefficient and the frequency bandpass, gets data from the ADC and processes them.

The Stirling is powered directly from $24-\mathrm{V}$ regulated voltage provided by the ACS-BE. A dedicated power PCB creates all other needed voltages $(-9,+3.3,+5,+6.5,+12 \mathrm{~V})$.

The survival heaters are powered when the main TIRVIM electronics is OFF. This system includes three pairs of heaters-sensors (optical plate, interferometer and Black Body) and is powered directly from the spacecraft. The threshold values are set at $+30{ }^{\circ} \mathrm{C}$, except for the Black Body $\left(+60{ }^{\circ} \mathrm{C}\right.$.) Higher temperature of the Black Body allows warming the rear side of the scanner mirror to avoid its contamination during spacecraft outgassing. The consumption is $8 \mathrm{~W}$ regardless of the voltage value $(20-40 \mathrm{~V})$.

Measurement Modes The Fourier spectrometer subsystems allow for numerous settings and parameters, however few optimal combinations were selected and verified during calibrations. This parameter set is implemented in the embedded software of TIRVIM.

The interferometer pendulum can swing within its full range, resulting in a MOPD $=$ $5 \mathrm{~cm}$. Alternatively, a reduced swing with MOPD $=0.8-1 \mathrm{~cm}$ can be employed for measuring weaker signals. The full swing is devoted to Sun observations, and the reduced one is devoted to nadir observations. Also, the interferometer mirrors can move with a slower or faster motion. The slow mode results in a reference channel frequency of $\sim 10 \mathrm{kHz}$, and the fast one in $\sim 80 \mathrm{kHz}$. With the change of the interferometer speed, the bandpass of the main tract is modified accordingly. The full swing is always implemented with the fast mode, and the reduced swing can use both speeds, resulting in three main interferometer modes.

To remove possible parasite signals (due to a variety of vibrations) the speed setting can be slightly modified: the slow mode may become $10 \%$ quicker, and the fast mode may become $10 \%$ slower. The $10 \%$ variation is enough to move the parasite signals along the wavenumber axis so they don't distort the critical portions of the spectrum. So, in all, six interferometer modes (aliased as $\# 0 . . . \# 5$ ) are possible.

TIRVIM interferograms are always two-sided. The interferograms recorded in the smallswing mode are much shorter, and the central processor can perform their on-board centering and stacking, increasing the SNR and decreasing the data downlink. The interferograms are averaged separately for forward and retrograde motion of the interferometer mirrors. It is possible to average $2+2$ interferograms ( 2 "forward" and 2 "retrograde"), $4+4$ or $8+8$.

The central processor adds to every interferogram a header containing its parameters, onboard time, housekeeping and other data.

The TIRVIM parameters and observing modes are summarized in Table 4.

\subsection{Main Electronics}

The main electronics (BE) serves as a single electrical interface of the ACS to the spacecraft. The spacecraft harness including power, commands, data lines and auxiliary interfaces is wired to the BE. The main electronics is fully redundant (see Fig. 14).

The BE consists of two PCBs, located in a separate unit. The Processor PCB (visible in Fig. 14b) includes two redundant sets of FPGA, 32 GB of flash-memory, auxiliary controller, interface controller, etc. The Power PCB carries two redundant sets of filters, DC/DC converters, and power switches. As one may note in Fig. 14b, the electronics occupies a smaller volume than the one available in the BE box. In fact, the volume allocation had to be decided before the final definition of the electronics, and some margins had to be added. 
Table 4 Main parameters of TIRVIM in the most used modes of observation

\begin{tabular}{|c|c|c|c|}
\hline Mode of operation & \multicolumn{2}{|c|}{ Nadir dayside/night side } & Solar occultation \\
\hline Spectral range & \multicolumn{2}{|c|}{$\begin{array}{l}5-17 \mu \mathrm{m} \\
2000-590 \mathrm{~cm}^{-1}\end{array}$} & $\begin{array}{l}1.7-17 \mu \mathrm{m} \\
5900-590 \mathrm{~cm}^{-1}\end{array}$ \\
\hline FOV & \multicolumn{2}{|l|}{$2.5^{\circ}$} & Sun disk $\left(\approx 0.35^{\circ}\right)$ \\
\hline Working aperture, $\mathrm{cm}^{2}$ & \multicolumn{2}{|l|}{18} & 0.8 \\
\hline Mode alias & \#5 & $\# 5 / 8+8$ & \#3 \\
\hline Maximum OPD, $\mathrm{cm}$ & \pm 1.0 & \pm 0.8 & \pm 5 \\
\hline Spectral resolution, non-apodized FWHM, $\mathrm{cm}^{-1}$ & 0.60 & 0.8 & 0.13 \\
\hline Time to measure two IFGs (forward and retrograde), $\mathrm{s}$ & 0.82 & 6.6 & 3.7 \\
\hline Smear (nadir)/altitude shift (SO), $\mathrm{km}$ & 2.5 & 20 & $5.5^{*}$ \\
\hline Number of points in one two-sided IFG & 26,430 & 20,480 & 127,600 \\
\hline Data volume for a pair of IFGs, Mbit & 0.81 & 0.63 & 3.9 \\
\hline Data rate, Mbit/s & 0.97 & 0.09 & 1.06 \\
\hline
\end{tabular}

Note: ${ }^{*}$ If line of sight moves perpendicular to the limb

The power interface includes the main power switch, power conditioning, and specific switches for each scientific channel. All power switches and relays are controlled by High Voltage High Power Command (HV-HPC) spacecraft lines. A Bi-level Switch Monitor (BSM) interface is used for the TGO system to acquire a signal from the instrument switch loads. The final power distribution to the channels is done using regulated voltage lines from BE. Redundant sets of MIR and NIR internal electronics can be used with either set of the BE electronics. The choice of nominal or redundant set of MIR or NIR electronics to be turned $\mathrm{ON}$ is defined by a telecommand. Upon request, BE is generating HV-HPC for the dedicated channel. BE is able control any science channel in any combination; in particular both MIR and NIR can be operated at the same time, regardless of which set of electronics controls them.

The survival heaters in the scientific channels are powered by a dedicated TGO power line, bypassing the ACS BE. There is no survival heater in the BE; its thermal regime in cruise is maintained by thermal conduction from surrounding MIR and NIR channels (see Fig. 5).

The command and data interfaces to TGO are MIL1553 and SpaceWire, respectively.

After powered on, the BE receives 64-byte telecommands (TC) from TGO. MIR and NIR TCs include a small header interpreted by the BE to generate appropriate HV-HPC for the science channel and overall time of observation. TIRVIM will be permanently ON during the nominal science operations, and it periodically receives TC blocks, programming a midterm operation sequence. The BE itself nominally doesn't require any TC during routine science operation.

The data/command interfaces between the BE and the scientific channels are LVDS with a maximum speed of $8 \mathrm{Mbit} / \mathrm{s}$. The data from the science channels can be acquired simultaneously. They are stored in blocks with certain system headers, specific for each channel, and are transferred via SpaceWire to the TGO (21 Mbit/s). The BE internal memory will be used only in case of the temporary unavailability of the TGO memory. The mass memory was also included to validate the design solution for the ExoMars 2020 Surface platform where a similar main electronics will be serving several instruments on the landing platform (Rodionov et al. 2017). 

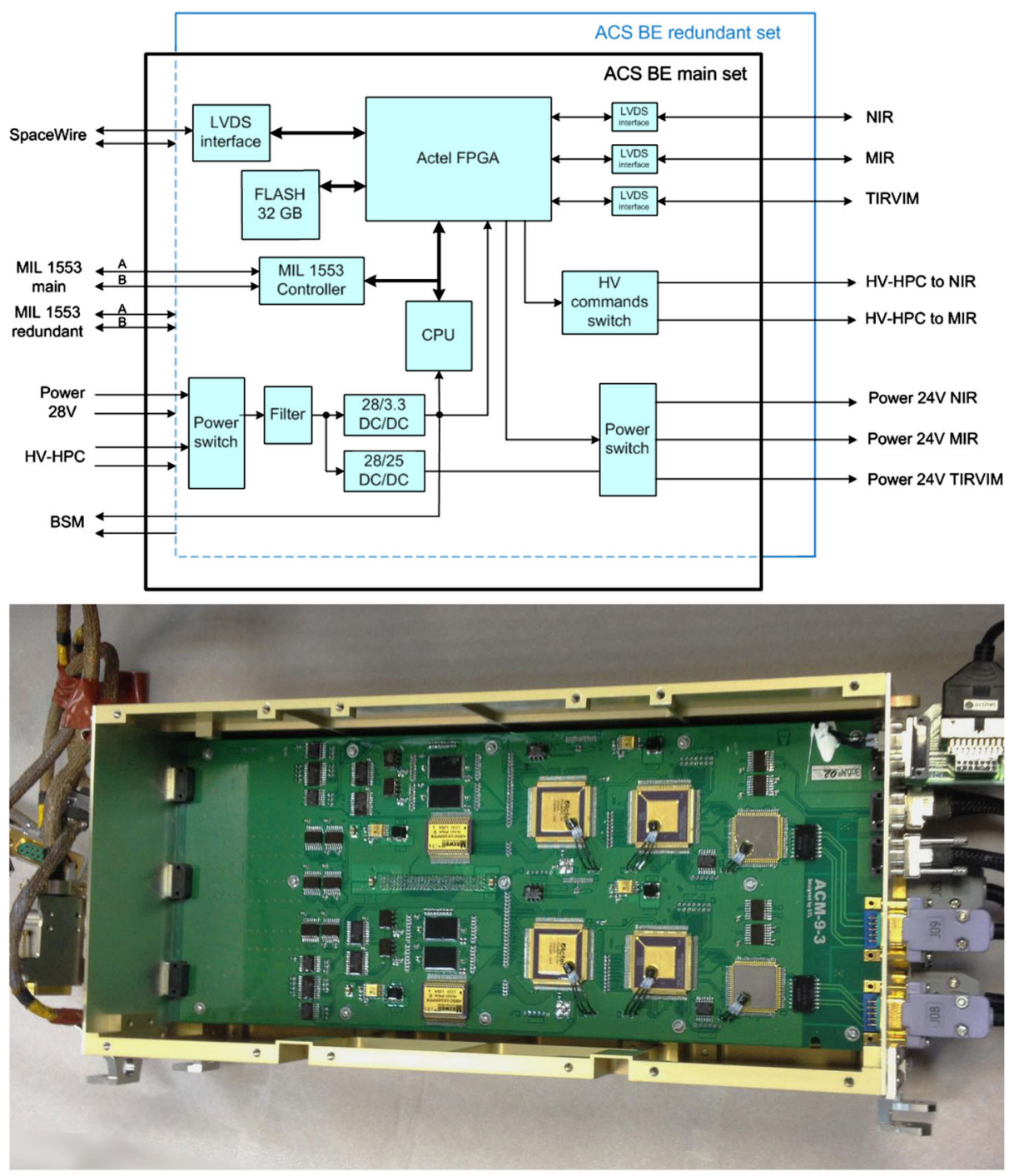

Fig. 14 (a) ACS-BE block diagram. (b) A photo of the BE with open cover during autonomous tests

\section{Ground and Flight Calibration Results}

\subsection{Calibration Plan}

Laboratory Calibrations As mentioned above, the development time of the ACS instrumentation was short. The experiment was decided in 2012, and the team received Roscosmos funding in January 2013. The proto-flight model (PFM) of ACS has been assembled in March 2015, and on the 4th of June 2015 the PFM was sent to Thales Alenia Space facility in Cannes for an immediate integration with TGO. The short time slot in April-May 2015 was occupied mostly with the PFM test campaign, which involved moving the instrument from IKI to distant facilities. Some characterizations were done before the final integration 
of the relevant channels, but the calibrations of the completed instrument were therefore performed in a very constrained time in between the qualification tests. Because of that the three scientific channels were calibrated separately, and not all planned calibrations could be completed. Nevertheless, the ACS channels were thoroughly verified on the ground, and all three were pointed to the Sun.

Laboratory measurements with NIR included: standalone calibrations of the AOTF, measurements of different line spectrum sources (lasers, Pen-Ray ${ }^{\circledR}$ low pressure emission lamps), observations of the Sun, simulation of the nadir observation, and also the detector's flat field and field of view measurements. Absolute radiometric calibrations were not completed and they will be done in flight using coordinated measurements with SPICAMIR/MEX and CRISM/MRO.

Laboratory measurements with MIR included measurements of a laser emission line, observations of the Sun, detector's flat field and dark current, and field of view measurements. Only the direction of the FOV was controlled. The latter procedure involved complicated cross-alignment against the TGO axes and the NOMAD FOV.

Laboratory measurements with TIRVIM were mostly dedicated to radiometric calibrations in the thermo-vacuum chamber. Also observations of the Sun, measurements of a laser emission line, and measurements of transmission of a gas cell filled with nitrogen-methane mixture were exercised. Finally, the angular diameter of the field of view was characterized.

In-Flight Calibrations After successful launch of TGO on 14 March 2016 and en route to Mars, ACS was turned ON several times during Near-Earth Commissioning (NEC) in April 2016, and Mid-Cruise Check-up (MCC, June 2016) campaigns. The instrument's main electronics was verified; functional checks, and several observations pointing to the Sun with all three ACS channels were carried out. Scanning over the solar disk was performed to characterize mutual alignment of different FOVs. Simultaneous observation by ACS channels in solar occultations are fully supported, corresponding pointing will be used on all available orbits. Unfortunately, the angle between the FOV of ACS MIR and NOMAD SO measured in-flight is 22 arc min, more than angular size of the Sun thus making joint observations by these channels impossible.

After the Mars orbit insertion on 19 October 2016 the Mars Capture Orbit (MCO) campaign of observations was carried out in November 2016. On the top of the checks done during the MCC, this campaign allowed for first Mars observations from near the pericenter of two highly elliptical orbits $(380 \times 66,000 \mathrm{~km})$. The first orbit involved nadir pointing, which viewed the near-equatorial region from 4 to 21 hours of local time. On the second one, inertial pointing of Mars was performed. The second MCO-2 campaign is planned for March 2017. The intermediate TGO orbit does not permit solar occultation before May 2017. Their observation during the aerobraking phase is not confirmed.

For a number of reasons (changing temperature environment and associated mechanical strain, availability of the out-of-atmosphere solar flux, etc.) the focus of the ACS calibration analysis is on the in-flight calibrations. Some specific calibrations, in turn can be only performed in the laboratory. The in-flight calibration of ACS is in progress and will be ultimately completed during the commissioning on the science orbit. In the following sections we present some selected results of this on-going activity.

\subsection{NIR Channel}

AOTF Characterization The AOTF used for the selection of spectral orders in the echelle-AOTF spectrometer is a critical component in terms of the laboratory characterization, because this kind of calibration in flight proved difficult (Vandaele et al. 2013). The 

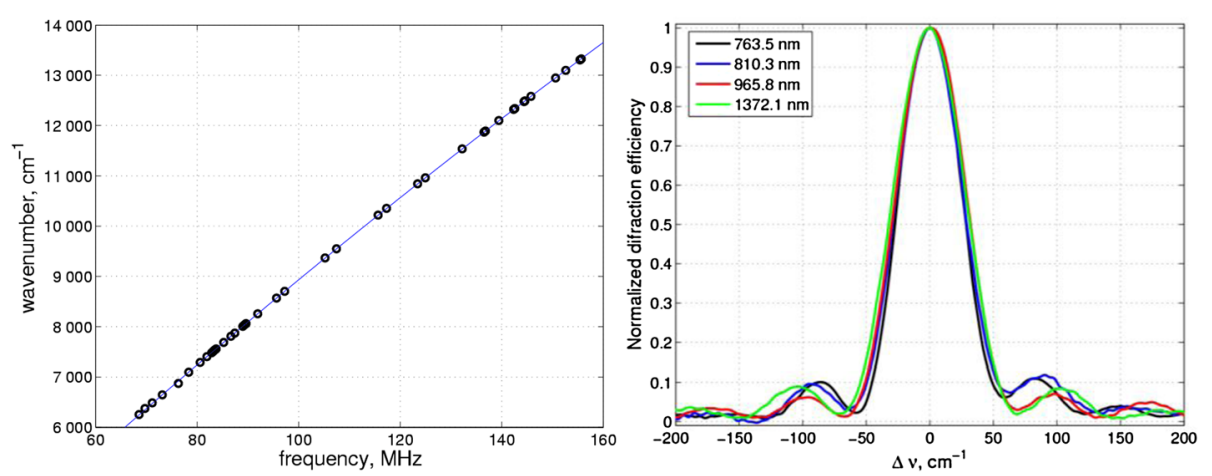

Fig. 15 The ACS-NIR AOTF dispersion curve (a) and the passband function (b) at several wavelengths

side lobes of the AOTF cause spectral leakage from the adjacent and more distant diffraction orders. To model the measured spectrum it might be necessary to sum the signal from up to seven diffraction orders (the main one and the three leaking orders on each side). The temperature dependence of the AOTF passband function complicates the problem even further. Even though the NIR temperature is stabilized at $\sim 25^{\circ} \mathrm{C}$, during the operation the AOTF crystal is warming up by dissipation of the RF power.

The laboratory calibrations included the determination of the AOTF dispersion curve and its temperature dependence, characterization of the AOTF passband function including distant side lobes in the entire spectral range, and verification of its homogeneity within the spatial extent covered by the AOTF (along the echelle-spectrometer slit).

To characterize the AOTF passband and to obtain its dispersion curve over a spectral range as wide as possible, we used argon and krypton low-pressure lamps. Some results are demonstrated in Fig. 15. The measured passband FWHM is $65 \mathrm{~cm}^{-1}$. The spectral homogeneity of the AOTF within its imaging range was verified at several wavelengths. The shift of the passband maximum within the FOV of NIR is always $<0.1 \mathrm{MHz}$, or $0.1 \%$. The shift is smaller for shorter wavelengths. Such a small modification of the passband is evidence of good homogeneity of the acoustic field within the crystal. For practical reasons it may be neglected. For comparison, the AOTF of SOIR/Venus Express revealed a 1\% shift of $\sim 0.2 \mathrm{MHz}$ for frequencies of $13-25 \mathrm{MHz}$ which had to be taken into account (Mahieux et al. 2008).

The modification of the AOTF characteristics with temperature was calibrated in a climatic chamber in the temperature range of $+5{ }^{\circ} \mathrm{C} \ldots+35^{\circ} \mathrm{C}$ using argon Pen Ray ${ }^{\circledR}$ lamp as a source. Five different temperatures were recorded. This calibration was mostly intended to determine the shift of the passband function with temperature, but will also serve to verify the modification of the passband shape. With the temperature difference of $30 \mathrm{~K}$ the shift amounts to $15 \mathrm{~cm}^{-1}$ at $\lambda=800 \mathrm{~nm}$, and $8 \mathrm{~cm}^{-1}$ at $\lambda=1500 \mathrm{~nm}$. This is well within the passband FWHM, but has to be taken into account.

Imaging capabilities of NIR were also studied during adjustments and tests. For instance, a 1-mm illuminated pattern was imaged through the AOTF onto the spectrometer's slit from 5 meters to form a $20-\mu \mathrm{m}$ image. This image quality is conserved in the echelle-spectrometer up to the detector. The corresponding instantaneous spatial resolution for nadir observation is 80 meters on the surface and 300 meters on the limb for occultation. It must be noted that during occultation sessions NIR slit is oriented nearly parallel to the surface, which gives an opportunity to use the spatial resolution to constrain the local atmospheric variability. 

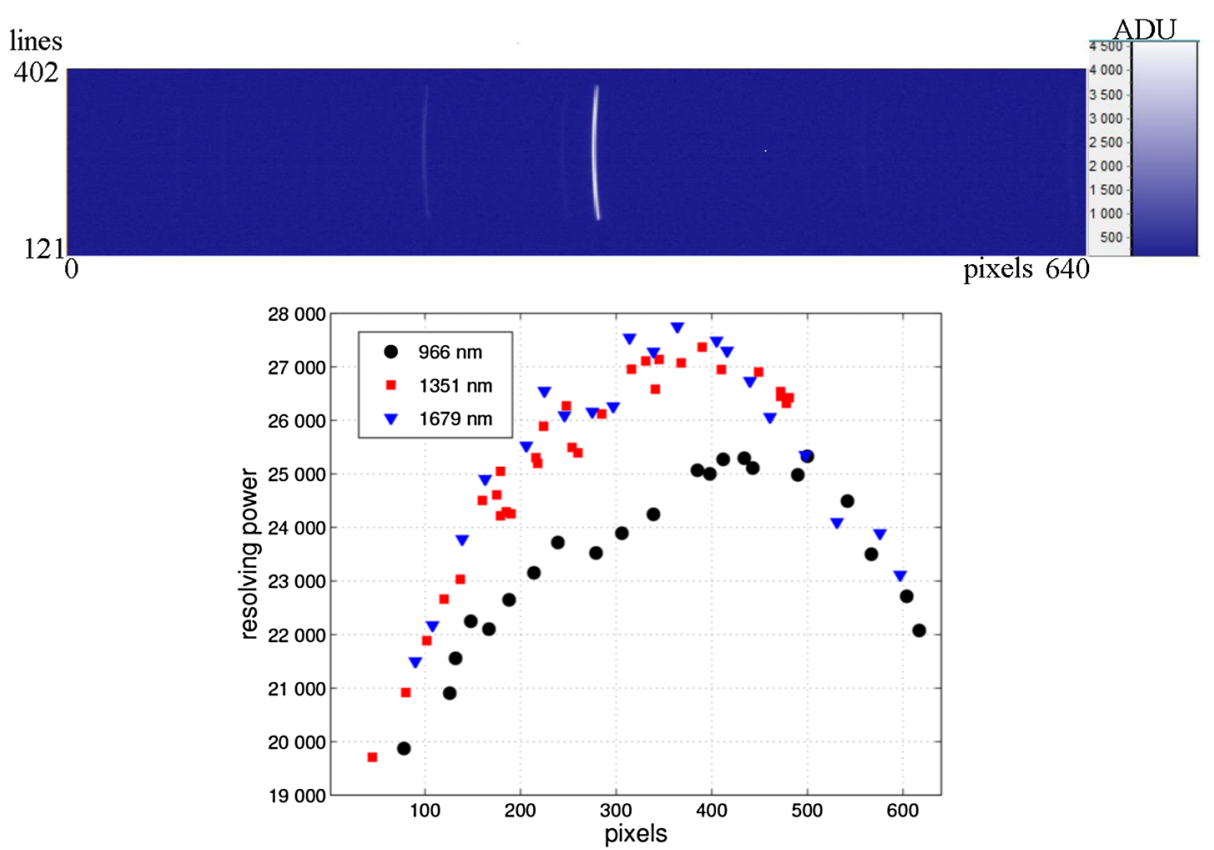

Fig. 16 (a) An image of the 1351-nm Ar line at the ACS-NIR detector; (b) Resolving power of NIR for three diffraction orders centered at 965,1350 , and $1680 \mathrm{~nm}$

Echelle-Spectrometer Characterization One of the most regarded characteristics for an echelle spectrometer is spectral resolution, which is defined by the Point Spread Function (PSF) Full-Width at Half Maximum (FWHM). This characteristic was measured experimentally on a fully assembled NIR with only the grating not fixed. As mentioned above, the spectrometer is almost in a Littrow configuration, with a slight rotation of the grating to obtain the most effective coverage of diffraction orders over the spectral range. To study the resolving power over the detector we adjusted the grating to project a narrow line of the low-pressure Ar lamp onto multiple positions along the detector. The recorded PSF were analyzed and the resolving power for individual line on the detector was calculated (Fig. 16). For nadir mode we plan to average all lines inside the slit to increase the SNR, and to decrease the downlink. It would decrease the resolving power by $20 \%$ (in case of averaging of all lines).

Furthermore, a precise pixel-wavelength calibration was done with the grating in nominal position. This calibration was started with monochromatic light sources, and then tuned to fit real Earth atmospheric spectra including the direct measurements of solar spectrum. Water absorption lines near $1.36 \mu \mathrm{m}$ (AOTF frequency $81.5 \mathrm{MHz}$ and order 57) in the laboratory air have been recorded observing a halogen lamp reflected on a Lambertian screen (Fig. 17) to simulate nadir observations of the Martian surface. The total optical path in the atmosphere was $138 \mathrm{~cm}$. The effective exposure to measure one spectrum was $3.8 \mathrm{~s}$. The comparison with a spectroscopic model of water absorption shows very good agreement. The complete instrumental modeling accounts for the contribution of five overlapping diffraction orders adjacent to the main observed order 57 . 


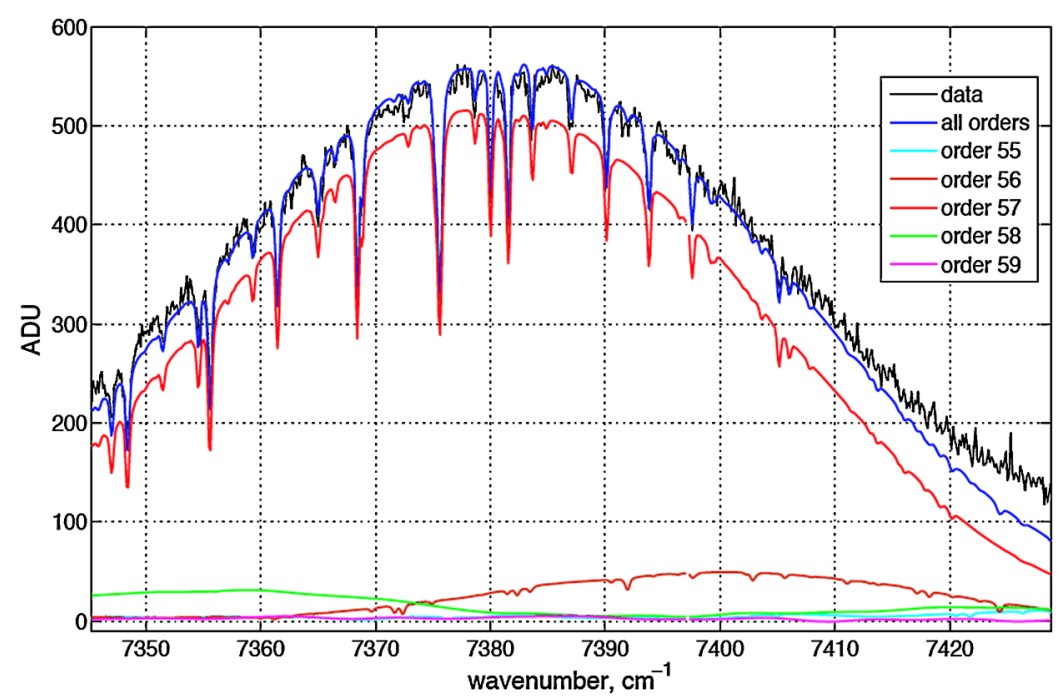

Fig. 17 A spectrum of a halogen lamp recorded with NIR in the laboratory for diffraction order 57 and showing water vapor absorption lines near $1.36 \mu \mathrm{m}$ (black curve). A synthetic spectrum model demonstrating contributions from five orders adjacent to the main observed 57 order is shown. These contributions reflect the leakage from the AOTF passband function side lobes (Fig. 15). The blue curve is the resulting synthetic spectrum

SNR In-flight calibration of NIR includes solar spectrum measurements to improve pixelwavelength calibration for working temperature in flight and to construct the SNR ratio for solar occultation mode. An example of solar spectrum is shown in Fig. 18.

The SNR of the NIR channel in occultation mode was tested during Mars Capture Orbit operation by observing direct Sun in the whole wavelength range with $1 \mathrm{~ms}$ integration time and 32 single frames accumulated for each frequency. A single-pixel $\mathrm{S} / \mathrm{N}$ ratio was estimated to be $\sim 1400$ for most of the spectral range covered by NIR. Signal is slightly decreasing to the red and violet edges of the range, but only by a factor of 1.5. Averaging 25 NIR lines should increase SNR by a factor of 5, but in the experiment we observe lower values. This can be explained by some instability in AOTF radio frequency power, but further analysis and testing with dedicated instrument pre-warming is needed. For the performance study of NIR in occultation, we have chosen to use SNR $=4000$.

For nadir observations NIR setup parameters are still being tuned, but estimation and the first Mars observation predict reaching the SNR $\sim 100$.

\subsection{MIR Channel}

ACS-MIR is intended to work in solar occultations only, and during each occultation it is self-calibrated using the out-of-atmosphere solar spectrum, and the dark spectrum. Therefore the radiometric calibration as well as the dark current, flat field, etc. calibrations are of secondary importance. The emphasis of the ground and flight calibrations was so far put on the spectral resolution and the SNR of the instrument.

The spectral resolution of $\lambda / \Delta \lambda \geq 50,000$ was verified multiple times with the $3.39 \mu \mathrm{m}$ $\mathrm{He}-\mathrm{Ne}$ laser line in the laboratory during the alignment and the integration of the instrument. However, this value has to be confirmed with the Sun and gaseous absorption lines in flight (see Sect. 3.3). Also, the ground calibrations testing included the study of dark 

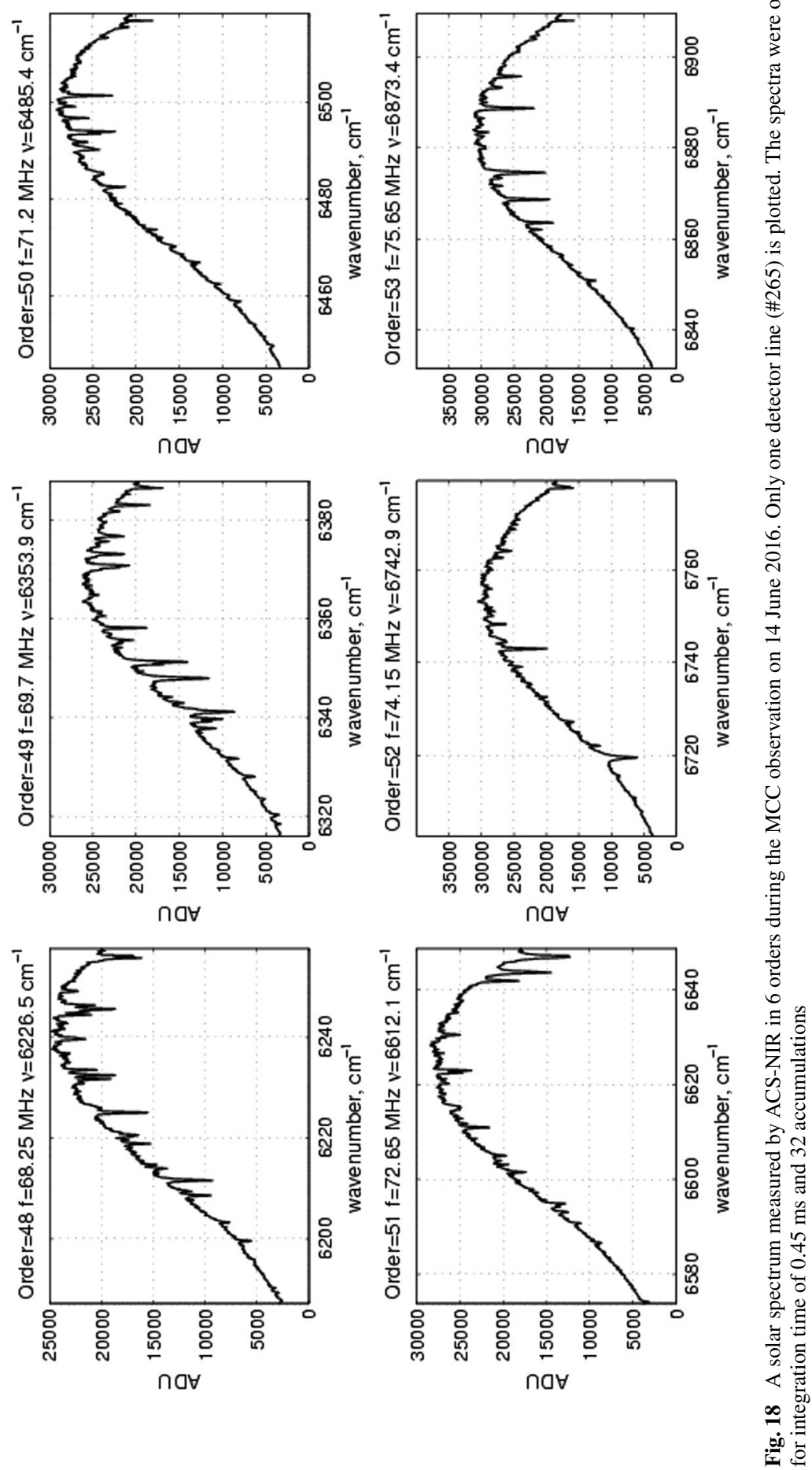
Fig. 19 (a) A raw detector frame recorded by ACS-MIR when observing Sun through terrestrial atmosphere in May 2015. The secondary grating angle was $-5.1^{\circ}$, and the spectral range covered was $3.7-4 \mu \mathrm{m}$. In the horizontal direction the echelle spectra are spread along 640 pixels, and in the vertical direction the diffraction orders from 151 at the top to 164 at the bottom are visible. (b) Spectra from the same frame (detector lines from 175 to 187$)$. The diffraction order 159 with water vapor absorption lines is plotted
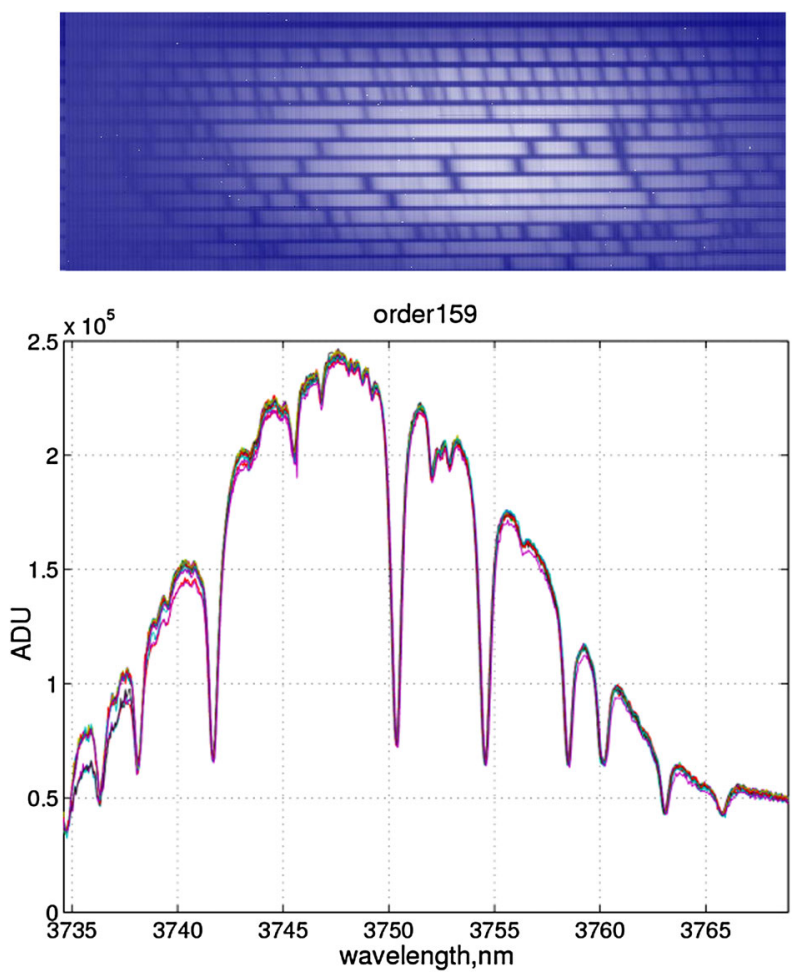

current evolution with the integration time, and observation of the Sun though the Earth atmosphere to verify pixel-wavelength calibration and order positions. An example of the raw detector frame obtained from the ground-based observations of Sun is shown in Fig. 19. Unfortunately after the solar measurements MIR has undergone additional alignment and the wavelength calibrations obtained from the ground were revised during the cruise measurements.

In flight the series of Sun and the dark current measurements was done for different sets of the integration time and accumulation number. Two example detector frames, showing the order separation are shown in Fig. 20 for two secondary grating rotation angles indicated in Table 3 as a rotation 9 and 11 for integration time of $3 \mathrm{~ms}$ and 32 accumulations. In Fig. 21 we present an example of solar spectrum out of this frame compared to a highly-resolved out-of-atmosphere spectrum of the Sun.

In Fig. 22 we present the signal intensity for all positions of the secondary grating recorded with the integration time of $3 \mathrm{~ms}$. The dark signal is removed, and only the useful signal is shown. The dark signal is approximated from a dedicated dark sky observation, while on the science orbit it will be measured before or after the occultation event. In the 2.4-2.6 $\mu \mathrm{m}$ range the signal is close to the detector saturation, while for other positions the integration time can be further increased. Thus for the methane measurements at $\sim 3.3 \mu \mathrm{m}$ a $6 \mathrm{~ms}$ integration time will be used, and was tested during the MCO operations.

The ACS MIR channel performance regarding the SNR was estimated similar to that of NIR, by observing direct Sun with the most sensitive mode (192 frames accumulation). For a single pixel in the middle of the frame, where the signal intensity is at maximum, the SNR reaches 6000. A typical variation of SNR along the detector line (along one echelle 

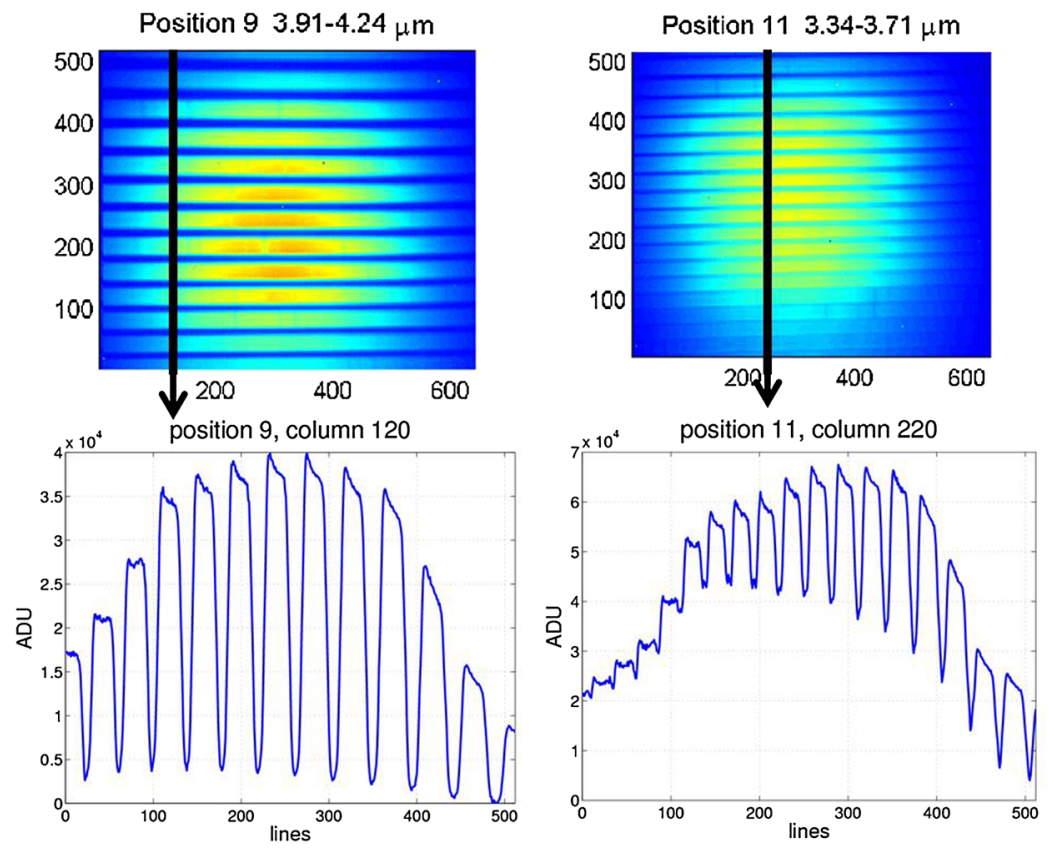

Fig. 20 (a) Example of the solar spectrum for two MIR frames (diffraction orders 142-149; position 9, see Table 3, and orders 162-174; position 11) obtained during the MCC observations on 15 June 2016. (b) "Vertical" cut for a single detector's column demonstrating the order separation

Fig. 21 Spectrum of the Sun for the diffraction order 147 out of the frame shown in Fig. 20 compared with solar spectrum from ATMOS/Spacelab-3 and Atlas-3 data with spectral resolution of $0.01 \mathrm{~cm}^{-1}$ (Seo et al. 2007)

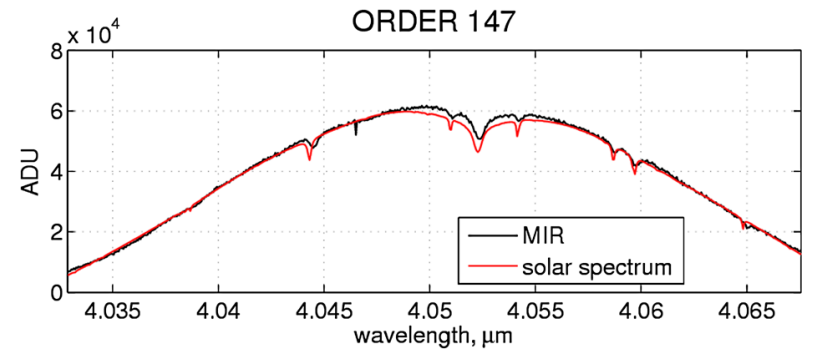

order) is shown in Fig. 23. In Sect. 5 we use a conservative SNR $=2500$ as a mean value. Separate sensitivity calculations for the most interesting parts of spectra deserve additional study. Pixels' averaging along the slit is not yet implemented. This offers the potential of increased performance.

\subsection{TIRVIM Channel}

Radiometric Calibration A quantity directly measured by a Fourier-transform spectrometer is the interferogram, the autocorrelation function of the electro-magnetic field (e.g. Bell 1972). Fourier transform of the interferogram gives the non-calibrated spectrum. The radiometric calibration is a conversion of the instrument counts to the radiance units. Principles of the radiometric calibration of a Fourier transform spectrometer are well known (e.g. Hanel 

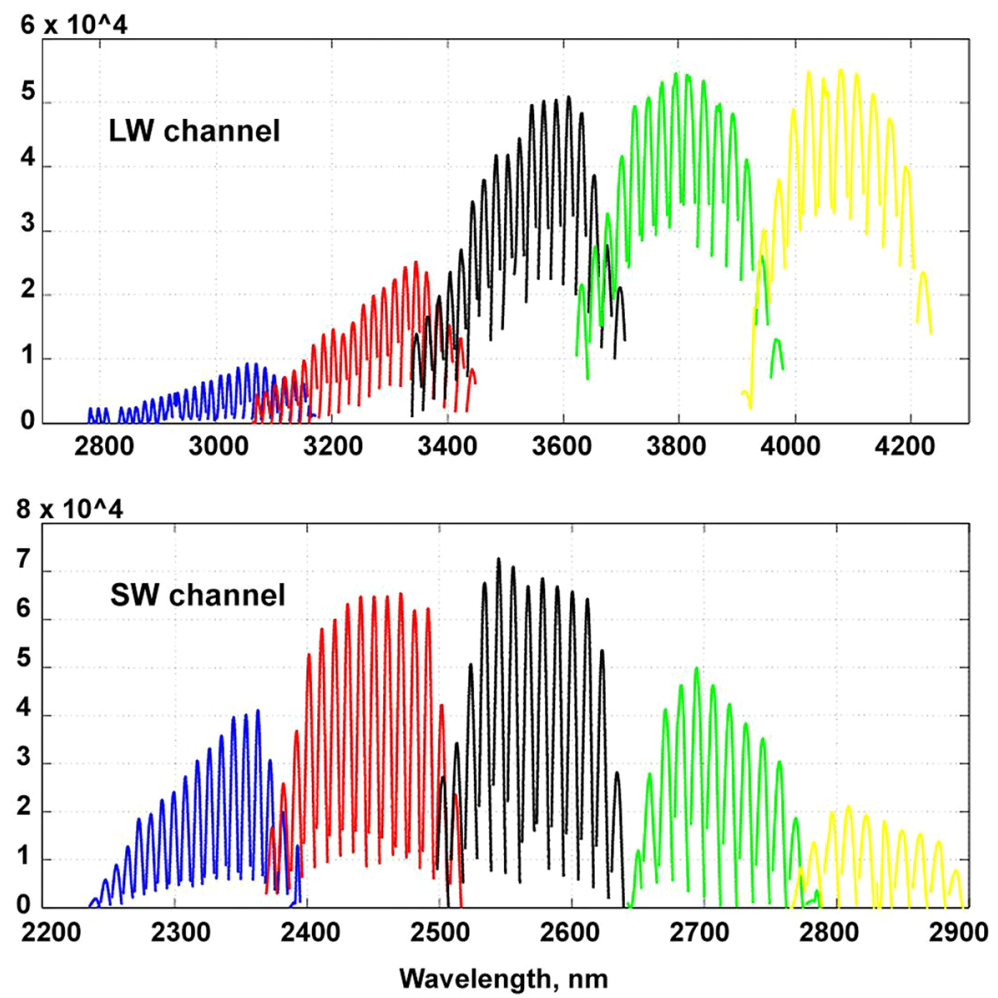

Fig. 22 Average signal level measured by ACS-MIR when observing out-of-atmosphere Sun for all diffraction orders and secondary grating rotations. The figure reflects relative SNR of MIR at different wavelengths

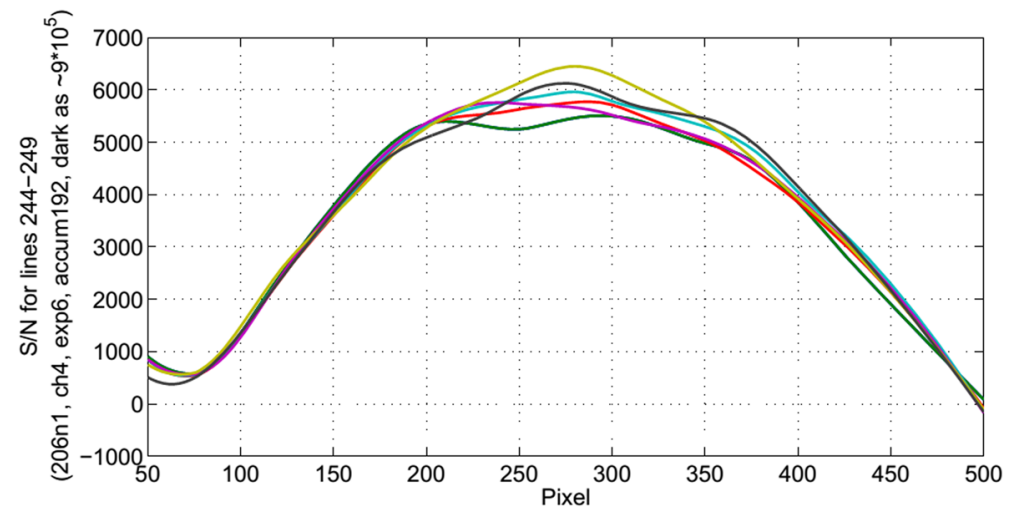

Fig. 23 SNR of ACS-MIR in the " $\mathrm{CH}_{4}$ diffraction order" (grating position 12; detector lines 244-249)

et al. 1970). The calibrated radiance of any target can be derived from measurements of two objects with known spectral brightness. 


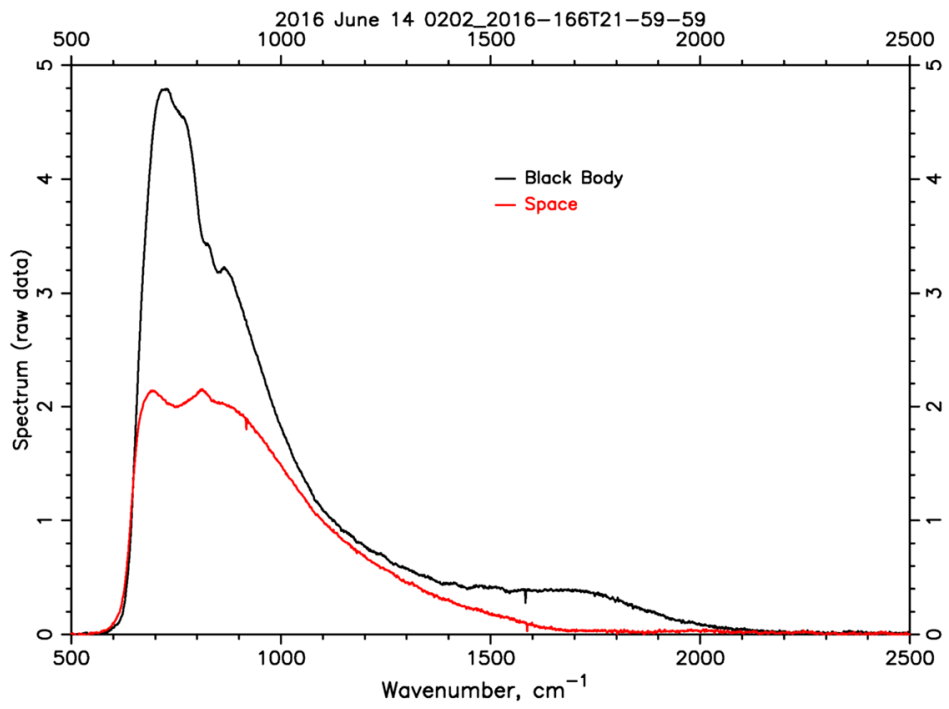

Fig. 24 Raw spectra of the internal black body and of space measured by ACS-TIRVIM in flight (in arbitrary units). The sign of the spectra is removed. The black body is warmer and space is colder than the instrument, so the corresponding signed spectra should be positive and negative, respectively

In the laboratory the instrument was verified in a thermo-vacuum chamber at different temperatures, observing sequentially the black body simulator, and the chamber shroud cooled by liquid nitrogen. This allowed the first approach to radiometric calibrations.

In flight, the calibration sources are usually cold space and an internal black body imitator with known spectral emissivity and controlled temperature (Fig. 24), which are observed, before and after each a series of measurements, by means of the scanner system.

The radiance emitted by the black body at a temperature $\sim 300 \mathrm{~K}$ becomes too low for the given sensitivity of the detector already at $5 \mu \mathrm{m}$ or $2000 \mathrm{~cm}^{-1}$. Therefore the radiometric calibration is effective only below this wavenumber. The short wavelength part of the TIRVIM spectral range $(1.7-5 \mu \mathrm{m})$ is mostly dedicated to observations in the solar occultation mode, which does not require absolute radiometric calibrations. The sensitivity in this part of the spectrum is too low for nadir observations.

The sensitivity of the instrument and its noise level are characterized by the noise equivalent spectral radiance $\operatorname{NESR}(v)$, which is determined as a standard deviation of the set of measurements of the same target (Fig. 25). A signal-to-noise ratio reaches its maximum at a wavenumber $v \approx 770 \mathrm{~cm}^{-1}$ : on the dayside of Mars at warmest conditions it amounts to approximately 1500 (compare NESR to spectra shown in Fig. 24). Spikes at 800 and $1600 \mathrm{~cm}^{-1}$ are caused by the acoustic disturbances generated by the Stirling cryocooler.

A simple calibration approach formulated by Hanel et al. (1970) has been successfully applied to a number of space-born Fourier-transform spectrometers (Oertel et al. 1985; Christensen et al. 2001; Giuranna et al. 2005). However, Revercomb et al. (1988) formulated a more general case applied by Saggin et al. (2011) to the calibration of the PFS spectrometer on Mars Express. Without entering into further details, we notice here that the calibration of TIRVIM, which will be a subject of a separate study, should be done in this way.

First thermal IR spectra of Mars were recorded on November 22, 2016, covering a longitude interval from $-176^{\circ}$ to $9^{\circ}$, latitudes from $-9^{\circ}$ to $9^{\circ}$, and local times from 4 to 21 hour 


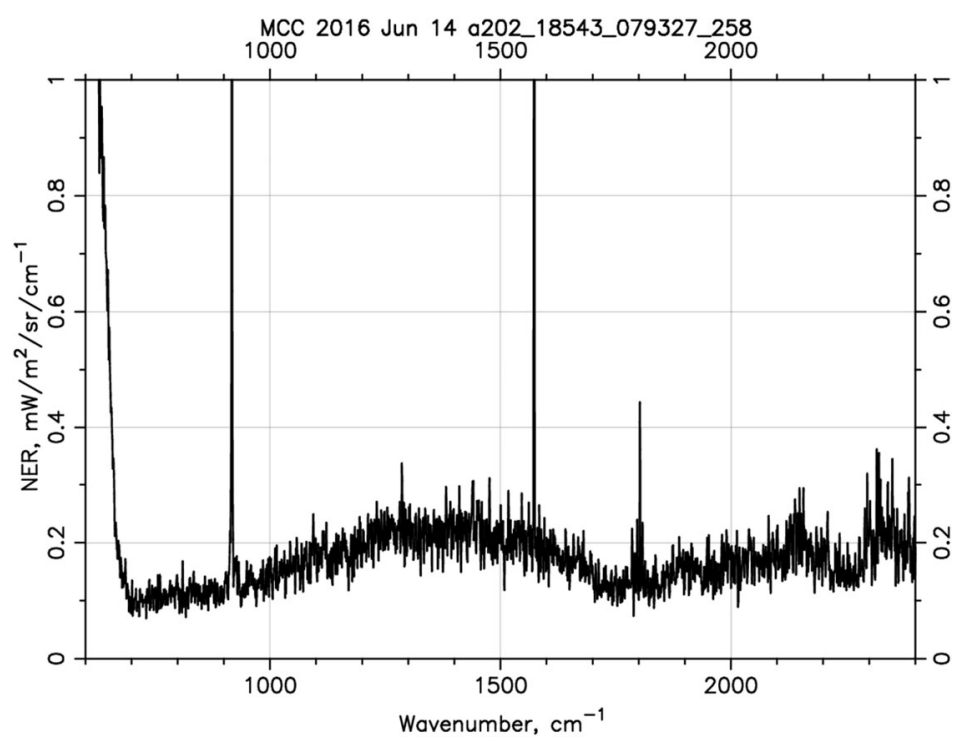

Fig. 25 Noise equivalent spectral radiance of the ACS-TIRVIM

(Fig. 26). The trajectory of the field of view footprint on Mars covered a wide range of temperature conditions and topography. Night and early morning spectra demonstrate prominent temperature inversions near the surface, manifested as a wide spectral feature at 700$1100 \mathrm{~cm}^{-1}$. Near noon the surface temperature is as high as $300 \mathrm{~K}$, and the signal-to-noise ratio in the spectrum reaches its maximum. A broad absorption band at $900-1300 \mathrm{~cm}^{-1}$ is produced by the atmospheric dust. The spectrum observed over the Asia Mons is characterized by a lower surface temperature and low dust column (i.e. absence of the dust absorption band), while the spectrum in the deep local depression Hebes Chasma reveals a very strong dust absorption band, produced by a joint effect of the higher dust abundance and specific temperature conditions: cold atmosphere above the hot surface. An increasing trend of the brightness temperature in the interval $1200-2000 \mathrm{~cm}^{-1}$ seen in the cold nighttime and morning spectra is caused by the low radiance value going below the noise level.

Measurements in Solar Occultation Mode Solar occultation mode does not require absolute radiometric calibration, and the most important characteristic becomes the best achievable spectral resolution and the SNR.

In the laboratory the TIRVIM spectral resolution was checked for the maximum interferometer swing. The zoomed spectrum of the infrared He-Ne $3.39 \mu \mathrm{m}$ laser line is shown in Fig. 27. A double sided interferogram contained $2 N=111400$ points, which provides the resolution without interferogram apodization of $0.14 \mathrm{~cm}^{-1}$ : at half-maximum the full width of the spectral spread function (the spectral resolution) is $\Delta v \approx \frac{1.2}{2 N \Delta x}$, where $\Delta x=0.76 \mu \mathrm{m}$ is the interferogram sampling.

Measurements of solar spectrum were carried out in laboratory and in flight in April, June, and November 2016 (Fig. 28). The maximum SNR appears to be quite low $\sim 170$ in its maximum at $4000 \mathrm{~cm}^{-1}$ (for a measurement time of $1.8 \mathrm{~s}$, see Table 4). In the following we use a conservative $\mathrm{SNR}=50$ as a mean value over the spectral range. However for narrow spectral intervals in the vicinity of solar spectrum lines the SNR may be considerably 

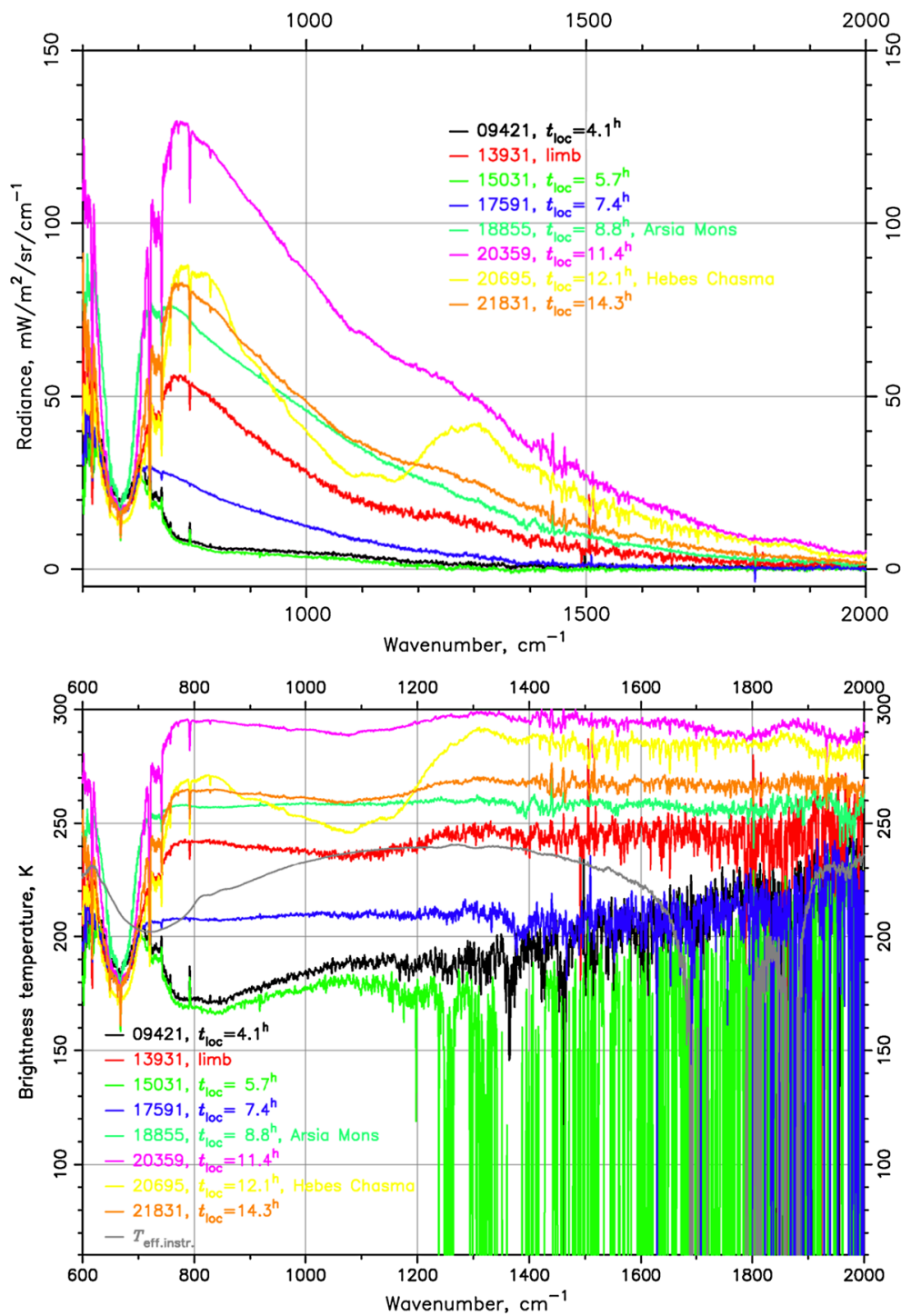

Fig. 26 First calibrated spectra of Mars in units of radiance (a) and brightness temperature (b) measured with ACS-TIRVIM on Nov 22, 2016 in nadir mode. Local times are given in the legend. Spectra recorded over Arsia Mons and Hebes Chasma are noted in the legend

improved pointing the nadir channel to the Sun by means of the scanner. With such measurements, the central peak of the interferogram, which is responsible for continuum and broad spectral features, is saturated and the true continuum level is therefore lost. Strong solar lines observed both with the occultation and nadir channels could be used as a proxy to the correct the continuum level. No such measurements could be implemented so far during the in-flight observation campaigns. 


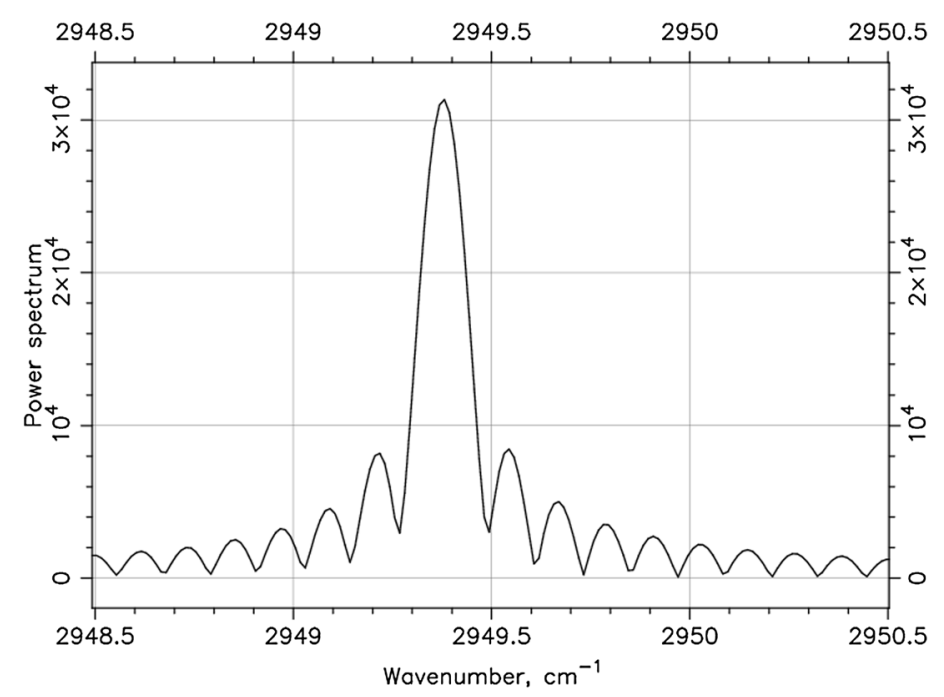

Fig. 27 SRF of TIRVIM obtained by measuring the $\lambda=3.39 \mu \mathrm{m} \mathrm{He}-\mathrm{Ne}$ laser line with MOPD $=5 \mathrm{~cm}$. A two-side interferogram contained 111,461 points, padded with zeroes up to 1,048,576 points. The spectral resolution is $\Delta v(F W H M)=0.14 \mathrm{~cm}^{-1}$, in agreement with the theoretical limit

\section{Expected Performances}

In the following section we estimate the performances of ACS to detect/measure the atmospheric constituents or to retrieve the atmospheric structure following the instrument parameters determined in Sect. 4, and summarized in Table 2.

The performances are considered separately for detection in solar occultation and for monitoring/climatology measurements in nadir. The NIR and TIRVIM sensitivity in nadir is given in Table 2. The expected performances of ACS are summarized in Table 5.

\subsection{Solar Occultations}

For solar occultation the detection limits and quantification of known molecules is based on the latest knowledge of calibration for each ACS channel:

1. For ACS-NIR, $\lambda / \Delta \lambda=25,000$ and $\mathrm{SNR}=4000$ for an integration time of $1 \mathrm{~ms}$ and with 32 accumulations.

2. For ACS-MIR $\lambda / \Delta \lambda=50,000$ and $\mathrm{SNR}=2500$. This is the SNR for all secondary grating positions for an integration time of $3 \mathrm{~ms}$ and for 32 accumulations.

3. For ACS-TIRVIM the estimated detection limits are based on $\mathrm{SNR}=50$ in the range of 3-10 $\mu \mathrm{m}$ and spectral resolution of $\Delta v=0.13 \mathrm{~cm}^{-1}(\sim 1 \mathrm{~nm})$.

The detection limits were estimated using look-up-tables built for spherical geometry in the range of $0.7-1.7$ (NIR), 2.3-10 $\mu \mathrm{m}$ (MIR+TIRVIM) obtained with a line-byline radiative transfer model. The model was based on the HITRAN 2012 spectroscopic database (Rothman et al. 2013), using broadening coefficients in $\mathrm{CO}_{2}$ from Lavrentieva et al. $(2014,2015)$ for $\mathrm{H}_{2} \mathrm{O}$ and $\mathrm{HDO}$, and Sung and Varanasi (2005) for CO. For $\mathrm{CO}_{2}$ the self-broadening was applied. To model the Martian atmosphere, we used an average temperature-pressure profile extracted from the Martian Climate Database (MCD 5.2; Millour et al. 2015), corresponding to the equatorial region for a surface pressure of $6.1 \mathrm{mbar}$ 

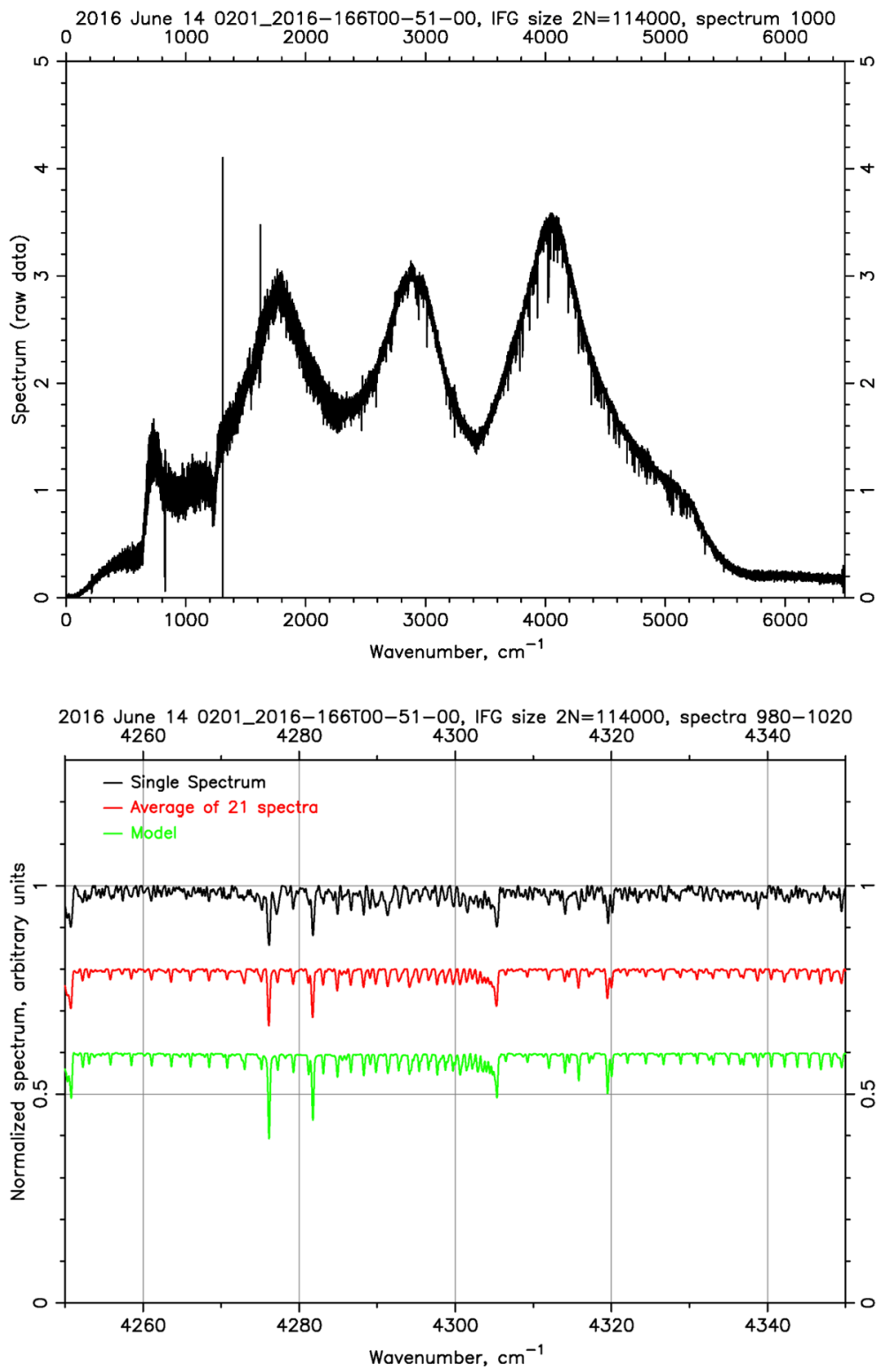

Fig. 28 Spectrum of the Sun measured with the solar channel of TIRVIM in June 2016. (a) The full range. (b) Zoom on a selected region: single and average measured spectra compared to a model solar spectrum (Fiorenza and Formisano 2005)

(so-called "zero level" on Mars). The final transmittance has been calculated for a set of altitudes from 10 to $80 \mathrm{~km}$ for minor species, and from 10 to $160 \mathrm{~km}$ for the abundant molecules, $\mathrm{CO}_{2}, \mathrm{CO}$, and $\mathrm{H}_{2} \mathrm{O}$.

The sensitivity in solar occultation critically depends on the dust loading. Not only is dust confined closer to the surface, but limb geometry imposes a growing airmass factor 


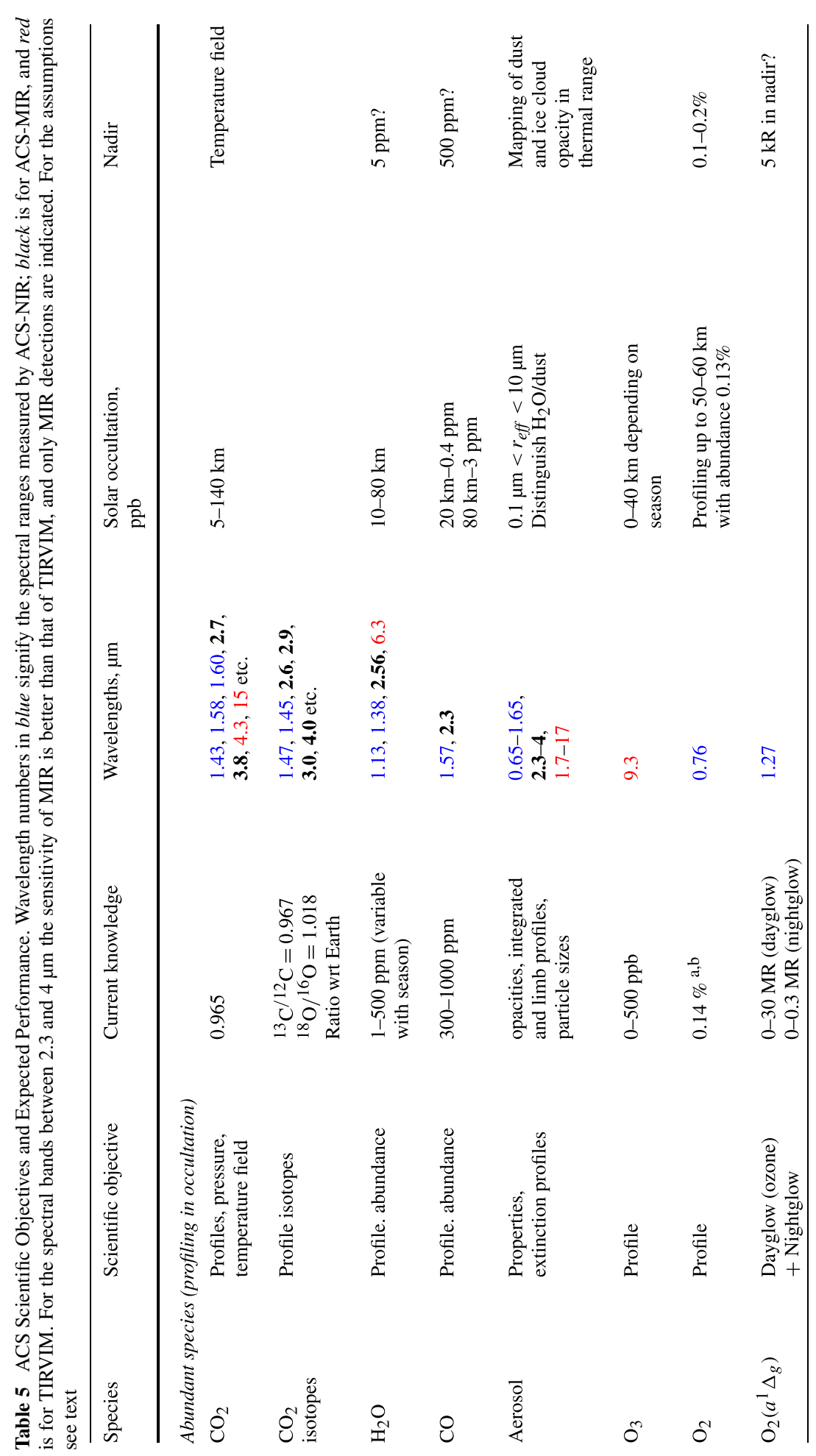




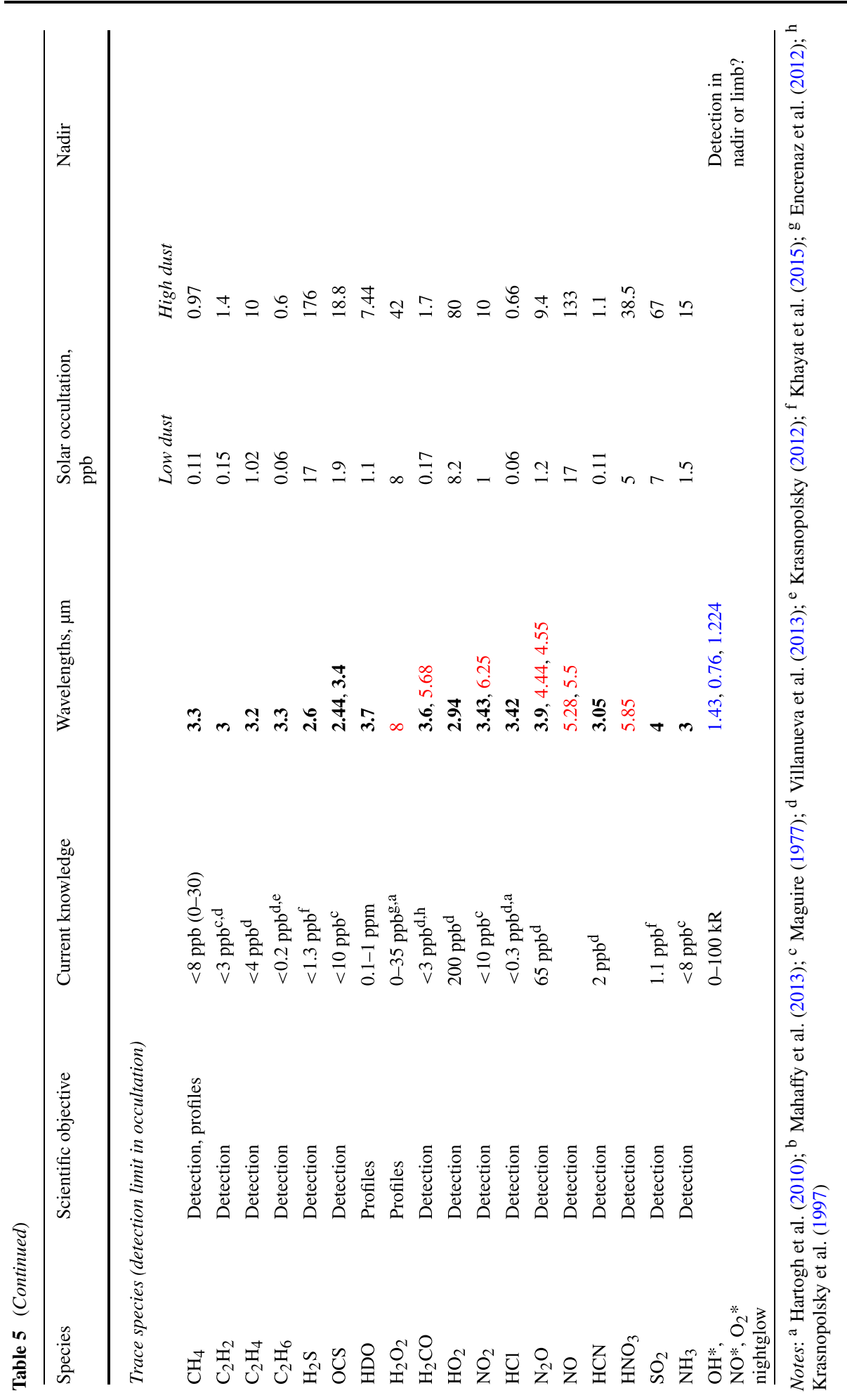


as one looks closer to the surface and thus an even higher dust opacity. Under clear conditions ( $\tau=0.1$, like during the "dust-free" aphelion season), a lower limit of 5 to $10 \mathrm{~km}$ is typically achieved whereas under dusty conditions ( $\tau \geq 5$, e.g. during a dust storm), the horizon for the observer can rise up to $>20-30 \mathrm{~km}$. The model accounts for dust opacity using a spectrally-dependent extinction coefficient in the range of $0.7-15 \mu \mathrm{m}$ for two characteristic optical depths at $1 \mu \mathrm{m}: \tau=0.2$ (low dust) and $\tau=2.0$ (high dust). The extinction coefficient of dust was computed using Mie theory (http://www.giss.nasa.gov/ crmim/brf/; Mishchenko et al. 1999), for a particle effective radius of $1.5 \mu \mathrm{m}$ and an effective variance of 0.25. The refraction index was taken from Wolff et al. (2009) and Ockert-Bell et al. (1997).

Trace Gases Trace gas detection will be carried out with the solar occultation mode of both MIR and TIRVIM channels. Their spectral range encompasses the absorption bands of many molecules, including all the high-priority hydrocarbon species, such as $\mathrm{CH}_{4}, \mathrm{C}_{2} \mathrm{H}_{2}$, $\mathrm{C}_{2} \mathrm{H}_{4}, \mathrm{C}_{2} \mathrm{H}_{6}$, etc., owing to intense $\mathrm{C}-\mathrm{H}$ vibrational stretch transitions around $3 \mu \mathrm{m}$. Also, between 2.3 and $3.8 \mu \mathrm{m}$ halogens and sulfur-bearing species can be detected. As discussed in Sect. 4, current status of TIRVIM calibrations demonstrates in the spectral range 2.3 to $4 \mu \mathrm{m}$ far better spectral resolution and SNR for the MIR channel than for TIRVIM. For this reason, all detection limits listed for the whole ACS assembly in this wavelength range were obtained for MIR (cf. Table 5).

Figure 29 shows the absorption by different trace species in the MIR spectral range for a simulated solar occultation at $22 \mathrm{~km}$ tangent altitude. The instantaneous coverage for a single rotation of the secondary grating (see Table 3 ) is also indicated. MIR will measure one or two positions during one solar occultation. The rotations between 3.1 and $3.6 \mu \mathrm{m}$ marked in Fig. 29 are the most suitable for the detection of minor species such as $\mathrm{CH}_{4}, \mathrm{C}_{2} \mathrm{H}_{4}, \mathrm{C}_{2} \mathrm{H}_{6}$, $\mathrm{HCl}, \mathrm{H}_{2} \mathrm{CO}, \mathrm{OCS}, \mathrm{NO}_{2}$, and allow for simultaneous profiling of $\mathrm{H}_{2} \mathrm{O}, \mathrm{HDO}$, and $\mathrm{CO}_{2}$. The vertical profiles of MIR sensitivity in occultation for various gases and different dust backgrounds are shown in Fig. 30. The best performances at which a detection limit can be determined are achieved at an altitude of $20 \mathrm{~km}$ for low dust conditions.

TIRVIM covers this whole (and much wider, 1.7-17 $\mu \mathrm{m}$ ) spectral range with a spectral resolution of $0.13 \mathrm{~cm}^{-1}$, non-apodized $(\lambda / \Delta \lambda \approx 23,000$ at $3.3 \mu \mathrm{m})$. Longward of the MIR spectral upper limit of $4.3 \mu \mathrm{m}$, nitrogen compounds like $\mathrm{NO}$ and $\mathrm{HNO}_{3}$ can be detected. $\mathrm{O}_{3}$, an efficient tracer of the Martian photochemical processes can be detected at $9.3 \mu \mathrm{m}$, while odd hydrogen $\mathrm{H}_{2} \mathrm{O}_{2}$, the main oxidizing species exhibits strong absorption bands at $7.7 \mu \mathrm{m}$. Their bands lie in the TIRVIM range, and $\mathrm{H}_{2} \mathrm{O}_{2}$ in particular is not covered by any other instrument on TGO.

Table 5 shows that for many species the detection limits will significantly improve our current knowledge, except for sulfur-bearing species $\mathrm{H}_{2} \mathrm{~S}$ and $\mathrm{SO}_{2}$ for which the MIR performances are inferior to past observations. It is to be noted however, that we used a conservative set of parameters to predict ACS performances. However, optimizing integration time and applying averages for each molecule will allow a significant improvement of these estimates by a twofold factor at least.

Profiling of Known Species The broad spectral range of ACS offers multiple possibilities for profiling of the Mars atmospheric gases. We could only consider few examples. The solar occultation by ACS-NIR is mostly aimed to study vertical distribution of water vapor and $\mathrm{CO}_{2}$ density. Figure 31 illustrates a possible NIR sequence during a solar occultation, which includes measuring of 10 diffraction orders. Three orders are dedicated to different $\mathrm{CO}_{2}$ bands, allowing one to profile the atmospheric density over a wide range of altitudes, three orders for $\mathrm{H}_{2} \mathrm{O}$, one mixed order, two orders without significant gaseous absorption for measuring aerosols, and one order aimed for the $\mathrm{O}_{2}$ at $0.76 \mu \mathrm{m}$ band. 
O. Korablev et al.

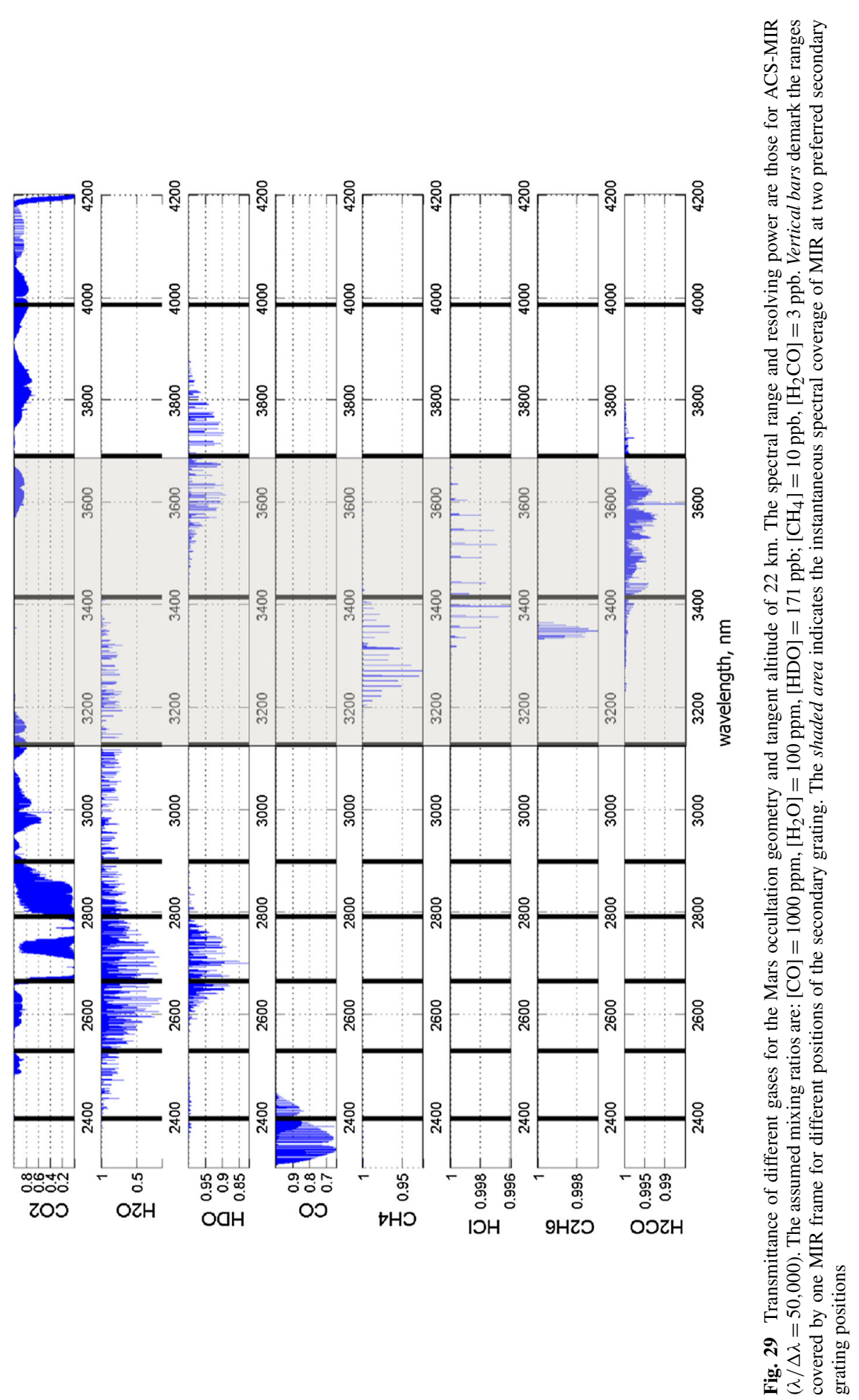


Fig. 30 The sensitivity of different ACS channels in solar occultation mode computed for two dust loadings, the optical depth $\tau=0.2$ (solid curves), and $\tau=2$ (dashed curves). (a) MIR sensitivity for trace gases.

(b) Sensitivity to measure $\mathrm{H}_{2} \mathrm{O}$ in different water vapor bands, and to HDO. (c) Sensitivity to measure $\mathrm{CO}_{2}, \mathrm{CO}$ and $\mathrm{O}_{2}$. Dotted lines in panel (c) indicate theoretical abundances from MCD5.2 GCM (Millour et al. 2015)
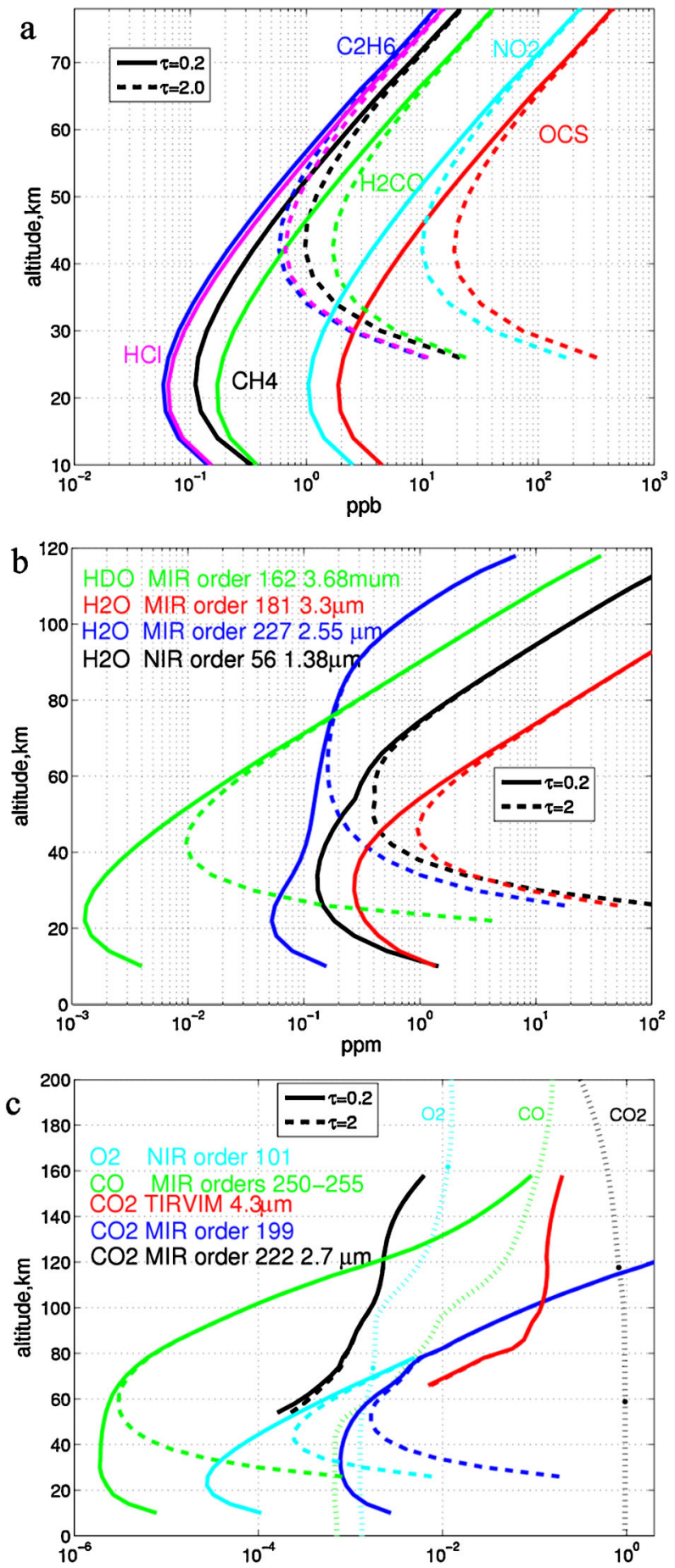

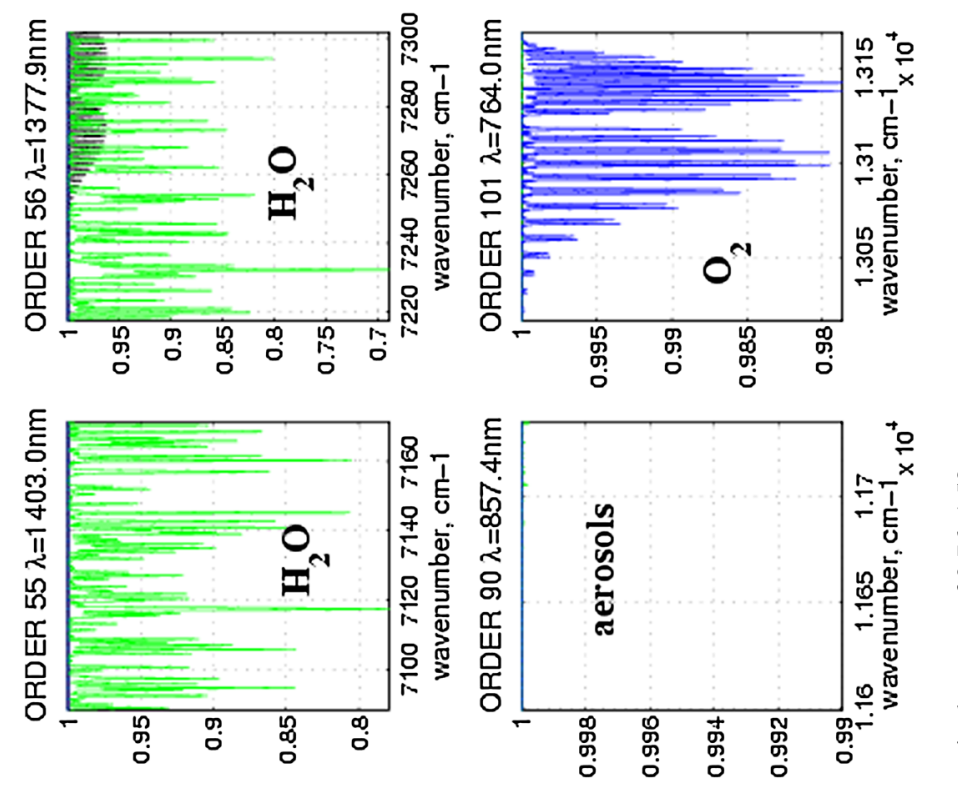

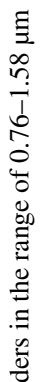
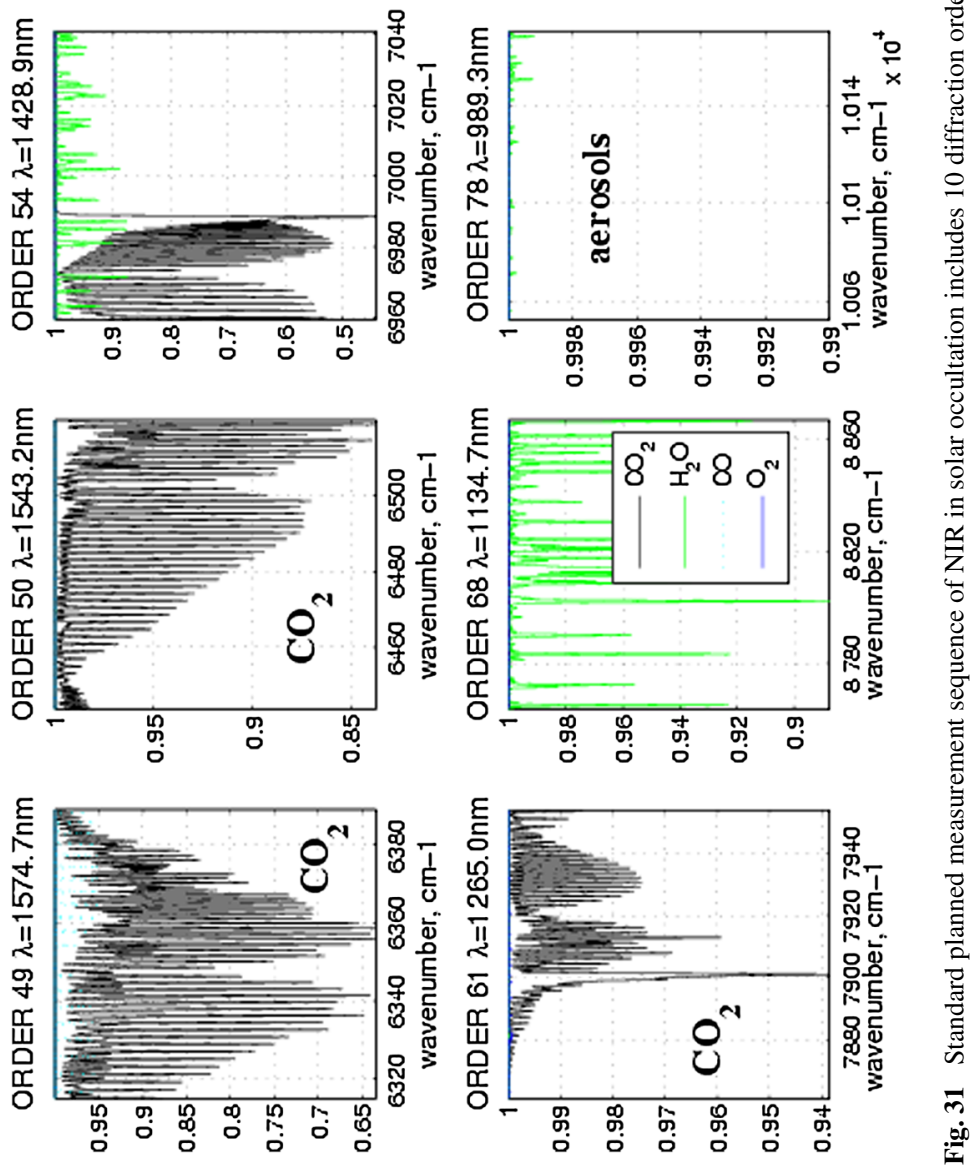
Figure $30 \mathrm{~b}$ shows how sensitive the instrument is to water and to HDO in different spectral ranges. The $\mathrm{H}_{2} \mathrm{O}$ is best measured with the strong $2.6 \mu \mathrm{m}$ band in MIR range. ACS will be sensitive up to $100 \mathrm{~km}$ with an accuracy better than $1 \mathrm{ppm}$. But measuring this band requires a secondary grating position (position 4, see Table 3 and Fig. 29) different from the preferred rotation (position 12) dedicated to hydrocarbon species and HDO. As noted in Sect. 3.3, this requires the overturn of the secondary grating, and therefore a dedicated occultation. Therefore, for routine monitoring of water profiles we plan to use mostly the NIR measurements in the $1.38 \mu \mathrm{m}$ band. Such measurements can be performed in parallel with any other ACS channel. The $\mathrm{H}_{2} \mathrm{O}$ measurements by MIR in the $2.6-\mu \mathrm{m}$ band can be used for dedicated sensitive campaigns.

To profile the $\mathrm{HDO} / \mathrm{H}_{2} \mathrm{O}$ and access therefore $\mathrm{D} / \mathrm{H}$ via their main carrier, we plan to use the strongest HDO band near $3.7 \mu \mathrm{m}$ within the MIR spectral range as well as water lines near $3.3 \mu \mathrm{m}$. These lines of water and deuterated water acquired within the same MIR frame will permit a $\mathrm{HDO} / \mathrm{H}_{2} \mathrm{O}$ vertical profiling from $\sim 10$ to $>60 \mathrm{~km}$. Combining $\mathrm{HDO}$ at $3.7 \mu \mathrm{m}$ with $\mathrm{H}_{2} \mathrm{O}$ at $2.6 \mu \mathrm{m}$ would allow extending the measured $\mathrm{D} / \mathrm{H}$ profiles even higher, but as explained above they would not be perfectly collocated.

Accurate measurements of $\mathrm{CO}_{2}$ will be retrieved to obtain vertical profiles of atmospheric density, which integrated from the top yields the pressure (with some uncertainty though as the lowest scale height is not accessible), and the temperature assuming hydrostatic equilibrium. There are several $\mathrm{CO}_{2}$ bands within the MIR and NIR spectral range allowing the retrieval in a wide range of altitudes. Strong bands allow for sounding the upper atmospheric levels, whereas weaker bands are suitable for lowermost altitudes. Figure 30c demonstrates the sensitivity of the $\mathrm{CO}_{2}$ lines with MIR order 222 within the strong $2.7-\mu \mathrm{m}$ band and in the order 191 with relatively weak $\mathrm{CO}_{2}$ lines near $3 \mu \mathrm{m}$. The first order allows to probe the upper

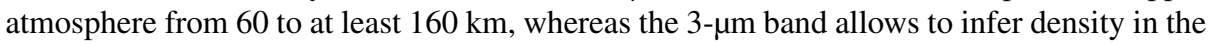
low atmosphere from the near-surface up to $80-100 \mathrm{~km}$. The strongest $\mathrm{CO}_{2} 4.3 \mu \mathrm{m}$ band lies partly outside of the MIR range but can be measured by TIRVIM. The current estimation of the TIRVIM SNR suggests however that a similar band of $\mathrm{CO}_{2}$ at $2.7 \mu \mathrm{m}$ measured by MIR will yield better accuracy.

$\mathrm{CO}$ is a long-lived abundant species, and its variations (similar to $\mathrm{O}_{2}$ ) are due to condensation and sublimation of $\mathrm{CO}_{2}$ in the polar and subpolar regions. The $\mathrm{CO}$ profiling is a good tracer of these processes and atmospheric dynamics. MIR will allow to measure the $\mathrm{CO}$ mixing ratio in the $2.3 \mu \mathrm{m}$ band from the surface (for low dust) to $\sim 140 \mathrm{~km}$ (Fig. 30c).

Very few measurements of the $\mathrm{O}_{2}$ density on Mars have been made, and its profiling at $0.76 \mu \mathrm{m}$ will be a unique aspect of the ACS-NIR scientific return in occultation, since no other instrument on a Mars orbiting platform is sensitive to $\mathrm{O}_{2}$ in the 10 to $>60 \mathrm{~km}$ altitude range (Fig. 30c).

\subsection{Monitoring in Nadir}

The nadir measurements will be performed by ACS with NIR and TIRVIM channels. The main task of NIR channel in nadir will be measurements of the water vapor in $1.38 \mu \mathrm{m}$ and the $\mathrm{O}_{2}\left(\mathrm{a}^{1} \Delta_{g}\right)$ emission as a proxy for ozone at $1.27 \mu \mathrm{m}$. The high spectral resolution of NIR allows measuring $\mathrm{H}_{2} \mathrm{O}$ mixing ratio with accuracy of $\leq 5 \mathrm{ppm}$ and to monitor rotational temperature using resolved structure of the $1.27 \mu \mathrm{m} \mathrm{O}_{2}\left(\mathrm{a}^{1} \Delta_{g}\right)$ emission measured with an accuracy $\leq 5 \mathrm{kR}$.

The multiple scattering by dust and clouds is an important source of error in the determination of $\mathrm{H}_{2} \mathrm{O}$ abundance from near-IR band in the dusty atmosphere (Fedorova et al. (Fedorova et al. 2004; Trokhimovskiy et al. 2015). Simultaneous measurements of the silicate dust and water ice absorption bands at $9 \mu \mathrm{m}$ and $12 \mu \mathrm{m}$, respectively, by TIRVIM will 
Fig. 32 Weighting functions for selected spectral channels (wavenumbers given in the legend) calculated for TIRVIM. See text for details

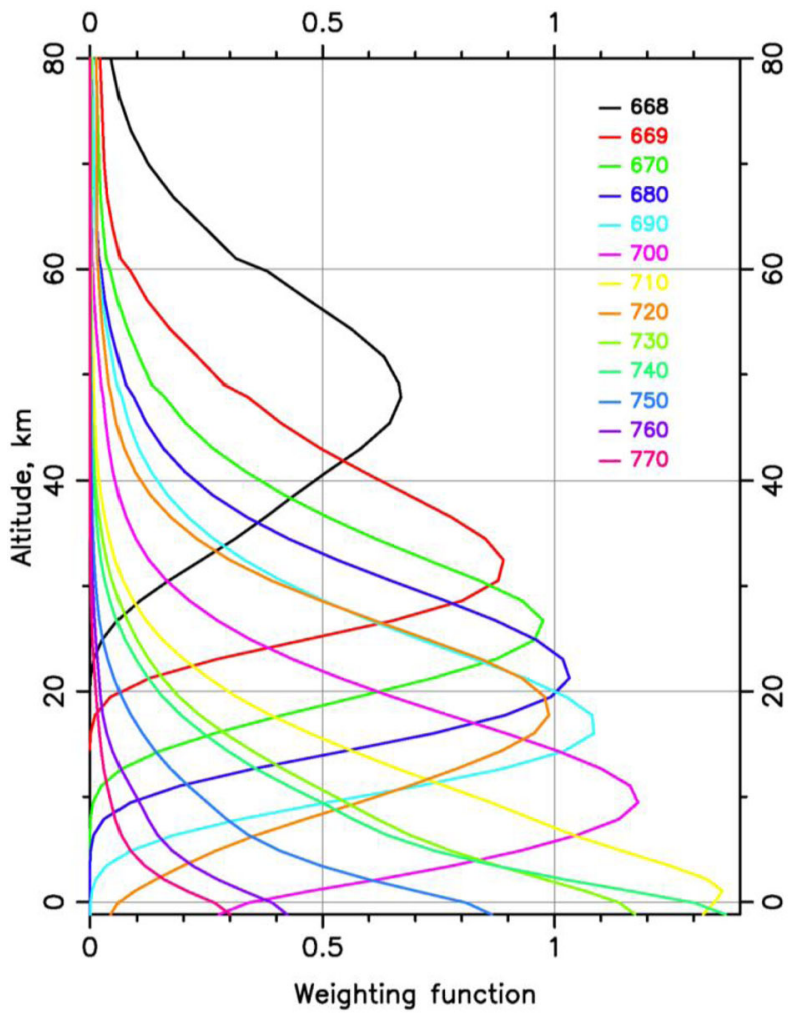

be used to monitor simultaneously their optical depths. This knowledge would allow for a significant improvement of the $\mathrm{H}_{2} \mathrm{O}$ retrievals in the solar spectral range.

Thermal sounding of the Mars atmosphere is the main monitoring task of ACS. The temperature profile will be retrieved from the inversion of the $15 \mu \mathrm{m} \mathrm{CO}_{2}$ band measured by TIRVIM. Mars has been sounded in this band already in a number of missions: IRIS/Mariner 9 (Hanel et al. 1970; Zasova et al. 2002), TES/MGS (Smith 2004; Smith et al. 2001), PFS/Mars Express (Giuranna et al. 2016). The most used global results are obtained from TES/MGS data. Better spectral resolution of TIRVIM with respect to the previous measurements improves both the altitude range (from the surface up to 55-60 km) and the vertical resolution of the retrieved temperature profiles, which will be of the order of few kilometers. The inversion technique is described by e.g. Grassi et al. (2005). Examples of spectra measured by TIRVIM in various conditions are shown in Fig. 26. In Fig. 32 we present the weighting functions showing the sensitivity of the measured spectrum to temperature at different altitudes. They are computed for a theoretical spectrum simulated with the spectral resolution $\Delta v=1.17 \mathrm{~cm}^{-1}$ (20400 points in a double sided interferogram with Hamming apodization), and for a Mars atmosphere model on the dayside, $\mathrm{Ls}=315^{\circ}$, Lat $=0^{\circ}$.

Near-IR emissions detected on the night side of Mars are useful tracers of atmospheric dynamics. The $\mathrm{O}_{2}$ emission at $1.27 \mu \mathrm{m}$ was detected first by OMEGA/MEX (Bertaux et al. 2012), and then regularly monitored by SPICAM-IR (Fedorova et al. 2012). The OH emission at $1.45 \mu \mathrm{m}$ and $2.9 \mu \mathrm{m}$ was detected by CRISM/MRO (Clancy et al. 2013). The emissions occur during the polar night. Recent discovery of NO nightglow on Venus at $1.224 \mu \mathrm{m}$ 
$(\mathrm{C}(0) \rightarrow \mathrm{A}(0)$ band) (García Muñoz et al. 2009) by the VIRTIS instrument on VEX makes its searches in the Martian atmosphere encouraging. It can provide a wealth of information on the high-altitude chemistry and dynamics of the Martian atmosphere. The current estimate for NIR SNR in nadir does not indicate significant sensitivity to weak night side emissions. In addition, the TGO orbit inclined at $74^{\circ}$ will not favor routine monitoring of the polar areas. The possibility to detect and to monitor the night side emissions by ACS-NIR shall be confirmed later during the mission after the commissioning of the science phase.

\subsection{Aerosols}

Heating and cooling associated with aerosols play a key role in the Martian climate. Heterogeneous processes are important for atmospheric chemistry, and even a heterogeneous loss of methane is considered. The major fraction of Martian aerosols is accounted for by mineral dust, while the condensation-induced particles, $\mathrm{H}_{2} \mathrm{O}$ ice and $\mathrm{CO}_{2}$ ice crystals, are also encountered depending on season and location. Dust abundance (mostly represented by its column opacity at visible or infrared wavelengths) has been continuously monitored since 1997 by MGS/TES (Smith 2004), PFS/MEX (Giuranna et al. 2016), and MCS/MRO (Heavens et al. 2011). ACS will continue this monitoring both in nadir and solar occultation mode employing the whole spectral range of TIRVIM, and a number of NIR spectral ranges $(0.763,0.857,0.99,1.26,1.38,1.43$, and $1.55 \mu \mathrm{m}$ with ACS-NIR and the 3.2-3.7 $\mu \mathrm{m}$ range by MIR). Such measurements, and especially the silicate dust and water ice absorption bands at 9 and $12 \mu \mathrm{m}$ measured by TIRVIM will permit a spectral separation between dust and $\mathrm{H}_{2} \mathrm{O}$ ice clouds particles.

In addition to this main task ACS offers unique potential in constraining the physical properties of atmospheric aerosols. The properties of dust are still poorly constrained: there is an uncertain factor between the thermal IR and visible absorption by dust, and the spectrum of a terrestrial mineral analogue is used in between (Ockert-Bell et al. 1997; Korablev et al. 2005). Solar occultation measurements by TIRVIM complemented with NIR and MIR continuum intervals will provide regular measurements of the full absorption spectrum of the dust, allowing for complete characterization of its composition. The properties of the dust particles will be best constrained by ACS-NIR in the spectral range of $0.6-1.7 \mu \mathrm{m}$, which is the most sensitive to particle sizes from 0.1 to $1.5 \mu \mathrm{m}$. Similar measurements by SPICAMIR have demonstrated a high sensitivity at the altitudes from 10 to $80 \mathrm{~km}$ even in a narrower spectral range of 1-1.7 $\mu \mathrm{m}$ (Fedorova et al. 2009). ACS-NIR in its extended spectral range will be suitable to determine a smaller fraction of dust (particle size $\leq 0.5 \mu \mathrm{m}$ ), which is present above $40 \mathrm{~km}$. The smallest fraction with sizes $\leq 0.2 \mu \mathrm{m}$ (Montmessin et al. 2006; Fedorova et al. 2014) will require measuring in the spectral range from UV to near-IR that would be possible on TGO using coordinated ACS-NIR and NOMAD-UVIS observations. The altitude range of the aerosol sounding in solar occultation mode may be defined as near the surface $(<10 \mathrm{~km})$ to $80 \mathrm{~km}$ depending on the season.

\section{Science Operations}

The ExoMars TGO Science Operations mission phase will start after the aerobraking phase when TGO reaches the nominal operation quasi-circular (eccentricity of 0.0069) orbit in the beginning of 2018. The orbit will be near-polar $\sim 400-\mathrm{km}$ altitude, with an inclination of $74^{\circ}$, and an orbital period of approximately two hours. The ground track repeats after 31 
Fig. 33 A sketch of TGO observations in solar occultation (SO) and in nadir

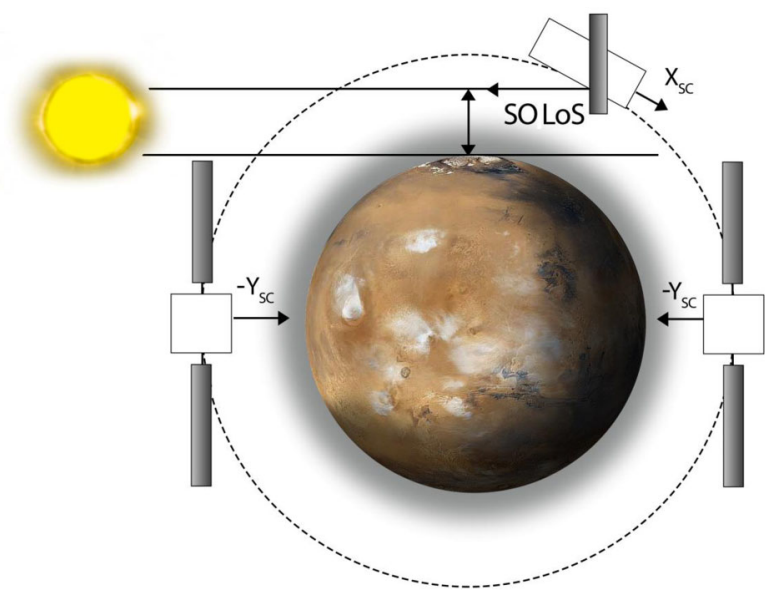

days. The orbit is optimized for atmospheric observations, allowing diurnal monitoring and observation of solar eclipses at each revolution.

During the science phase the spacecraft attitude ensures that for the most of the time the $\overrightarrow{-Y}$ axis is pointed toward nadir and the direction to the Sun remains perpendicular to the $\mathrm{S} / \mathrm{C} \mathrm{Z}$ axis. This yaw steering motion is to maximize the power available from solar panels. The pointing law is violated for sun observations (solar occultations) and for offpointing (high resolution imaging), but the deviation of $\overrightarrow{-Y}$ from nadir is less than $10^{\circ}$, so atmospheric nadir measurements can still be done during occultation measurements and target observations.

The ACS will perform the occultation measurements by all three channels, and nadir measurements only by NIR and TIRVIM. MIR will operate exclusively in solar occultation. In nadir, both dayside and night side observations will be performed, TIRVIM operating evenly on the dayside and night side, and NIR preferentially on the dayside (Fig. 33).

\subsection{Solar Occultations}

With 12 orbits per day, and observations every egress and ingress, there are up to 24 occultations slots per day. The latitudes covered in solar occultation range from $88{ }^{\circ} \mathrm{N}$ to $90^{\circ} \mathrm{S}$, change with time as shown in Fig. 34. The exact phase of this coverage will be defined after reaching the science orbit. During one day, occultations are evenly distributed along the longitudes at two latitudes, one in the southern and the other in the northern hemisphere (see yellow marks in Fig. 35).

The colors in Fig. 34 stand for different beta angles, which is the angle between the orbit plane and the vector originating from the spacecraft and pointing to the Sun. This angle is changing throughout the year and affects in particular the duration of the occultation event. Only occultations for beta angles less than $60^{\circ}$ (blue markers on Fig. 34) will be completed. The limit for the beta angle at $60^{\circ}$ is imposed by the project and limits the observing time of occultations to less than $450 \mathrm{~s}$. Note that the longer the measurements, the more numerous are the samplings along the vertical profile. For example, for a beta angle of $61.3^{\circ}$ the duration of observations from $200 \mathrm{~km}$ tangent altitudes to the surface is 8 minutes, while for beta less than $60^{\circ}$ this duration is typically $2-4$ minutes only. A beta angle of $63.46^{\circ}$ corresponds to a perfectly grazing occultation, in which the lowest sounded altitude coincides with the surface. The nearly grazing occultations, and the occultations with beta 


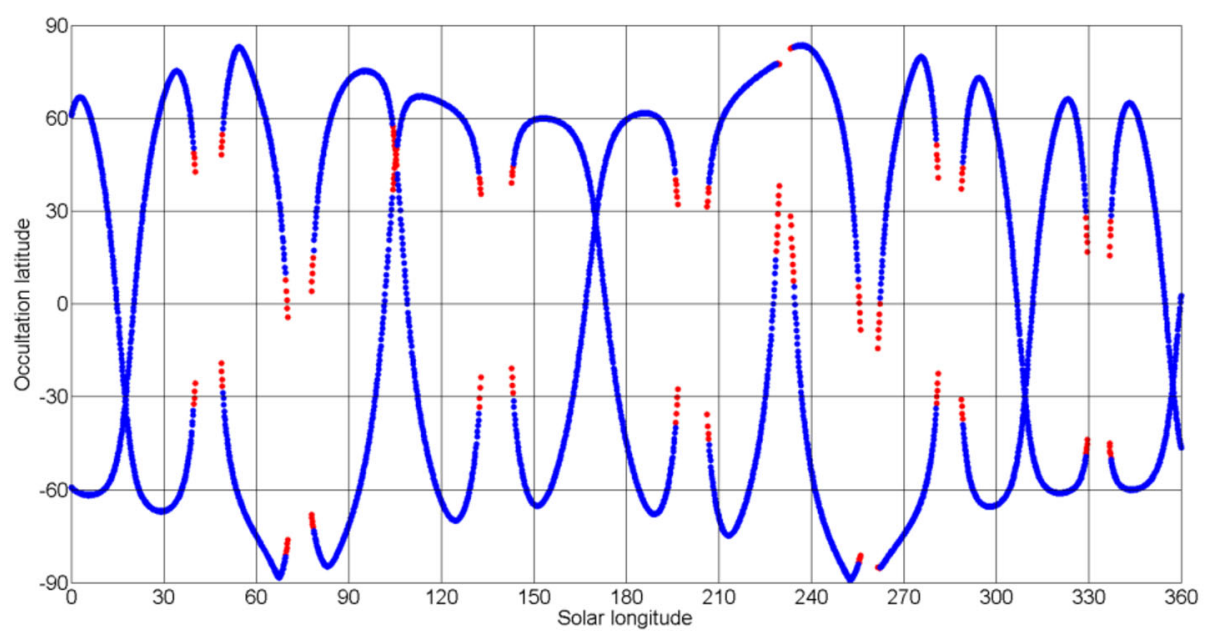

Fig. 34 Seasonal dependence of the TGO solar occultation latitude (for tangent altitude of $100 \mathrm{~km}$ ). Blue color corresponds to beta angles $\leq 60^{\circ}$, red signifies beta angles between $60^{\circ}$ and $63.46^{\circ}$

angle above $63.46^{\circ}$ are characterized with very dense altitude sampling, but the projection of the tangential point spans large distances. The retrieved profiles are therefore interesting, but might be in particular affected by horizontal variability of the terminator atmosphere. ACS plans to make use of the grazing occultations, if permitted by the project, otherwise the gaps in occultation coverage could be used for intense nadir campaigns.

At the sunset, the measurement sequence will start at tangent altitudes of about $250 \mathrm{~km}$ to record reference solar spectra outside the atmosphere, and will continue until the line of sight crosses the planet. At the sunrise recording will begin from looking at Mars and continue until looking at the Sun above the atmosphere.

During the occultation the instantaneous field of view (IFOV) of NIR channel is limited by the apparent size of the solar disk ( $\sim 20 \mathrm{arc} \mathrm{min})$ and by the slit width (1.2 $\operatorname{arc} \mathrm{min})$, the long side of the slit being $9^{\circ}$ inclined to the limb. For the MIR channel IFOV is fully determined by instrument slit and is $1 \times 14$ arc min with the long side perpendicular to the limb. For TIRVIM it is only limited by the solar disk angular size. TGO is performing occultations in inertial pointing mode and a rectangular IFOV actually drifts along the session, being, for MIR for instance, strictly perpendicular to the limb at $30 \mathrm{~km}$ above the surface. The vertical resolution of the measurements will be determined by the IFOV on the limb, the duration of the spectra record and vertical velocity $(\leq 2 \mathrm{~km} / \mathrm{s})$. The instantaneous spatial resolution at the limb at $60 \mathrm{~km}$ height for NIR channel is $0.6 \mathrm{~km}$ vertically and $9 \mathrm{~km}$ horizontally, for MIR it is $6 \mathrm{~km}$ vertically and $0.5 \mathrm{~km}$ horizontally, for TIRVIM it is $\sim 9 \mathrm{~km}$ circular. In order to improve the vertical resolution of MIR measurements spectral lines from the detector will be downloaded and processed independently, without binning. The slit is imaged at the detector forming a stripe 10 to 20 pixels high, depending on the spectral range, allowing accordingly better spatial sampling (see Figs. 19, 20).

When pointed to the Sun, all ACS channels can observe together, unfortunately the difference in alignment between centres of the ACS-MIR and NOMAD-SO boresights is 22 arcseconds, which is greater than the diameter of sun as viewed from Mars; therefore, the two cannot carry out solar occultations at the same time. 

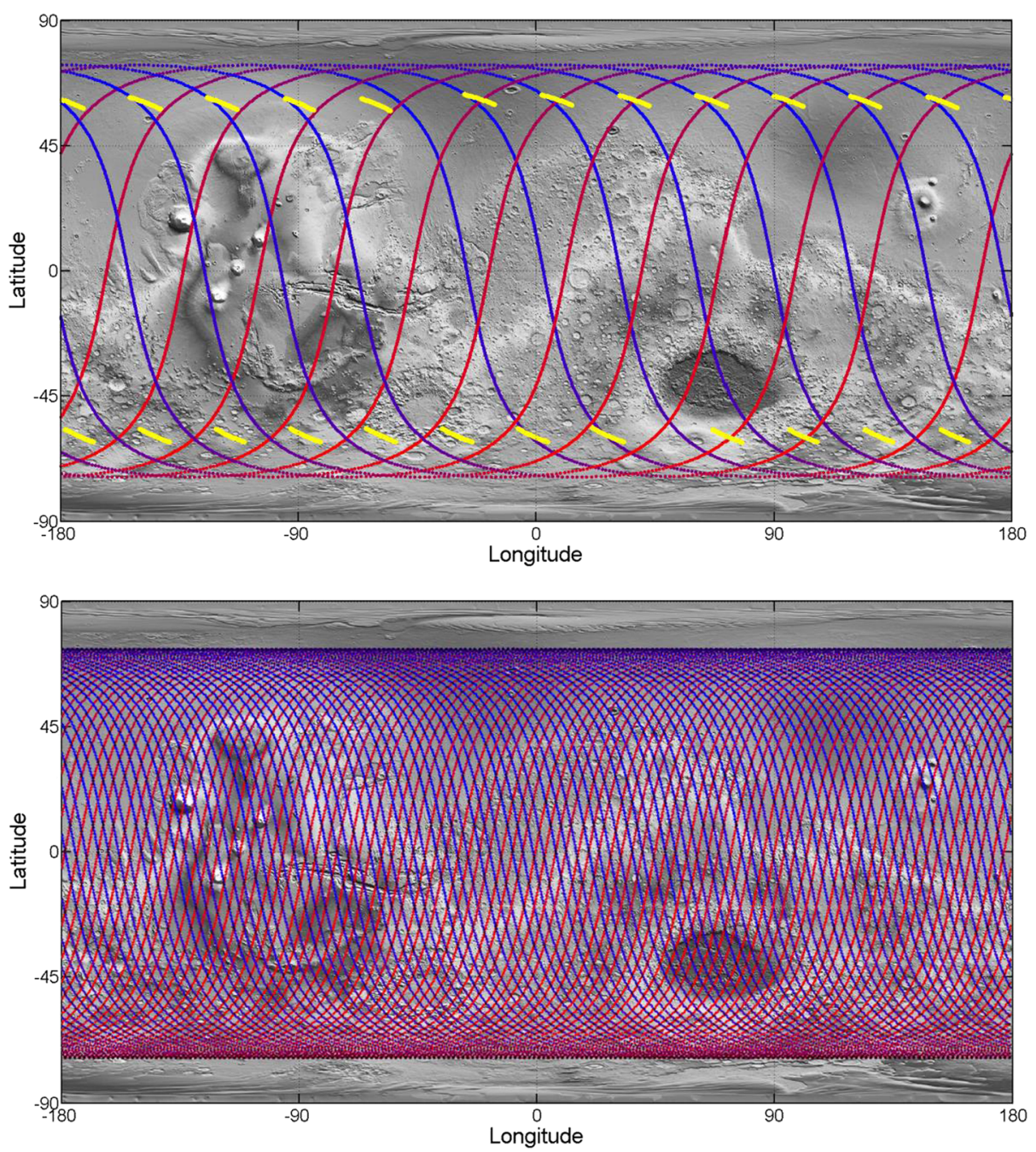

Fig. 35 (a) The TGO ground track after 1 sol. The red color indicates dayside passes and the blue color is for the night time. The drift of the tangent altitude during occultation events is shown in yellow, with occultations ranging from $200 \mathrm{~km}$ to $0 \mathrm{~km}$ altitude (or from 0 to $200 \mathrm{~km}$ for sunrise) and moving in latitude from day-to-day. (b) The ground track after 7 days

\subsection{Nadir}

Simultaneous nadir observations by ACS NIR and TIRVIM channels will give a unique opportunity to carry out rich and self-consistent measurements of Martian climatology. Nadir tracks cover latitudes $\pm 74^{\circ}$ and with 12 orbits per day provide sampling of the entire planet with the exception of the polar areas (Fig. 35). The ground tracks are colored to show dayside and night side observation. Occultation evens are also shown in yellow. After 7 sols the planet will be fully mapped.

The instantaneous field of view of the NIR's slit from $400 \mathrm{~km}$ orbit corresponds to a $14 \times 0.1 \mathrm{~km}$ ground track; for TIRVIM it is circular with a diameter of $14 \mathrm{~km}$. In order to 
keep the solar panels in maximum illumination during nadir observations TGO will rotate around its nadir pointed axis $(\overrightarrow{-Y}$, see Fig. 2$)$. This will rotate the NIR slit with respect to the ground track and the two cases are possible, a rectangular IFOV parallel or perpendicular to the ground track. The velocity of the spacecraft is $\sim 3.4 \mathrm{~km} / \mathrm{s}$ projected on the ground or of $\sim 1.3^{\circ}$ latitude per min near the equator. In order to meet the science requirements for spatial resolution the overall accumulation time for one measurement in nadir by any ACS channel will be limited to $40 \mathrm{~s}$.

\subsection{Planning}

Each of the three channels can generate a wealth of information, and the total number of measurements will be limited by the available downlink volume. Nevertheless, very flexible instrument settings allow matching main science goals and downlink possibilities. All instruments have onboard averaging: with NIR it is possible to sample from 1 to 10 wavelength ranges, during nadir, NIR and TIRVIM can operate intermittently (with a duty factor), MIR allows for reducing the data volume by windowing the detector. For example it is possible to downlink not the whole MIR frame of 640 by 512 pixels, which corresponds to $\sim 200 \mathrm{~nm}$ wavelength interval (see Figs. 19, 20), but only a stripe with a single diffraction order, e.g. 640 by 10 pixels (a factor of 50 less data), with a spectrum length of $\sim 20 \mathrm{~nm}$. This would allow studying a specific species within a narrow spectral band and to make use of larger number of occultations for its denser mapping even with a low data budget. It must be noted that the increase of accumulation results in a better signal to noise ratio and allows for data budget economy, but degrades the vertical resolution on the limb.

The nominal data allocation for ACS is $1.6 \mathrm{Gbit} /$ day, however the overall mission budget will variable (preliminary estimated as a factor of 0.2-5) with Earth-Mars distances along the year because of different downlink speed. Use of two Russian deep space antennas is agreed and will increase initial allocations. Final numbers, and the sharing between the TGO instruments are yet not figured. Also, the number of ACS occultations per day will be defined by sharing policy with NOMAD, since the co-alignment between instruments is not reached (see Sect. 6.1).

For the science phase, the ACS team will plan observation within the allocated resources and will attempt to meet its scientific goals along with those of the TGO mission. In general, planned measurements will be distributed along the planet and seasons as evenly as possible. For well-known atmospheric constituents, like water vapor, observations shall be evenly distributed to reveal geographical, seasonal, and diurnal patterns. The strategy for the "detection" observations will be developed depending on the first results. The most promising and interesting portions of the spectra and areas will be measured consistently to improve the statistics and to understand the behavior of trace gases. Dust loading and its distribution in the atmosphere will also be taken into account in the planning since aerosols strongly affect the detection capabilities (see Fig. 30). Some measurements may be concentrated around a specific location to study short time-scale phenomena and/or local time variations. Joint or close time/place observations with other TGO instruments (NOMAD and CaSSIS) will be planned as well as aligned observations with other missions, Mars Express, MRO, MAVEN. The data sharing within the ACS channels will be a subject of discussion and prioritizing at each mission stage.

Table 6 presents a possible measurement plan for one day (12 orbits, 24 occultations) with nominal data allocation. Here we consider only 12 occultations since NOMAD instrument requires separate pointing and thus might use the other 12 occurrences. TIRVIM observations in the science orbit will include not only occultations and nadir observations 
Table 6 An example of a possible measurement plan for one day (12 orbits, 24 occultations) with $1.6 \mathrm{Gbit} /$ day data allocation

\begin{tabular}{|c|c|c|}
\hline Mode & $\begin{array}{l}\text { Occultations ( } 6 \text { northern hemisphere, } \\
6 \text { southern hemisphere), } 180 \text { s duration }\end{array}$ & Nadirs \\
\hline MIR & $\begin{array}{l}1 \text { occultation with two secondary } \\
\text { grating positions (overall range } \\
\sim 400 \mathrm{~nm} \text { ), } 32 \text { frame accumulations for } \\
\text { each position, } 25 \% \text { windowing, } 0.9 \mathrm{~s} \\
\text { for each of two positions, } 450 \mathrm{Mbit} \text { of } \\
\text { data } \\
11 \text { occultations with maximum } \\
\text { sensitivity focused at a specific } \\
\text { molecule: one grating position, } \\
192 \text { accumulations, } 1 \text { window for } \\
\text { specific diffraction order, } 2.1 \mathrm{~s} \text { per } \\
\text { measurement, } \\
11 * 30 \mathrm{MBit}=330 \mathrm{MBit} \text { of data }\end{array}$ & - \\
\hline NIR & $\begin{array}{l}12 \text { occultations, detector lines co } \\
\text { adding, three diffraction orders, } \\
32 \text { accumulations, } 2 \text { s per measurement, } \\
12 * 11 \mathrm{MBit}=132 \mathrm{MBit} \text { of data }\end{array}$ & $\begin{array}{l}12 \text { dayside } 20 \text {-min observations, } \\
\text { detector lines co adding, nine } \\
\text { diffraction orders, } 96 \text { accumulations } \\
\text { for each diffraction order, } 5 \text { s total } \\
\text { integration time, ground resolution } \\
15 \mathrm{~km}, 12 * 5 \mathrm{MBit}=60 \mathrm{MBit}\end{array}$ \\
\hline TIRVIM & 1 occultation, $160 \mathrm{MBit}$ of data & $\begin{array}{l}\text { Continuous monitoring (day and } \\
\text { night) with a duty factor of } 1 / 14, \\
6.6 \text { second for each " } 8+8 \text { " } \\
\text { averaging, latitude spacing near the } \\
\text { equator } \approx 4.5^{\circ}, 570 \text { MBit of data per } \\
\text { day ( } 915 \text { sets of interferogram) }\end{array}$ \\
\hline $\begin{array}{l}\text { Data volume } \\
\text { per day }\end{array}$ & $1072 \mathrm{MBit}$ & $630 \mathrm{MBit}$ \\
\hline
\end{tabular}

of Mars, both day and night sides, but also absolute calibration (twice per day) by pointing its scanner to open space or towards the internal black body.

\section{Conclusions}

The Atmospheric Chemistry Suite of the ExoMars TGO mission is at the dawn of its quest to solve some of the most outstanding questions regarding the composition and the activity of the Martian atmosphere, quoting Hitchcock and Lovelock (1967): "Furthermore, any planetary biota which interacts with its atmosphere will drive that atmosphere to a state of disequilibrium which, if recognized, would also constitute direct evidence of life, provided the extent of the disequilibrium is significantly greater than abiological processes would permit. It is shown that the existence of life on Earth can be inferred from knowledge of the major and trace components of the atmosphere, even in the absence of any knowledge of the nature or extent of the dominant life forms. Knowledge of the composition of the Martian atmosphere may similarly reveal the presence of life there." ACS will carry forward this old legacy of the science community who has long desired that a detailed inventory of the Mar- 
tian atmospheric composition be established to point towards a potential residual activity on the planet.

With its design, ACS will be able to perpetuate the decadal climatology of major species $\left(\mathrm{CO}_{2}, \mathrm{H}_{2} \mathrm{O}\right.$, aerosols) observed at nadir by numerous instruments (some of them still operating), while providing outstanding detection capabilities outmatching by a factor of 100 to 1,000 the detection limits of previous attempts for a grand list of trace gases.

ACS also introduces a novel concept with its MIR channel that combines both a crosseddispersion scheme and a spectral scanning capability with the rotation of its secondary grating. ACS is thus both highly capable from a resolving power standpoint and also highly versatile for the wide spectral range that can be potentially sampled during the same acquisition. Because ACS MIR channel will potentially establish long-lasting detection performances around Mars for trace gases, it is from this channel that the major scientific "breakthroughs" are expected, following the philosophy of the main ACS science objectives at Mars.

The NIR channel duplicates a concept that proved highly efficient for the SOIR/VEX channel with the coupling of a fast diffraction order selector (the AOTF) and an echelle grating to catch the high diffraction orders and achieve a resolving power higher than 20,000 in its visible-to-near infrared range. It is to be noted that beyond its routine observing capabilities (aerosol, oxygen emission, etc.), NIR will provide, for the first time from the orbit around Mars, monitoring capabilities of the $\mathrm{O}_{2}$ fundamental A-band that is commonly used on Earth to obtain proxy measurements of the effective air mass when probing in a nadir geometry.

Finally, TIRVIM maintains the long legacy of Fourier transform spectrometers introduced by V. Moroz in IKI, and will carry the main task of supplying critical information on the environmental background (temperature, dust, surface temperature, etc.) of Mars to the TGO mission. TIRVIM is expected to outperform PFS and will thus provide temperature profiling with higher accuracy along with better estimated of dust/clouds opacity while supplying unique capability to ACS for the retrieval of gases otherwise not detected by the two other channels, i.e. $\mathrm{O}_{3}$ and $\mathrm{H}_{2} \mathrm{O}_{2}$, two gases of fundamental importance for photochemistry.

Acknowledgements ExoMars is a space mission by ESA and Roscosmos. The development and fabrication of ACS was funded by Roscosmos with contributions from LATMOS (France) funded by CNES. Science operations are funded by Roscosmos and ESA. AAF, NII, DAB, JLB, DSB, ML acknowledge the grant \#14.W03.31.0017 of Ministry for Education and Science of Russian Federation for science support of the ACS experiment. AT, AVS, and BEM acknowledge support from Russian Science Foundation (grant RSF 16-12-10453), which enabled assessment of measurement characteristics of the instrument and the associated modeling. LMZ acknowledges RSF funding (grant RSF 16-42-01103). Other authors affiliated with IKI acknowledge FANO, contracts 0120.0602993 (0028-2014-0004) and 0120.0303422 (0028-2014-0007). MRP acknowledges funding under the UK Space Agency grant ST/I003061/1 and ST/P001262/1. LV acknowledges the support of Ministerio de Economía y Competitividad of Spain under project ESP2016-79135-R. We are grateful to Richard Zurek and an anonymous reviewer for useful comments and suggestions, which helped improving this paper. We thank Sylvain Cnudde, Evgeny Germanyuk, and Ekaterina Korableva for help in rendering graphics. We also express our sincere gratitude to the space agencies, countries, companies, and project teams who made the ExoMars 2016 mission possible.

ACS Science Team: O. Korablev, F. Montmessin, A.V. Grigoriev, A. Fedorova, N.I. Ignatiev, A. Shakun, A. Trokhimovskiy, B.E. Moshkin, F. Forget, F. Lefevre, F. Altieri, G. Arnold, D.A. Belyaev, J.-L. Bertaux, N. Duxbury, T. Encrenaz, T. Fouchet, J.-C. Gerard, S. Guerlet, D. Grassi, P. Hartogh, Y. Kasaba, I.V. Khatunstsev, V.A. Krasnopolsky, R.O. Kuzmin, E. Lellouch, M.A. Lopez-Valverde, A. Määtänen, E. Marcq, J. Martin Torres, A. Medvedev, E. Millour, T. Navarro, M. Patel, K. Quantin-Nataf, A.V. Rodin, V.I. Shematovich, M. Vincendon, I. Thomas, N. Thomas, V. Wilquet, L. Vazquez, C. Wilson, L.V. Zasova, L.M. Zelenyi, M.P. Zorzano

Science Collaborators: I. Arruego, L. Baggio, D. Betsis, C. Cordoba Jabonero, D. Evdokimova, D. Gorinov, R. Haus, V. Hipkin, P. Irwin, D. Kappel, G. Lacombe, R. Larsson, A. Ledkov, L.M. Llorente, M. Luginin, D. McCleese, I. Maslov, C. Olsen, A. Pankine, N. Pertsev, S. Rafkin, N. Teanby, F. Valero, J.L. VázquezPoletti, P. Wennberg. 
ACS Technical Team: A. Shakun, A. Trokhimovskiy, A.V. Grigoriev, K. Anufreichik, O. Andreev, I. Averyanova, O. Batanov, I. Dzuban, E. Efremenkova, D. Glazkin, D. Gorinov, J.-P. Goutail, K. Grechnev, A. Irbah, Y. S. Ivanov, Y.K. Kalinnikov, A. Konovalov, F. Korotkov, O.E. Kozlov, T.O. Kozlova, A. Kungurov, N. Kupriyanov, L. Lapauw, V. Makarov, F. Martynovich, I. Maslov, M. Meftah, D. Merzlyakov, P. P. Moiseev, B. E. Moshkin, Y. Nikolskiy, A. Patrakeev, D. Patsaev, G. Poiet, N. Rotova, N. Semena, D. Timonin, A. Santos-Skripko, A. Sapgir, O. Sazonov, A. Semenov, D. Serbinov, V. Shashkin, A. Sidorov, I. Siniyavsky, A. Smirnova, A.V. Stepanov, I. Stupin, A. Terentiev, A.Y. Titov, A. Viktorov, A. Zharkov.

Open Access This article is distributed under the terms of the Creative Commons Attribution 4.0 International License (http://creativecommons.org/licenses/by/4.0/), which permits unrestricted use, distribution, and reproduction in any medium, provided you give appropriate credit to the original author(s) and the source, provide a link to the Creative Commons license, and indicate if changes were made.

\section{References}

S.K. Atreya, A.-S. Wong, N.O. Renno, W.M. Farrell, G.T. Delory, D.D. Sentman, S.A. Cummer, J.R. Marshall, S.C.R. Rafkin, D.C. Catling, Oxidant enhancement in Martian dust devils and storms: implications for life and habitability. Astrobiology 6, 439-450 (2006)

R.J. Bell, Introductory Fourier Transform Spectroscopy (Academic Press, New York/London, 1972)

J.L. Bertaux, B. Gondet, F. Lefèvre, J.P. Bibring, F. Montmessin, First detection of $\mathrm{O}_{2} 1.27 \mu \mathrm{m}$ nightglow emission at Mars with MEX and comparison with general circulation model predictions. J. Geophys. Res., Planets 117, E00J04 (2012)

I.C. Chang, Noncollinear acoustooptic filter with large angular aperture. Appl. Phys. Lett. 25(7), 370-372 (1974)

R.T. Clancy, B.J. Sandor, A. García-Muñoz, F. Lefèvre, M.D. Smith, M.J. Wolff, F. Montmessin, S.L. Murchie, H. Nair, First detection of Mars atmospheric hydroxyl: CRISM Near-IR measurement versus LMD GCM simulation of OH Meinel band emission in the Mars polar winter atmosphere. Icarus 226, 272-281 (2013)

J.T. Clarke, M. Mayyasi, D. Bhattacharyya, N.M. Schneider, W.E. McClintock, J.I. Deighan, A.I.F. Stewart, J.Y. Chaufray, M.S. Chaffin, S.K. Jain, A. Stiepen, M. Crismani, G.M. Holsclaw, F. Montmessin, B.M. Jakosky, Variability of D and H in the Martian upper atmosphere observed with the MAVEN IUVS echelle channel. J. Geophys. Res. Space Phys. 122, 2336-2344 (2017). doi:10.1002/2016JA023479

A. Coradini, F. Capaccioni, P. Drossart, G. Arnold, E. Ammannito, F. Angrilli, A. Barucci, G. Bellucci, J. Benkhoff, G. Bianchini, J.P. Bibring, M. Blecka, D. Bockelee-Morvan, M.T. Capria, R. Carlson, U. Carsenty, P. Cerroni, L. Colangeli, M. Combes, M. Combi, J. Crovisier, M.C. Desanctis, E.T. Encrenaz, S. Erard, C. Federico, G. Filacchione, U. Fink, S. Fonti, V. Formisano, W.H. Ip, R. Jaumann, E. Kuehrt, Y. Langevin, G. Magni, T. McCord, V. Mennella, S. Mottola, G. Neukum, P. Palumbo, G. Piccioni, H. Rauer, B. Saggin, B. Schmitt, D. Tiphene, G. Tozzi, VIRTIS: an imaging spectrometer for the Rosetta mission. Space Sci. Rev. 128(1-4), 529-559 (2007)

P.R. Christensen, J.L. Bandfield, V.E. Hamilton, S.W. Ruff, H.H. Kieffer, T.N. Titus, M.C. Malin, R.V. Morris, M.D. Lane, R.L. Clark, B.M. Jakosky, M.T. Mellon, J.C. Pearl, B.J. Conrath, M.D. Smith, R.T. Clancy, R.O. Kuzmin, T. Roush, G.L. Mehall, N. Gorelick, K. Bender, K. Murray, S. Dason, E. Greene, S. Silverman, M. Greenfield, Mars global surveyor thermal emission spectrometer experiment: investigation description and surface science results. J. Geophys. Res. 106, 23823-23872 (2001)

G.T. Delory, W.M. Farrell, S.K. Atreya, N.O. Renno, A.-S. Wong, S.A. Cummer, D.D. Sentman, J.R. Marshall, S.C.R. Rafkin, D.C. Catling, Oxidant enhancement in Martian dust devils and storms: storm electric fields and electron dissociative attachment. Astrobiology 6, 451-462 (2006)

T. Encrenaz, T.K. Greathouse, F. Lefèvre, S.K. Atreya, Hydrogen peroxide on Mars: observations, interpretation and future plans. Planet. Space Sci. 68(1), 3-17 (2012)

W.M. Farrell, G.T. Delory, S.K. Atreya, Martian dust storms as a possible sink of atmospheric methane. Geophys. Res. Lett. 33, L21203 (2006)

A.A. Fedorova, I.V. Baklanova, A.V. Rodin, Mars atmospheric water vapor in the southern hemisphere: MAWD observations revisited. Adv. Space Res. 34, 1677-1682 (2004)

A.A. Fedorova, O.I. Korablev, J.L. Bertaux, A.V. Rodin, F. Montmessin, D.A. Belyaev, A. Reberac, Solar infrared occultation observations by SPICAM experiment on Mars-Express: simultaneous measurements of the vertical distributions of $\mathrm{H}_{2} \mathrm{O}, \mathrm{CO}_{2}$ and aerosol. Icarus 200(1), 96-117 (2009)

A.A. Fedorova, F. Lefèvre, S. Guslyakova, O. Korablev, J.L. Bertaux, F. Montmessin, A. Reberac, B. Gondet, The $\mathrm{O}_{2}$ nightglow in the martian atmosphere by SPICAM onboard of Mars-Express. Icarus 219(2), 596-608 (2012) 
A.A. Fedorova, F. Montmessin, A.V. Rodin, O.I. Korablev, A. Määttänen, L. Maltagliati, J.-L. Bertaux, Evidence for a bimodal size distribution for the suspended aerosol particles on Mars. Icarus 231, 239-260 (2014)

C. Fiorenza, V. Formisano, A solar spectrum for PFS data analysis. Planet. Space Sci. 53, 1009-1016 (2005)

F. Forget, F. Hourdin, R. Fournier, C. Hourdin, O. Talagrand, M. Collins, S. Lewis, P. Read, J. Huot, Improved general circulation models of the Martian atmosphere from the surface to above $80 \mathrm{~km}$. J. Geophys. Res., Planets 104(E10), 24155-24175 (1999)

V. Formisano, V.I. Moroz, F. Angrilli, G. Bianchini, E. Bussoletti, N. Cafaro, F. Capaccioni, M.T. Capria, P. Cerroni, G. Chionchio, L. Colangeli, A. Coradini, A. di Lellis, S. Fonti, R. Orfei, E. Palomba, G. Piccioni, B. Saggin, A. Ekonomov, A. Grigoriev, V. Gnedykh, I. Khatuntsev, A. Kiselev, I. Matsygorin, B. Moshkin, V. Nechaev, Y. Nikolsky, D. Patsaev, A. Russakov, D. Titov, L. Zasova, M.I. Blecka, A. Jurewicz, M. Michalska, W. Novosielski, P. Orleanski, G. Arnold, H. Hirsch, H. Driesher, J. LopezMoreno, R. Rodrigo, J. Rodriguez-Gomez, G. Michel, PFS: a Fourier spectrometer for the study of martian atmosphere. Adv. Space Res. 19, 1277-1280 (1997)

V. Formisano, S. Atreya, T. Encrenaz, N. Ignatiev, M. Giuranna, Detection of methane in the atmosphere of Mars. Science 306, 1758-1761 (2004)

V. Formisano, F. Angrilli, G. Arnold, S. Atreya, G. Bianchini, D. Biondi, A. Blanco, M.I. Blecka, A. Coradini, L. Colangeli, A. Ekonomov, F. Esposito, S. Fonti, M. Giuranna, D. Grassi, V. Gnedykh, A. Grigoriev, G. Hansen, H. Hirsh, I. Khatuntsev, A. Kiselev, N. Ignatiev, A. Jurewicz, E. Lellouch, J.L. Moreno, A. Marten, A. Mattana, A. Maturilli, E. Mencarelli, M. Michalska, V. Moroz, B. Moshkin, F. Nespoli, Y. Nikolsky, R. Orfei, P. Orleanski, V. Orofino, E. Palomba, D. Patsaev, G. Piccioni, M. Rataj, R. Rodrigo, J. Rodriguez, M. Rossi, B. Saggin, D. Titov, L. Zasova, The Planetary Fourier Spectrometer (PFS) onboard the European Mars Express mission. Planet. Space Sci. 53(10), 963-974 (2005)

T. Fouchet, E. Lellouch, Vapor pressure isotope fractionation effects in planetary atmospheres: application to deuterium. Icarus 144, 114-123 (2000)

A. García Muñoz, F.P. Mills, T.G. Slanger, G. Piccioni, P. Drossart, Visible and near-infrared nightglow of molecular oxygen in the atmosphere of Venus. J. Geophys. Res., Planets 114(E12), E12002 (2009)

M. Giuranna, V. Formisano, D. Biondi, A. Ekonomov, S. Fonti, D. Grassi, H. Hirsch, I. Khatuntsev, N. Ignatiev b, M. Malgoska, A. Mattana, A. Maturilli, E. Mencarelli, F. Nespoli, R. Orfei, P. Orleanski, G. Piccioni, M. Rataj, B. Saggin, L. Zasova, Calibration of the Planetary Fourier Spectrometer longwavelength channel. Planet. Space Sci. 53, 993-1007 (2005)

M. Giuranna, D. Grassi, A. Aronica, D. Scaccabarozzi, B. Saggin, S. Aoki, P. Wolkenberg, V. Formisano, 12 years of atmospheric monitoring by the Planetary Fourier Spectrometer onboard Mars Express, in EGU General Assembly Conference Abstracts (2016), p. 8609

D. Grassi, N.I. Ignatiev, L.V. Zasova, A. Maturilli, V. Formisano, G.A. Bianchini, M. Giuranna, Methods for the analysis of data from the Planetary Fourier Spectrometer on the Mars Express Mission. Planet. Space Sci. 53, 1017-1034 (2005)

R.A. Hanel, B. Schlachman, F.D. Clark, C.H. Prokesh, J.B. Taylor, W.M. Wilson, L. Chaney, The Nimbus III Michelson interferometer. Appl. Opt. 9, 1767 (1970)

P. Hartogh, A.S. Medvedev, T. Kuroda, R. Saito, G. Villanueva, A.G. Feofilov, A.A. Kutepov, U. Berger, Description and climatology of a new general circulation model of the Martian atmosphere. J. Geophys. Res. 110, E11008 (2005). doi:10.1029/2005JE002498

P. Hartogh, C. Jarchow, E. Lellouch, M. de Val-Borro, M. Rengel, R. Moreno, A.S. Medvedev, H. Sagawa, B.M. Swinyard, T. Cavalié, D.C. Lis, M.I. Błęcka, M. Banaszkiewicz, D. Bockelée-Morvan, J. Crovisier, T. Encrenaz, M. Küppers, L.-M. Lara, S. Szutowicz, B. Vandenbussche, F. Bensch, E.A. Bergin, F. Billebaud, N. Biver, G.A. Blake, J.A.D.L. Blommaert, J. Cernicharo, L. Decin, P. Encrenaz, H. Feuchtgruber, T. Fulton, T. de Graauw, E. Jehin, M. Kidger, R. Lorente, D.A. Naylor, G. Portyankina, M. SánchezPortal, R. Schieder, S. Sidher, N. Thomas, E. Verdugo, C. Waelkens, N. Whyborn, D. Teyssier, F. Helmich, P. Roelfsema, J. Stutzki, H.G. Leduc, J.A. Stern, Herschel/HIFI observations of Mars: first detection of $\mathrm{O}_{2}$ at submillimetre wavelengths and upper limits on $\mathrm{HCl}$ and $\mathrm{H}_{2} \mathrm{O}_{2}$. Astron. Astrophys. 521, L49 (2010)

N.G. Heavens, M.I. Richardson, A. Kleinböhl, D.M. Kass, D.J. McCleese, W. Abdou, J.L. Benson, J.T. Schofield, J.H. Shirley, P.M. Wolkenberg, The vertical distribution of dust in the Martian atmosphere during northern spring and summer: observations by the Mars Climate Sounder and analysis of zonal average vertical dust profiles. J. Geophys. Res., Planets 116, E04003 (2011)

D.R. Hitchcock, J.E. Lovelock, Life detection by atmospheric analysis. Icarus 7(2), September (1967). doi:10.1016/0019-1035(67)90059-0

A.S. Khayat, G.L. Villanueva, M.J. Mumma, A.T. Tokunaga, A search for $\mathrm{SO}_{2}, \mathrm{H}_{2} \mathrm{~S}$ and SO above Tharsis and Syrtis volcanic districts on Mars using ground-based high-resolution submillimeter spectroscopy. Icarus 253, 130-141 (2015) 
O.I. Korablev, J.-L. Bertaux, I.I. Vinogradov, Compact high-resolution IR spectrometer for atmospheric studies. Proc. SPIE 4818, 272-281 (2002)

O. Korablev, V.I. Moroz, E.V. Petrova, A.V. Rodin, Optical properties of dust and the opacity of the Martian atmosphere. Adv. Space Res. 35(1), 21-30 (2005). doi:10.1016/j.asr.2003.04.061

O. Korablev, J. Bertaux, A. Fedorova, D. Fonteyn, A. Stepanov, Y. Kalinnikov, A. Kiselev, A. Grigoriev, V. Jegoulev, S. Perrier, E. Dimarellis, J. Dubois, A. Reberac, E. Van Ransbeeck, B. Gondet, F. Montmessin, A. Rodin, SPICAM IR acousto-optic spectrometer experiment on Mars Express. J. Geophys. Res., Planets 111(E9), E09S03 (2006)

O. Korablev, A. Grigoriev, B. Moshkin, D. Patsaev, V. Makarov, S. Maksimenko, K. Grechnev, V. Kotlov, L. Zasova, A. Shakun, A. Fedorova, A. Terentiev, A. Ekonomov, I. Khatuntsev, B. Mayorov, Y. Nikolsky, I. Maslov, A. Gvozdev, F. Montmessin, R. Kuzmin, The AOST miniature Fourier spectrometer for space studies. J. Opt. Technol. 76(5), 316-322 (2009)

O. Korablev, A. Trokhimovskii, I. Vinogradov, A. Fedorova, A. Ivanov, A. Venkstern, V. Barke, O. Roste, Y. Kalinnikov, A. Titov, A. Kalyuzhnyi, A. Rodin, E. Kostrova, Y. Smirnov, M. Poluarshinov, The RUSALKA device for measuring the carbon dioxide and methane concentration in the atmosphere from on board the International Space Station. J. Opt. Technol. 78(5), 317-327 (2011)

O.I. Korablev, A.V. Grigor'ev, B.E. Moshkin, L.V. Zasova, F. Montmessin, A.B. Gvozdev, V.N. Shashkin, D.V. Patsaev, V.S. Makarov, S.V. Maksimenko, N.I. Ignatiev, A.A. Fedorova, G. Arnold, A.V. Shakun, A.I. Terentiev, A.V. Zharkov, B.S. Mayorov, Y.V. Nikol'sky, I.V. Khatuntsev, G. Bellucci, M. Giuranna, R.O. Kuz'min, A.V. Rodin, AOST: Fourier spectrometer for studying Mars and Phobos. Sol. Syst. Res. 46, 31-40 (2012)

O. Korablev, F. Montmessin, A. Trokhimovsky, A.A. Fedorova, A.V. Kiselev, J.-L. Bertaux, J.-P. Goultail, D.A. Belyaev, A.V. Stepanov, A.Y. Titov, Y.K. Kalinnikov, Compact echelle spectrometer for occultation sounding of the Martian atmosphere: design and performance. Appl. Opt. 52, 1054-1065 (2013)

O. Korablev, A. Trokhimovsky, A.V. Grigoriev, A. Shakun, Y.S. Ivanov, B. Moshkin, K. Anufreychik, D. Timonin, I. Dziuban, Y.K. Kalinnikov, F. Montmessin, Three infrared spectrometers, an atmospheric chemistry suite for the ExoMars 2016 trace gas orbiter. J. Appl. Remote Sens. 8, 4983 (2014)

V.A. Krasnopolsky, J.P. Maillard, T.C. Owen, Detection of methane in the martian atmosphere: evidence for life? Icarus 172, 537-547 (2004)

V. Krasnopolsky, Search for methane and upper limits to ethane and $\mathrm{SO}_{2}$ on Mars. Icarus 217(1), 144-152 (2012)

V. Krasnopolsky, G. Bjoraker, M. Mumma, D. Jennings, High-resolution spectroscopy of Mars at 3.7 and $8 \mu \mathrm{m}$ : a sensitive search for $\mathrm{H}_{2} \mathrm{O}_{2}, \mathrm{H}_{2} \mathrm{CO}, \mathrm{HCl}$, and $\mathrm{CH}_{4}$, and detection of HDO. J. Geophys. Res., Planets 102(E3), 6525-6534 (1997)

N.N. Lavrentieva, B.A. Voronin, O.V. Naumenko, A.D. Bykov, A.A. Fedorova, Linelist of HD 160 for study of atmosphere of terrestrial planets (Earth, Venus and Mars). Icarus 236, 38-47 (2014)

N.N. Lavrentieva, B.A. Voronin, A.A. Fedorova, $\mathrm{H}_{2}{ }^{1} 6 \mathrm{O}$ line list for the study of atmospheres of Venus and Mars. Opt. Spectrosc. 118, 11-18 (2015)

F. Lefèvre, S. Lebonnois, F. Montmessin, F. Forget, Three-dimensional modeling of ozone on Mars. J. Geophys. Res., Planets 109, E07004 (2004)

F. Lefèvre, J.-L. Bertaux, R.T. Clancy, T. Encrenaz, K. Fast, F. Forget, S. Lebonnois, F. Montmessin, S. Perrier, Heterogeneous chemistry in the atmosphere of Mars. Nature 454, 971-975 (2008)

F. Lefèvre, F. Forget, Observed variations of methane on Mars unexplained by known atmospheric chemistry and physics. Nature 460, 720-723 (2009)

W.C. Maguire, Martian isotopic ratios and upper limits for possible minor constituents as derived from Mariner 9 infrared spectrometer data. Icarus 32, 85-97 (1977)

P.R. Mahaffy, C.R. Webster, S.K. Atreya, H. Franz, M. Wong, P.G. Conrad, D. Harpold, J.J. Jones et al., Abundance and isotopic composition of gases in the Martian atmosphere from the Curiosity rover. Science 341, 263-266 (2013)

A. Mahieux, S. Berkenbosch, R. Clairquin, D. Fussen, N. Mateshvili, E. Neefs, D. Nevejans, B. Ristic, A. Carine Vandaele, V. Wilquet, D. Belyaev, A. Fedorova, O. Korablev, E. Villard, F. Montmessin, J.-L. Bertaux, In-flight performance and calibration of SPICAV SOIR onboard Venus Express. Appl. Opt. 47, 2252-2265 (2008)

E. Millour, F. Forget, A. Spiga, T. Navarro, J.-B. Madeleine, L. Montabone, A. Pottier, F. Lefevre, F. Montmessin, J.-Y. Chaufray, M.A. Lopez-Valverde, F. Gonzalez-Galindo, S.R. Lewis, P.L. Read, J.-P. Huot, M.-C. Desjean, M.C.D. Team, The Mars Climate Database (MCD version 5.2), in European Planetary Science Congress 2015, EPSC 2015-438, Nantes, France, 27 September-2 October, 2015, vol. $10(2015)$

M.I. Mishchenko, Z.M. Dlugach, E.G. Yanovitskij, N.T. Zakharova, Bidirectional reflectance of flat, optically thick particulate layers: an efficient radiative transfer solution and applications to snow and soil surfaces. J. Quant. Spectrosc. Radiat. Transf. 63, 409-432 (1999) 
F. Montmessin, T. Fouchet, F. Forget, Modeling the annual cycle of HDO in the Martian atmosphere. J. Geophys. Res., Planets 110(E3), E03006 (2005)

F. Montmessin, E. Quemerais, J. Bertaux, O. Korablev, P. Rannou, S. Lebonnois, Stellar occultations at UV wavelengths by the SPICAM instrument: retrieval and analysis of Martian haze profiles. J. Geophys. Res., Planets 111(E9), JE002662 (2006)

F. Montmessin, O. Korablev, F. Lefèvre, J.-L. Bertaux, A. Fedorova, A. Trokhimovskiy, J.Y. Chaufray, G. Lacombe, A. Reberac, L. Maltagliati, Y. Willame, S. Guslyakova, J.-C. Gérard, A. Stiepen, D. Fussen, N. Mateshvili, A. Määttänen, F. Forget, O. Witasse, F. Leblanc, A.C. Vandaele, E. Marcq, B. Sandel, B. Gondet, N. Schneider, M. Chaffin, N. Chapron, SPICAM on Mars Express: a 10 year in-depth survey of the Martian atmosphere. Icarus 297, 195-216 (2017)

V.I. Moroz, V. Formisano, P. Orleansky et al., Fourier-spectrometry from Mars-94 spacecraft, in Proceedings of the IV International Seminar "Manufacturing of Scientific Space Instrumentation”, USSR, Frunze, Sept. 18-24, 1989 (1990), pp. 43-52. Preprint IKI (2)

M.J. Mumma, R.E. Novak, M.A. DiSanti, B.P. Bonev, N. Dello Russo, Detection and mapping of methane and water on Mars, in Bulletin of the American Astronomical Society (2004), p. 1127

M.J. Mumma, G.L. Villanueva, R.E. Novak, T. Hewagama, B.P. Bonev, M.A. DiSanti, A.M. Mandell, M.D. Smith, Strong release of methane on Mars in Northern Summer 2003. Science 323(5917), 10411045 (2009)

D. Nevejans, E. Neefs, E. Van Ransbeeck, S. Berkenbosch, R. Clairquin, L. De Vos, W. Moelans, S. Glorieux, A. Baeke, O. Korablev, I. Vinogradov, Y. Kalinnikov, B. Bach, J. Dubois, E. Villard, Compact high-resolution spaceborne echelle grating spectrometer with acousto-optical tunable filter based order sorting for the infrared domain from 2.2 to $4.3 \mu \mathrm{m}$. Appl. Opt. 45(21), 5191-5206 (2006)

M. Ockert-Bell, J. Bell, J. Pollack, C. McKay, F. Forget, Absorption and scattering properties of the Martian dust in the solar wavelengths. J. Geophys. Res., Planets 102(E4), 9039-9050 (1997)

D. Oertel, V.I. Moroz, I. Nopirakovskii, V.M. Linkin, H. Jahn, R.S. Kremnev, H. Becker-Ross, W. Stadthaus, V.V. Kerzhanovich, I.A. Matsygorin, A.V. D’Yachkov, L.I. Khlyustova, W. Berwald, M. Ulich, H. Dreischer, W. Skrbek, H. Studemund, R. Schuster, G. Kaiser, S.P. Ignatova, I.A. Zelenov, I.D. Tserenin, D. Spankuch, W. Dohler, K. Schafer, L.V. Zasova, E.A. Ustinov, G. Fellberg, A.N. Lipatov, A.A. Shurupov, N.G. Khavenson, VENERA-15 and VENERA-16 infrared experiment. Technique and first results. Cosm. Res. 23, 62-175 (1985)

S. Perrier, J. Bertaux, F. Lefevre, S. Lebonnois, O. Korablev, A. Fedorova, F. Montmessin, Global distribution of total ozone on Mars from SPICAM/MEX UV measurements. J. Geophys. Res., Planets 111(E9), JE002681 (2006)

H.E. Revercomb, H. Buijs, H.B. Howell, D.D. LaPorte, W.L. Smith, L.A. Sromovsky, Radiometric calibration of IR Fourier transform spectrometers: solution to a problem with the high-resolution interferometer sounder. Appl. Opt. 27, 3210 (1988)

D. Rodionov, O. Korablev, L.M. Zelenyi, J. Vago, Mars atmospheric measurements planned at ExoMars 2020 surface platform, in Mars Atmosphere: Modelling and Observation, ed. by F. Forget (2017). http://www-mars.lmd.jussieu.fr/granada2017/program_granada2017.htm

L.S. Rothman, I.E. Gordon, Y. Babikov, A. Barbe, D. Chris Benner, P.F. Bernath, M. Birk, L. Bizzocchi, V. Boudon, L.R. Brown, A. Campargue, K. Chance, E.A. Cohen, L.H. Coudert, V.M. Devi, B.J. Drouin, A. Fayt, J.-M. Flaud, R.R. Gamache, J.J. Harrison, J.-M. Hartmann, C. Hill, J.T. Hodges, D. Jacquemart, A. Jolly, J. Lamouroux, R.J. Le Roy, G. Li, D.A. Long, O.M. Lyulin, C.J. Mackie, S.T. Massie, S. Mikhailenko, H.S.P. Müller, O.V. Naumenko, A.V. Nikitin, J. Orphal, V. Perevalov, A. Perrin, E.R. Polovtseva, C. Richard, M.A.H. Smith, E. Starikova, K. Sung, S. Tashkun, J. Tennyson, G.C. Toon, V.G. Tyuterev, G. Wagner, The HITRAN2012 molecular spectroscopic database. J. Quant. Spectrosc. Radiat. Transf. 130, 4-50 (2013)

B. Saggin, D. Scaccabarozzi, M. Tarabini, Instrumental phase-based method for Fourier transform spectrometer measurements processing. Appl. Opt. 50, 1717-1725 (2011)

J.T. Schofield, D.M. Kass, A. Kleinböhl, D.J. McCleese, M.A. Allen, M.C. Foote, M. Jeganathan, F. Forget, A. Spiga, O. Talagrand, F. Lefèvre, A. Määttänen, T. Fouchet, N. Bowles, S.B. Calcutt, P.G.J. Irwin, P.L. Read, S.R. Lewis, J.R. Barnes, S.W. Bougher, R.M. Haberle, E. Millour, The ExoMars Climate Sounder (EMCS) investigation, in Mars Atmosphere: Modelling and Observation, ed. by F. Forget (2011), pp. 488-492

H. Seo, S.J. Kim, S. Hwang, A. Jung, J.H. Kim, J.H. Kim, K.-S. Kim, J. Lee, M. Jang, Synthetic highresolution near-IR spectra of the Sun for planetary data reductions made from ATMOS/Spacelab-3 and Atlas-3 data. Icarus 192, 287-295 (2007)

M.D. Smith, J.C. Pearl, B.J. Conrath, P.R. Christensen, One Martian year of atmospheric observations by the thermal emission spectrometer. Geophys. Res. Lett. 28, 4263-4266 (2001)

M.D. Smith, Interannual variability in TES atmospheric observations of Mars during 1999-2003. Icarus 167, 148-165 (2004) 
K. Sung, P. Varanasi, $\mathrm{CO}_{2}$-broadened half-widths and $\mathrm{CO}_{2}$-induced line shifts of ${ }^{12} \mathrm{C}^{16}$ relevant to the atmospheric spectra of Venus and Mars. J. Quant. Spectrosc. Radiat. Transf. 91(3), 319-332 (2005)

A. Trokhimovskiy, A. Fedorova, O. Korablev, F. Montmessin, J.-L. Bertaux, A. Rodin, M.D. Smith, Mars' water vapor mapping by the SPICAM IR spectrometer: five Martian years of observations. Icarus 251, 50-64 (2015)

A.C. Vandaele, A. Mahieux, S. Robert, S. Berkenbosch, R. Clairquin, R. Drummond, V. Letocart, E. Neefs, B. Ristic, V. Wilquet, F. Colomer, D. Belyaev, J.-L. Bertaux, Improved calibration of SOIR/Venus Express spectra. Opt. Express 21, 21148 (2013)

A.C. Vandaele, J.-J. Lopez-Moreno, M.R. Patel, G. Bellucci, M. Allen et al., NOMAD, an integrated suite of three spectrometers for the ExoMars Trace Gas mission: technical description, science objectives and expected performances. Space Sci. Rev., this issue

G.L. Villanueva, M.J. Mumma, R.E. Novak, Y.L. Radeva, H.U. Käufl, A. Smette, A. Tokunaga, A. Khayat, T. Encrenaz, P. Hartogh, A sensitive search for organics $\left(\mathrm{CH}_{4}, \mathrm{CH}_{3} \mathrm{OH}, \mathrm{H}_{2} \mathrm{CO}, \mathrm{C}_{2} \mathrm{H}_{6}, \mathrm{C}_{2} \mathrm{H}_{2}, \mathrm{C}_{2} \mathrm{H}_{4}\right)$, hydroperoxyl $\left(\mathrm{HO}_{2}\right)$, nitrogen compounds $\left(\mathrm{N}_{2} \mathrm{O}, \mathrm{NH}_{3}, \mathrm{HCN}\right)$ and chlorine species $(\mathrm{HCl}, \mathrm{CH} \mathrm{Cl})$ on Mars using ground-based high-resolution infrared spectroscopy. Icarus 223, 11-27 (2013)

G.L. Villanueva, M.J. Mumma, R.E. Novak, H.U. Käufl, P. Hartogh, T. Encrenaz, A. Tokunaga, A. Khayat, M.D. Smith, Strong water isotopic anomalies in the martian atmosphere: probing current and ancient reservoirs. Science 348, 218-221 (2015). doi:10.1126/science.aaa3630

C.R. Webster, P.R. Mahaffy, S.K. Atreya, G.J. Flesch, M.A. Mischna, P.-Y. Meslin, K.A. Farley, P.G. Conrad, L.E. Christensen, A.A. Pavlov, J. Martín-Torres, M.-P. Zorzano, T.H. McConnochie, T. Owen, J.L. Eigenbrode, D.P. Glavin, A. Steele, C.A. Malespin, P.D. Archer Jr., B. Sutter, P. Coll, C. Freissinet, C.P. McKay, J.E. Moores, S.P. Schwenzer, J.C. Bridges, R. Navarro-Gonzalez, R. Gellert, M.T. Lemmon, T.M.S. Team, Mars methane detection and variability at Gale crater. Science 347, 415-417 (2015)

P.O. Wennberg, V.J. Hipkin, J.R. Drummond, U. Dalhousie, G.C. Toon, M. Allen, J.-F. Blavier, L.R. Brown, A. Kleinbohl, J.P.D. Abbatt, B. Sherwood Lollar, K. Strong, K.A. Walker, P.F. Bernath, R.T. Clancy, E.A. Cloutis, D.J. Desmarais, J.M. Eiler, Y.L. Yung, T. Encrenaz, J.C. McConnell, E. Millour, MATMOS: the Mars atmospheric Trace Molecule Occultation Spectrometer, in Mars Atmosphere: Modelling and Observation, ed. by F. Forget (2011), pp. 480-481

M.J. Wolff, M.D. Smith, R.T. Clancy, R. Arvidson, M. Kahre, F. Seelos, S. Murchie, H. Savijärvi, Wavelength dependence of dust aerosol single scattering albedo as observed by the Compact Reconnaissance Imaging Spectrometer. J. Geophys. Res., Planets 114(E9), E00D04 (2009)

I. Yoshikawa, O. Korablev, S. Kameda, D. Rees, H. Nozawa, S. Okano, V. Gnedykh, V. Kottsov, K. Yoshioka, G. Murakami, F. Ezawa, G. Cremonese, The Mercury sodium atmospheric spectral imager for the MMO spacecraft of Bepi-Colombo. Planet. Space Sci. 58(1-2), 224-237 (2010). doi:10.1016/j.pss.2008.07.008

L. Zasova, V. Formisano, D. Grassi, N. Ignatiev, A. Maturilli, Martian winter atmosphere at north high latitudes: Mariner 9 IRIS data revisited. Adv. Space Res. 29, 151-156 (2002)

R.W. Zurek, A. Chicarro, M.A. Allen, J.-L. Bertaux, R.T. Clancy, F. Daerden, V. Formisano, J.B. Garvin, G. Neukum, M.D. Smith, Assessment of a 2016 mission concept: the search for trace gases in the atmosphere of Mars. Planet. Space Sci. 59, 284-291 (2011) 